\title{
Vascular dysfunction in experimental diabetes
}

Citation for published version (APA):

Huijberts, M. S. P. (1994). Vascular dysfunction in experimental diabetes. [Doctoral Thesis, Maastricht University]. Datawyse / Universitaire Pers Maastricht. https://doi.org/10.26481/dis.19940527mh

Document status and date:

Published: 01/01/1994

DOI:

10.26481/dis.19940527mh

Document Version:

Publisher's PDF, also known as Version of record

\section{Please check the document version of this publication:}

- A submitted manuscript is the version of the article upon submission and before peer-review. There can be important differences between the submitted version and the official published version of record.

People interested in the research are advised to contact the author for the final version of the publication, or visit the DOI to the publisher's website.

- The final author version and the galley proof are versions of the publication after peer review.

- The final published version features the final layout of the paper including the volume, issue and page numbers.

Link to publication

\footnotetext{
General rights rights.

- You may freely distribute the URL identifying the publication in the public portal. please follow below link for the End User Agreement:

www.umlib.nl/taverne-license

Take down policy

If you believe that this document breaches copyright please contact us at:

repository@maastrichtuniversity.nl

providing details and we will investigate your claim.
}

Copyright and moral rights for the publications made accessible in the public portal are retained by the authors and/or other copyright owners and it is a condition of accessing publications that users recognise and abide by the legal requirements associated with these

- Users may download and print one copy of any publication from the public portal for the purpose of private study or research.

- You may not further distribute the material or use it for any profit-making activity or commercial gain

If the publication is distributed under the terms of Article $25 \mathrm{fa}$ of the Dutch Copyright Act, indicated by the "Taverne" license above, 
VASCULAR DYSFUNCTION IN EXPERIMENTAL DIABETES 


\section{VASCULAR DYSFUNCTION IN EXPERIMENTAL DIABETES}

\section{PROEFSCHRIFT}

ter verkrijging van de graad van doctor aan de Rijksuniversiteit Limburg te Maastricht, op gezag van de Rector Magnificus, Prof. dr. H. Philipsen, volgens het besluit van het College van Dekanen, in het openbaar te verdedigen op vrijdag, 27 mei 1994 om 14.00 uur

door

Maria Simone Petra Huijberts geboren op 4 december 1964 te Goirle

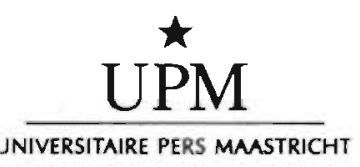




\section{Promotores}

Prof. dr. H.A.J. Struijker Boudier

Prof. dr. A.C. Nieuwenhuijzen Kruseman

\section{Co-promotor}

Dr. B.H.R. Wolffenbuttel

\section{Beoordelingscommissie}

Prof. dr. P.W. de Leeuw (voorzitter)

Prof. dr. J.W. Arends

Dr. B.I. Lévy (INSERM Unité 141, Parijs)

Prof. dr. G.J. Tangelder

Prof. J.R. Williamson (Washington University, St. Louis)

(ㅇ M.S.P. Huijberts, Maastricht 1994

CIP-DATA KONINKLIIKE BIBLIOTHEEK, DEN HAAG

Huijberts, Maria Simone Petra

Vascular dysfunction in experimental diabetes /

Maria Simone Petra Huijberts. - Maastricht: Universitaire Pers

Maastricht. - Ill.

Thesis Maastricht. - With ref. - With summary in Dutch.

ISBN 90-5278-138-9

Subject headings: diabetes / vascular complications.

Layout: Karin Scheele, A Point, Maastricht

Production: Datawyse, Maastricht

The studies in this thesis were made possible by support of Les Laboratoires Servier. Publication of this thesis was made possible by Les Laboratoires Servier, Servier Nederland, Novo Nordisk Nederland and the Diabetes Fonds Nederland. 
aan mijn ouders 


\section{CONTENTS}

GENERAL INTRODUCTION

CHAPTER I Vascular complications in diabetes mellitus

MICROVASCULAR DERANGEMENTS

CHAPTER 2 Changes in microvasculature diameters and density following diabetes induction

CHAPTER 3 In vivo arteriolar reactivity in experimental diabetes

CHAPTER 4 ACE-inhibition reduces urinary albumin excretion, but not regional albumin clearance in experimental diabetes

CHAPTER 5 Effects of aminoguanidine on urinary albumin excretion and regional albumin clearance in streptozotocin-induced diabetic rats

CHAPTER 6 Effects of diabetes on large artery properties in the rat 
CHAPTER 7 Aminoguanidine increases elasticity and decreases fluid filtration of large arteries from diabetic rats

CHAPTER 8 General discussion

SUMMARY

SAMENVATTING

DANKWOORD

PUBLICATIONS 


\section{GENERAL INTRODUCTION}





\section{CHAPTER 1}

Vascular complications in diabetes mellitus

M.S.P. Huijberts 



\section{INTRODUCTION}

Morbidity and mortality as well as quality of life of patients with diabetes mellitus are to a large extent determined by the development of vascular complications. Vascular dysfunction in diabetes has many features which vary from mild signs such as microalbuminuria and background retinopathy to severe conditions like end-stage renal failure, vision threatening proliferative retinopathy and critical leg ischemia.

The development of diabetic complications was not recognized until the introduction of insulin in the 1920's. At that time life expectation of the diabetic patient improved drastically. However, the progress that has been made in the field of diabetic angiopathy is still mainly limited to symptomatic intervention like the development of hemodialysis and kidney transplantation for endstage renal failure and the use of laser coagulation for diabetic retinopathy. Prevention and/or treatment of diabetic angiopathy can until now only be achieved by attaining optimal metabolic regulation, and pharmacological intervention is unfortunately so far still of limited value. Many physicians and health care workers in the field of diabetes care are confronted with the difficult task to anticipate the development of diabetic angiopathy and to treat these disabling complications once they are present. In recent years, however, a number of interesting new theories have been presented on the mechanisms by which vascular dysfunction in diabetes develops. Our knowledge of the sequelae finally leading to diabetic angiopathy is rapidly augmenting.

In this introduction a review will be given of the different forms of clinical diabetic angiopathy and specific features of diabetic vascular dysfunction in relation to microvascular structure and function, vascular reactivity, vascular permeability, arterial compliance, and etiologic mechanisms. In the final section the therapeutic modalities that are available or yet under investigation will be discussed.

\section{CLINICAL CHARACTERISTICS OF CHRONIC COMPLICATIONS}

\section{DIABETIC RETINOPATHY}

Diabetic retinopathy is usually subdivided into two types, the background or non-proliferative form that may develop rather early in the course of diabetes, and the proliferative form which evolves after longer duration of diabetes in a subset of -mainly insulin-dependent- diabetic patients (1). The microvascular alterations that emerge in the retina do have some characteristics that are 
specific for this organ and do not develop in other microvascular systems that are affected by the diabetic state.

Early lesions in the retina include characteristic saccular microaneurysms which are considered as the earliest visible sign of diabetic retinopathy. Other lesions are blot hemorrhages, thickening of the capillary basement membrane, increased vessel wall permeability and associated formation of hard exudates, nonperfused and obliterated capillaries, as well as the degeneration of pericytes leading to so-called pericyte ghosts, impressions of pericytes on the capillary basement membrane $(2,3,4)$. This pericyte loss does not develop in other ocular tissues or areas in the central nervous system where pericytes are present such as the optic nerve or the cerebral cortex, suggesting that factors restricted to the retina play a role in this process (5).

In the phase of non-proliferative retinopathy, visual acuity may already be threatened when retinal edema develops near the center of the macula as a result of increased vascular permeability. In fact, macular edema is the commonest cause of visual loss in diabetes (6). Progression into proliferative retinopathy takes place when neovascularization occurs. Ingrowth of vessels into the vitreous body leads to an increased risk of hemorrhage and scar formation $(7,8)$.

Several factors have been postulated to be associated with an increased risk of developing retinopathy. Among these are HLA types $(9,10)$, hypertension (11), smoking $(12,13)$ and age (14), but most of them are still controversial. Serum and vitreous IGF-I and prorenin levels seem to be increased in patients with retinopathy $(15,16)$ although the precise relevance of this finding is unclear. Fortunately, with the development of laser photocoagulation an effective method has been introduced to treat proliferative retinal lesions as well as maculopathy $(17,18,19)$. Early laser treatment may delay the progression of diabetic retinopathy and can prevent the development of blindness in many cases.

\section{DIABETIC NEPHROPATHY}

Diabetic nephropathy develops in a substantial percentage of the diabetic population, although recent publications demonstrate a marked decline in the incidence of nephropathy in insulin-dependent diabetes mellitus (20).

This condition leads in many cases to end-stage renal failure requiring intensive therapy such as hemodialysis or transplantation. An important early alteration is the increased size of the kidney $(21,22)$. Kidney enlargement is probably due to hyperperfusion and is only temporal. With advancing nephropathy the kidney becomes small and scarred with pronounced alterations in the intima and media of its larger vessels (23). 
Microscopic lesions that can be found at the onset of nephropathy include increased glomerular size and filtration surface $(24,25)$, mesangial expansion (26), and glomerular basement membrane thickening $(27,28)$. These early changes may develop finally into nodular and diffuse glomerulosclerosis leading to loss of glomerular filtration surface. With these anatomical lesions normal renal function can not be preserved. Early functional changes are characterized by an increased renal plasma flow and glomerular filtration rate (29). Subsequently microalbuminuria and overt proteinuria develop as well as hypertension, which may finally progress into end-stage renal failure (30). Mogensen and co-workers have designed a five-stage scheme representing the natural course of renal disease in IDDM (31, Table 1)

Table 1: Stages in the development of diabetic nephropathy

1. Renal hypertrophy and hyperfunction.

2. Renal lesions without clinical signs.

3. Incipient nephropathy (microalbuminuria)

4. Clinical diabetic nephropathy.

5. End-stage renal failure.

The phase in which microalbuminuria is demonstrable deserves special attention, as it might be regarded as the first visible sign of susceptibility to diabetes-induced renal damage. At the same time it indicates a phase in which morbidity and mortality due to cardiovascular disease gradually increases $(32,33)$. In general, microalbuminuria is associated with higher levels of blood pressure (34) and it has been shown that antihypertensive treatment can postpone the development of proteinuria and the decline in renal function (35).

A number of risk factors have been identified concerning the development and course of diabetic nephropathy. Hyperglycemia seems to be one of the major factors. There is evidence that tight metabolic control can delay the progression of nephropathy when at least the stage of overt proteinuria has not been reached $(36,37)$. Hypertension is another important factor in the development of diabetic renal disease. Blood pressure level and albumin excretion seem to be closely related $(38,39)$, although it is not yet clear which one precedes the other. A familial history of hypertension seems to predispose for the development of nephropathy $(40,41)$ and in groups of diabetic patients with renal 
complications increased activity of the sodium-lithium countertransport -a trait that is determined genetically- has been found (42). Protein intake is another factor that can influence the course of nephropathy. A reduction in dietary protein content can reduce microalbuminuria and GFR $(43,44)$. The role of obesity and smoking seems to be of less importance. In general, measures to prevent diabetic renal disease should comprise achievement of tight metabolic control, treatment of hypertension, and restriction of protein intake to $0.8 \mathrm{~g} / \mathrm{kg}$ body weight $(45,46)$.

\section{ATHEROSCLEROSIS}

From epidemiological studies it is known that patients with diabetes mellitus have an increased risk of developing atherosclerosis. In non insulin-dependent diabetes the risk of coronary heart disease is increased two- to fourfold (47). Especially in women this relative risk is increased, thereby reducing the differences in risks for coronary heart disease between males and females. Some studies indicate that the largest increase in risk occurs in the younger age groups of 40-55 years (48). Not only established diabetes but also impaired glucose tolerance results in an increased risk of developing atherosclerosis $(49,50)$. Some authors have pointed to clustering of risk factors related with atherosclerosis such as hypertension, insulin-resistance, dyslipidemia and obesity (syndrome X) (51).

In parallel with the elevated risk of developing coronary heart disease there is also a higher incidence of peripheral vascular disease in diabetic patients, and ulcers and gangrene develop in about 10 percent of elderly diabetic patients (52). The risk of stroke is to a similar extent increased in non-insulin dependent diabetic patients (53). In insulin-dependent patients only few long-term studies regarding the specific risks of developing atherosclerosis because of this disease have been performed. It seems well established though, that once proteinuria is present, cardiovascular morbidity and mortality rises dramatically $(32,33)$, accounting for most of the excess mortality observed in insulindependent diabetes. The precise mechanisms explaining these observations are not known yet, but might be related to generalized vascular damage associated with proteinuria (54).

The characteristics of atherosclerosis are not different in diabetic patients compared to the non-diabetic population, sharing the same features like focal distribution in areas of low shear stress, accumulation of lipoproteins, recruitment of monocytes/macrophages, generation of foam-cells, neo-intima formation and finally mural thrombosis (55). Atherogenic factors present in diabetes include dyslipidemia, increased levels of Lipoprotein (a) (56), endothelial 
dysfunction, defective phagocytosis (57), increased levels of von Willebrandfactor (58), and protein glycosylation inducing free radical formation (59) and altered platelet function $(60)$.

\section{DIABETIC NEUROPATHY}

Neuropathies are frequently observed in diabetic patients. Its manifestations range from delicate abnormalities only detectable by specific electrophysiologic testing, to advanced neurologic dysfunction leading to marked disability. There are only limited data on the exact prevalence of this complication but it has been suggested that after a diabetes duration of 25 years about $50 \%$ of patients show objective signs of polyneuropathy (61-63). Although diabetic neuropathy usually is not categorized as a vascular complication, there are indications that vascular dysfunction plays an important role in its etiology (64). Vascular alterations associated with diabetic neuropathy include an increased number of closed capillaries in sural nerve biopsies (65), thrombosis in intraneural arterioles (66) and reduced nerve oxygen tension (67). Other mechanisms which have been suggested to play a role are alterations in nerve $\mathrm{Na}^{+} / \mathrm{K}^{+}$ATPase activity, depletion of myo-inositol and sorbitol accumulation (see paragraph below), as well as alterations in neurotrophic factors (68), alcohol consumption (69), and autoimmune mechanisms (70).

\section{THE DIABETIC FOOT}

The diabetic foot poses a very complex clinical problem combining the consequences of neuropathy, macroangiopathy, microangiopathy, and altered joint mobility. Diabetic polyneuropathy leads to sensory, motor and autonomous dysfunction resulting in diminished perception of pain, temperature and pressure, as well as altered foot mechanics, together with increased shunt flow and anhidrosis (71). Macroangiopathy mainly plays a role in the older agegroups, with atherosclerotic lesions that are located in general more distally and multisegmental compared to non-diabetic patients. Microangiopathy may lead to impaired vasodilation and impaired autoregulation. Poorly controlled patients are especially prone to infection, possibly by immunologic alterations induced by hyperglycemia. Grossly, diabetic foot ulcers can be divided in neuropathic ulcers and angiopathic ulcers, although in the majority of cases etiologic factors are plurifold. Diabetic foot problems can be found in about $25 \%$ of diabetic patients (72). In a number of cases these lower extremity problems make amputation necessary. The incidence of major amputation has been estimated about $4000 /$ million/year $(73,74)$. The prognosis for patients after lower extremity amputation is poor, with a 3-year survival of $50 \%$ (75). 


\section{SPECIFIC FEATURES OF DIABETIC ANGIOPATHY}

The clinical entities that have been described in the previous section share a number of characteristic alterations at the microvascular and/or macrovascular level. In the following paragraphs these specific disturbances will be discussed in more detail.

\section{MICROVASCULAR STRUCTURE AND FUNCTION}

The sequence of microvascular alterations in diabetic retinopathy and diabetic nephropathy is relatively well documented. There are however also indications that specific diabetes-related lesions may develop in other vascular beds. One of the first signs of microangiopathy that was discovered is capillary basement membrane thickening. Thickening of capillary basement membranes of nerve (76), muscle (77) and skin (78) has been observed already many years ago. Siperstein et al. measured a marked increase of vascular basement membrane thickness in quadriceps muscle of about $98 \%$ of diabetic and $50 \%$ of -what they called-genetically prediabetic patients (79). This indicates that genetic factors play a role in the development of this vessel wall abnormality. Studies in identical twins suggested, in contrast, that the diabetic milieu per se rather then hereditary factors are of importance in the development of basement membrane thickening $(80)$. This is supported by the reduction of skeletal muscle capillary basement membrane width induced by two years of improved metabolic control (81). Expression of basement membrane components in endothelial cells might be directly influenced by hyperglycemia (82).

The functional consequences of increased basement membrane width might include impaired leucocyte migration across the vessel wall, decreased capillary distensibility, and altered vascular permeability (83), an item that will be discussed later. The formation of new vessels is one of the alarming signs in advanced retinopathy. It is not well known whether neovascularization occurs outside the eye as well. Studies on capillary densities in different tissues obtained from diabetic subjects and diabetic animals yielded controversial results $(84,85)$.

A set of important studies on experimental diabetic microangiopathy comes from the group of Bohlen, who investigated microvascular diameters and microvascular structure after diabetes induction or induction of local hyperglycemia. Their experiments indicated that microvascular alterations are not similar in all microcirculatory beds. Arteriolar constriction occurred in wings from diabetic bats (86) and cremaster muscle arterioles from diabetic mice (87), while vasodilation was shown in intestinal arterioles (88). 
Other authors also obtained evidence for vasodilation in diabetes, such as increased forearm blood flow $(89,90)$, capillary dilation in the nailfold of the toe, the cheek mucosa and the facial skin $(91,92)$. Also dilation of the retinal arteries and veins and increased retinal flow has been observed (93-95). These functional, hemodynamic alterations that occur early in the development of diabetic microangiopathy are sometimes regarded as the initiating events that finally lead to the anatomical lesions that become manifest in the course of the disease (96). In this theory diabetic (micro)angiopathy is a process in which hyperperfusion damage plays an important role (97).

However, many questions remain to be answered concerning this subject. The diversity of experimental microcirculatory and diabetes models, the relative inaccessibility of human microvascular beds, as well as probable differences between insulin-dependent and non-insulin dependent diabetic patients make this topic very complicated. As a consequence, both short-term and long-term structural as well as functional effects of (experimental) diabetes on different microvascular beds need further definition.

\section{VASCULAR REACTIVITY}

One of the first observations regarding vascular reactivity in diabetes mellitus dates from a study of Brody et al. (98), who measured vascular responses to vasoconstrictors in perfused hindquarters from diabetic and non-diabetic rats. The results showed a vascular hyperresponsiveness to epinephrine, norepinephrine and angiotensin II. Since then many studies have been performed regarding vascular reactivity to vasoconstricting and vasodilating agents in both clinical and experimental diabetes mellitus.

In experimental diabetes most of the studies regarding vasoreactivity to vasopressor agents indicate -in concordance with Brody's studies- an increased reactivity to $\alpha$-adrenoceptor-agonists as well as angiotensin II. Abebe et al. performed a number of studies in which they showed that in aortae and mesenteric arteries responses to norepinephrine and $\alpha-1$ receptor agonist are increased in diabetic rats, which might be related to increased release of intracellular calcium (99), protein kinase C activation (100), and augmented inositol phosphate production (101). Other studies $(102,103)$ also suggest an increased microvascular reactivity to norepinephrine in hindquarters and cremaster muscle arterioles of diabetic rats, although after prolonged diabetes duration (32 weeks) reactivity was restored towards normal (102). There are, however, studies that report depressed reactivity to vasoconstricting agents $(104,105)$. In diabetic patients responsiveness of superficial hand veins (106) and corpus cavernosum smooth muscle (107) to $\alpha$-adrenoceptor agonists was shown to be increased. Christlieb demonstrated already some years ago that 
in diabetic patients with vascular complications reactivity to angiotensin II and norepinephrine is increased (108).

In general the experimental studies in which the effects of vasodilating agents are studied in diabetic animals indicated an impairment of endotheliumdependent relaxation, while endothelium-independent relaxation remained unaltered. The studies have been performed in different species and different vessel types (109-113), indicating that this phenomenon may be a general feature of diabetic angiopathy. However, there are some methodological difficulties related to ambient glucose concentrations in the in vitro studies as well as the interpretation of some observations. In one human study, the finding of impaired endothelium-dependent and normal endothelium-independent vasodilation could be confirmed. Acetylcholine-induced relaxation but not nitroprusside responses were depressed in corpus cavernosum tissue from diabetic patients (114). Nevertheless, in two recent in vivo studies in diabetic patients no differences were observed in forearm endothelium-dependent relaxation (115), while endothelium-independent relaxation was impaired in one study (116).

It remains to be clarified how vasoreactivity is precisely affected in diabetes. Regional vascular differences may exist, and the duration of diabetes may have distinct effects on vascular function. Another factor that may play a role is the presence or absence of hyper- or dyslipidemia in the different experimental and human types of diabetes mellitus. It has been shown that high-density lipoprotein has beneficial effects on endothelium-dependent vasorelaxation (117), while oxidized low-density lipoprotein might attenuate this process (118).

\section{INCREASED VASCULAR PERMEABILITY}

Alterations in vascular permeability in diabetic patients as well as in models of experimental diabetes have been demonstrated in many studies. In the clinical situation, fluorescein angiography is an important tool in the diagnosis and classification of diabetic retinopathy. However, outside the retina vascular permeability may also be increased in diabetes. Parving et al. demonstrated that microvascular permeability, as assessed by determining the transcapillary escape rate of albumin (TER $\mathrm{alb}_{\mathrm{b}}$ ), was increased following a short period of poor control in diabetic patients (119). Not only poor metabolic control but also the presence of hypertension and/or microangiopathy was associated with increased $T E R_{\text {alb }}$ in diabetes (120). By measuring extravasation of fluorescein sodium through nailfold capillaries Bollinger et al. showed that permeability of the diffusion barriers was markedly increased in patients with long duration of diabetes (121). In addition, Feldt-Rasmussen showed that $\mathrm{TER}_{\mathrm{alb}}$ augments with increasing levels of albuminuria (122). 
In experimental models of diabetes there are also indications that vascular permeability is markedly increased. The group of Williamson performed many studies regarding this subject. They showed that in many tissues of both streptozotocin-induced and spontaneously diabetic $\mathrm{BB} / \mathrm{W}$ rats regional albumin permeation is increased. The tissues include granulation tissue (123), different ocular tissues, kidney, aorta, sciatic and brachial nerve, as well as cecum and colon (124). They hypothesized that increased vascular leakage is at least partially related to increased regional flow, since they observed parallel increases in blood flow in the tissues in which albumin permeation was increased (125). Recent studies from this group connect increased flow and increased regional albumin permeation to increased nitric oxide production $(126,127)$. It has also been demonstrated that transcapillary escape of albumin already increases very shortly $(24 \mathrm{hr}$ ) after diabetes induction. This suggests that functional alterations may play a role (128), although effects due to the administration of streptozotocin can not be excluded.

There are two main theories explaining the development of increased protein extravasation in diabetes. One line of evidence suggests that hemodynamic alterations such as increased local flow and increased intracapillary pressure promote transvascular passage of macromolecules as a result of increased hydrostatic forces (129). Most of the data supporting this theory originates from renal studies in which intraglomerular pressure was reported to be increased, indicating a relation with the concomitant rise in urinary albumin excretion. Only recently, direct in vivo intracapillary pressure measurements were performed in human skin nail-fold capillaries, demonstrating that capillary pressure was overall higher in diabetic patients compared to non-diabetic controls (130).

The second explanation refers to specific alterations in the vascular wall leading to enhanced vascular leakage in diabetes. Vessel wall alterations are suggested to relate mainly to the extracellular matrix in which some components such as collagen type IV are increased (131), while the content of the proteoglycan heparan-sulphate is decreased (132). Loss of heparan-sulphate proteoglycan results in loss of anionic sites leading to loss of size and charge selectivity of the capillary/glomerular wall (133). The so-called Steno hypothesis suggests that the development of albuminuria and the concomitant increase in transvascular albumin passage as demonstrated by Feldt-Rasmussen are exponents of the same process causing damage to both the glomerular and the (large) vascular wall (134). In this view, albuminuria reflects generalized vascular damage, which explains the increased mortality associated with albuminuria in diabetes $(33,54)$. In addition to these theories, other mechanisms such as increased number and size of pores through which plasma proteins permeate capillaries may also play a role. 


\section{ARTERIAL COMPLIANCE AND ELASTICITY}

Arterial compliance describes a change in (large) arterial volume as a result of a change in blood pressure. Compliance is dependent on intravascular pressure (135), and is determined by the elastical properties of the vessel wall but also by its dimensions. Arterial compliance is an important modulator of the transmission and damping of the pulse wave along the arterial tree, and has a marked impact on cardiac load $(136,137)$. A decrease in arterial compliance may be caused by an elevation of arterial pressure per se, vascular hypertrophy, and changes related with aging such as atherosclerosis.

In diabetes, there is remarkably little known about alterations in arterial compliance and arterial elasticity. One can imagine that, as a result of the accelerated atherosclerosis that exists in many (elderly) diabetic patients vascular elasticity will be decreased. However, glycation of proteins resulting from prolonged hyperglycemia can induce structural modification of proteins in the vascular wall; this might form another factor that influences arterial compliance in diabetes. Indeed it has been demonstrated that aortic stiffness in younger insulin-dependent diabetic men and women was markedly increased compared to control subjects with comparable levels of blood pressure (138). In another study in IDDM patients, aortic samples obtained outside the visible areas of atherosclerosis showed a marked increase in stiffness (139). Very few studies have addressed this subject in experimental diabetes. Recently, Patel et al reported that streptozotocin-induced diabetic rats had clearly stiffer right atria and venoatrial junctions than non-diabetic control rats (140).

\section{ETIOLOGIC MECHANISMS IN THE DEVELOPMENT OF DIABETIC ANGIOPATHY}

The specific disturbances in diabetic angiopathy both at a microvascular and macrovascular level are considered to be caused by one or possibly several mechanisms that interfere with cardiovascular processes at a basic level. These mechanisms are probably all related directly or indirectly to hyperglycemia. The important role of hyperglycemia as such in the genesis of diabetic complications has only recently been fully established. Hyperglycemia in diabetes may lead to the development of diabetic angiopathy through formation of advanced glycosylation endproducts (AGEs), by an increased flux through the polyol pathway or by alterations in hormonal and growth factor systems. 


\section{THE ROLE OF HYPERGLYCEMIA IN THE DEVELOPMENT OF DIABETIC ANGIOPATHY}

The role of hyperglycemia per se in the development of diabetic complications has been disputed for a long time. It has been uncertain whether improving blood glucose control could prevent the development or slow the progression of diabetic complications. Since, by the use of continuous subcutaneous insulin infusions (CSII) and the multiple insulin injections regimen, it became possible to attain near normoglycemia in insulin-dependent diabetic patients, several studies have addressed this controversy and compared groups of well controlled and less controlled patients to observe the development or progression of long-term angiopathic complications.

Confusion regarding the subject of diabetic control and complications originated from studies concerning patients with diabetic retinopathy. In some of these studies a worsening of the retinopathy after improvement of metabolic control was seen (141-143). Follow-up of these studies showed however that this worsening was only transient (144). Other studies reported that near normoglycemia slowed the progression of retinopathy $(145,146)$. Early stages of diabetic nephropathy, when microalbuminuria is present, seem to benefit from tight metabolic control (147-149), but when clinical proteinuria is reached, correction of hyperglycemia does not improve or preserve renal function $(150,151)$. Also patients with neuropathy seemed to profit from improved metabolic control $(152,153)$. It has been shown that even short periods of improved metabolic control can ameliorate motor nerve conduction velocity (154).

Only recently, conclusive answers with respect to this topic came from the Diabetes Control and Complications Trial (DCCT). This large multicenter controlled randomized trial was started in 1983 in order to study the relation between early metabolic control and the development of microangiopathy in insulin-dependent diabetic patients $(155,156)$. The results unequivocally showed that good metabolic control reduces the risk of developing microvascular complications and neuropathy. The risk reductions were very substantial, especially when is taken into account that the difference in mean $\mathrm{HbAlc}$ was only about $2 \%$ between the two study group ( $7.0 \%$ in the intensive treatment group versus $8.9 \%$ in the conventional treatment group).

\section{ADVANCED GLYCOSYLATION ENDPRODUCT FORMATION}

High blood and tissue glucose levels chemically modify various extracellular and intracellular macromolecules. The first modification step involves condensation of the sugar with a free amino group, resulting in the rapid formation 
of a Schiff base. Lysine is one of the amino-acids especially involved in this condensation reaction. The Schiff base subsequently undergoes a chemical rearrangement to a more stable Amadori product. This product is degraded into a number of highly reactive compounds, which react again with other free amino groups thus forming various intermediate and advanced glycosylation endproducts (AGEs). The exact chemical nature of reactions involved in the development of these AGEs is until now only poorly understood.

AGE formation has been implicated in the pathogenesis of several of the complications of aging and diabetes, including atherosclerosis and renal disease $(157,158)$. AGEs may accumulate on long-lived tissue proteins, for instance collagen. Not only glucose, but also other sugars may play part in the formation of glycosylation products: the rate of Schiff base formation from D-fructose (intracellularly) is 7 times faster than from glucose, and glyceraldehyde-3phosphate, an intermediate of glycolysis, is responsible for a 200 times more rapid glycosylation of proteins.

The formation of AGEs on proteins may alter their tertiary structure, and has several implications for their normal function. For instance, glycosylation of collagen increases tissue stiffness (157), while glycosylation of apolipoprotein Al reduces HDL-mediated efflux of cholesterol from the vessel wall (159). It was shown that AGEs stimulate the secretion by macrophages of tumor necrosis factor (TNF- $\alpha$ ) and interleukin-1 upon reaction with a specific receptor (160); this mechanism may be involved in the development of diabetic nephropathy (161). Already early glycosylation products stimulate formation of free radicals (59).

Formation of AGEs has several consequences for the extracellular matrix components: AGE-formation on collagen and laminin inhibits the normal network-like development of the matrix, and results in decreased binding of heparan sulphate-proteoglycan (HS-PG), an important negatively-charged basement membrane constituent $(162,163)$. Lower concentrations of HS-PG in the extracellular matrix have been implicated in the genesis of albuminuria, mesangial proliferation and increased transcapillary albumin permeation on one side, and enhancement of several processes related to atherosclerosis on the other side (134). Plasma proteins may be 'trapped' in the matrix by the reactive AGE-precursors situated on matrix proteins, which gives rise to a further expansion of an already thickened basement membrane. Furthermore, the biochemical alterations may give rise to changes in vascular tone and function as well, and it was suggested that the advanced glycosylation process impairs normal endothelium-dependent relaxative properties by quenching of nitric oxide (164). The injection of AGE-modified albumin into normal rats and rabbits induced vascular dysfunction that is very similar to the derangements observed in experimental diabetes (165). 
Aminoguanidine. Recently, drugs modifying the formation of advanced glycosylation end-products have been developed. Aminoguanidine is one of these drugs. Its putative mechanism of action is the reaction with Amadori-derived fragmentation products such as 3-deoxyglucosone in solution (166). One of the first reports on aminoguanidine and diabetic vascular dysfunction dates from 1986 when Brownlee et al. demonstrated that aminoguanidine prevented diabetes-induced arterial wall protein cross-linking (167). Many subsequent studies have demonstrated beneficial effects of aminoguanidine treatment on vascular dysfunction in experimental diabetes. In experimental diabetic retinopathy, long-term treatment with aminoguanidine markedly retarded the development of microaneurysms, acellular capillaries and pericyte loss (168). In addition, aminoguanidine prevented mesangial expansion (169), albuminuria $(169,170)$ as well as glomerular basement membrane thickening (171). In peripheral nerves from diabetic rats the drug was shown to restore nerve blood flow (172), to improve motor nerve conduction velocity, and to normalize partially axonal atrophy $(173,174)$. In tail tendons from diabetic rats, aminoguanidine reduced the increase in collagen stability (175).

Recently, attention has also been focused on effects of aminoguanidine that are not related to inhibition of AGE-formation, such as its effects on nitric oxide (NO) synthesis and its influence on aldose reductase. Tilton and colleagues have shown in a number of experiments that aminoguanidine inhibits both the inducible and the constitutive isoform of NO-synthase (126). In addition, aminoguanidine might also be an inhibitor of aldose reductase, although probably only in supraphysiologic concentrations $(126,127)$.

Clinical studies with aminoguanidine are currently underway: The first results showed that 1 month treatment with aminoguanidine resulted in significant lower hemoglobin-AGE levels in diabetic patients. Important toxic effects have not been reported so far. It is, however, conceivable that aminoguanidine might raise arterial blood pressure by its NO-synthase inhibiting effects.

\section{THE POLYOL PATHWAY}

In recent years, attention has been focused on an alternative route of glucose metabolism, the polyol pathway. In this pathway glucose is first reduced to sorbitol by the action of aldose reductase. Then it is oxidized to fructose by the enzyme polyol dehydrogenase. Aldose reductase has a rather low affinity for glucose so that this pathway only becomes important when hyperglycemia is present. Aldose reductase has been found in many tissues including nerves (176), retina and retinal microvessels (177) and glomeruli (178). At higher glucose levels the polyol pathway can account for as much as $30 \%$ of glucose metabolism (179). 
Activation of the polyol pathway leads to polyol accumulation, since these sugar alcohols can not easily pass cell membranes. Associated with polyol accumulation is the depletion of myo-inositol, a precursor of phosphoinositide metabolism. These phospholipids are thought to play a major role in cell signaling by activating protein kinase $C(180)$. Protein kinase $C$ has important effects on cellular functioning by influencing contraction and cell growth. Another mechanism by which an increased flux through the polyol pathway might affect vascular function in diabetes is the subsequent generation of an increased $\mathrm{NADH} / \mathrm{NAD}^{+}$ratio. This alteration in redox state creates a situation of so-called pseudohypoxia, which resembles circumstances in which ischemia is present (181).

Aldose reductase inhibitors. In some animal studies the prevention of polyol accumulation by aldose reductase inhibition seemed a promising new way to prevent or revert microvascular complications. Aldose reductase inhibition has been shown to prevent diabetes-induced increases in vascular permeability and enhanced regional blood flow in granulation chamber tissue and other tissues from streptozotocin-induced diabetic and spontaneously diabetic $\mathrm{BB} / \mathrm{W}$ rats $(124,125,182,183)$. It was postulated that aldose reductase inhibitors have advantageous effects in experimental diabetes by normalizing the increased $\mathrm{NADH} / \mathrm{NAD}^{+}$ratio resulting from increased sorbitol pathway metabolism (184). Concerning experimental diabetic nephropathy, Cohen et al. showed that sorbinil normalized the decreased glomerular $\mathrm{Na}^{+} / \mathrm{K}^{+}$-ATPase activity (185). There are also reports that the development of hyperfiltration (185) as well as albuminuria (186) were prevented. In addition aldose reductase inhibitors had positive effects on nerve $\mathrm{Na}^{+} / \mathrm{K}^{+}$-ATPase activity and neurophysiologic parameters (187-189).

Some studies did not reveal beneficial effects of aldose reductase inhibitors; in one study sorbinil was not effective in reducing the severity of diabetic retinopathy occurring after 5 years duration of galactosemia or alloxan-induced diabetes (190). In human studies the results were so far not very promising. Sorbinil did not slow the progression of retinopathy or prevent its development (191), while glomerular hyperfiltration was only reduced to a slight although significant extent (192). Possible explanations for this lack of effect in diabetic patients might be the interventional character of the performed studies as well as potentially inadequate levels of aldose reductase inhibition. Furthermore, aldose reductase activity is much higher in rodents compared to humans. 


\section{HORMONAL AND GROWTH FACTORS}

The renin-angiotensin system. The renin-angiotensin system (RAS) has been regarded for a long time as an endocrine system only. Renin, secreted by the kidney stimulates the conversion of the liver derived angiotensinogen to angiotensin I, which is then cleaved by the angiotensin converting enzyme (ACE), present in the blood and on endothelial cells, to the vasoactive peptide angiotensin II $(193,194)$. The release of angiotensin II has many effects including vasoconstriction, aldosterone production, and catecholamine release. In this way, the RAS has an important function in maintaining cardiovascular homeostasis.

Increasing evidence, however, suggests that in parallel with the circulating RAS a locally active thus paracrine or autocrine renin-angiotensin system exists. Components of the renin-angiotensin system have been found in many different organs like the brain, kidney, as well as adrenal and vascular tissue (195-200). The demonstration of renin and angiotensinogen gene expression in these tissues (201-203) is an even stronger indication of local production of these substances.

The local renin-angiotensin system is thought to be important in a number of physiologic and pathophysiologic conditions. Observations of increased arterial renin-angiotensin activities in spontaneously hypertensive rats that have normal plasma renin and ACE activities, suggest that regulation of vascular tone and thus regional blood flow are an important feature of the local RAS. Angiotensin II has been demonstrated to have mitogenic and hypertrophic effects in vivo and in vitro, mainly on smooth muscle cells (204-206), and to produce vascular proliferation when implanted into rabbit cornea (207). Vascular responses to inflammation and injury are considered to be mediated by the RAS.

In diabetes mellitus, serum levels of components of the RAS seem to be altered, although some controversy exists about this subject. Authors report low $(208,209)$, normal $(210,211)$ or even elevated plasma renin activity $(212,213)$ in diabetic patients. Explanations for the controversial observations include differences in metabolic control, the presence or absence of (autonomic) neuropathy and differences between insulin-dependent and non insulin-dependent diabetic patients. In general it is believed that diabetic patients without signs of microangiopathy have a normal functioning renin-angiotensin system, while in patients with angiopathy the renin-angiotensin system is suppressed. This has also been observed in experimental models of diabetes $(214,215)$. High levels of inactive renin have been found in diabetic subjects with microvascular disease and have been suggested to be potential markers of microangiopathic complications (16). These high prorenin levels are thought to result from increased extrarenal production or reduced clearance of prorenin from the 
circulation (216). In vitreous fluid of patients with proliferative retinopathy, high levels of renin could be demonstrated. This has led to the hypothesis that a local intraocular renin-angiotensin system might play a role in the development of diabetic retinopathy (217).

Angiotensin-converting enzyme inhibition. Angiotensin converting enzyme (ACE)inhibitors are very effective in the prevention or postponement of diabetic nephropathy. Besides lowering blood pressure (218), they appear to have a beneficial effect on albumin excretion as well $(219,220)$, without deleterious effects on carbohydrate metabolism (212) or lipid profile (222). The improvement in albuminuria is seen even in normotensive patients treated with ACE inhibition (223). It remains a matter of debate whether ACE-inhibitors are superior to other antihypertensive agents with respect to reduction of albuminuria and preservation of renal function. Anderson et al. demonstrated that captopril treatment but not triple therapy with reserpine, hydralazine and hydrochlorothiazide limited albuminuria and glomerular injury in experimental diabetes (224). In parallel, there are a number of clinical studies showing preferential effects of ACE-inhibitors when compared to B-blockers (225) or calcium-antagonists (226), whereas other studies could not detect differences in anti-albuminuric or renal function-preserving effects $(227,228)$.

The protective effect of ACE-inhibitors on the kidney may be due to advantageous hemodynamic effects such as a reduction in intraglomerular pressure. This reduction in intraglomerular pressure is probably exerted by the specific dilating effects on the efferent arteriole. There are, however, observations that have led some authors to the hypothesis that non-hemodynamic mechanisms might also be of importance. The establishment of the anti-proteinuric effect takes a relative long time compared to the development of the hemodynamic effects (229). Furthermore, angiotensin II infusions fail to increase proteinuria while the hemodynamic effects of ACE-inhibition are already abolished (230). It has also been reported that ACE-inhibitors modulate intrinsic membrane properties of the glomerular barrier (231). There is yet very little known on extrarenal effects of ACE-inhibitors in diabetes. With the possible relation between albuminuria and increased transvascular albumin passage in mind, studies addressing this subject are of considerable interest. 


\section{THE PRESENT THESIS}

In this thesis characteristics of vascular dysfunction were studied in an experimental diabetes model, the streptozotocin diabetic rat. In this model we studied the following questions, focusing on three features of diabetic angiopathy:

1. Microvascular structure and function. What is the effect of diabetes induction on microvascular diameters and microvascular density in the skeletal muscle: Are there signs of vasodilation? How is vasoreactivity affected by diabetes induction? Is there a specific endothelium-dependent defect in vasoreactivity?

2. Increased vascular permeability. Is there an etiologic role for the renin-angiotensin system or AGE-formation in the development of increased albumin leakage and albuminuria; Can treatment with ACE-inhibition or aminoguanidine prevent or retard the development of increased vascular permeability?

3. Arterial compliance and elasticity. Does experimental diabetes lead to a decrease in arterial elasticity; Can AGE-formation negatively affect arterial wall properties in diabetes?

\section{THE STREPTOZOTOCIN-INDUCED DIABETIC RAT MODEL}

The studies in this thesis were performed using an animal model of diabetes. This approach allowed us to study (micro)vascular beds that are relatively inaccessible in humans. Furthermore, it enabled us to assess the effects of diabetes directly after induction of hyperglycemia, since marked vascular changes can be observed already after a relatively short duration of diabetes. In addition, it was possible to test specific agents which can not yet be studied in humans. We chose the streptozotocin-induced diabetic rat since this is the most commonly used model. Therefore, comparisons can be made with numerous reports on different aspects of diabetes and diabetic angiopathy. In addition, not only cardiovascular alterations but also the characteristics of the endocrine system, and different organs such as the liver, kidney and central nervous system have been extensively studied (232).

Streptozotocin is a metabolite of Streptomyces Achromogenes that has antibiotic, antitumor and carcinogenic properties. The first reports regarding its diabetogenic characteristics date from 1963 (233). Streptozotocin is directly toxic for the pancreatic $B$-cells through damage to the plasma membrane, a decrease in NAD levels and possibly free radical production (234). It induces a form of diabetes that resembles insulin-dependent diabetes in humans. Streptozotocindiabetic rats are hyperglycemic, lean and hypo-insulinemic. Dependent on the 
administered dose of streptozotocin they do or do not need insulin for survival. In our studies a moderate dose of $70 \mathrm{mg} / \mathrm{kg}$ streptozotocin intraperitoneally was used, which induces hyperglycemia in the range of $16-25 \mathrm{mmol} / \mathrm{l}$.

\section{OUTLINE OF THE THESIS}

The thesis can be divided into three sections. In the first part, diabetes-induced alterations in microvascular diameters, microvascular density and microvascular reactivity are assessed in the dorsal microcirculatory chamber model. This model allows chronic measurements of skeletal muscle microcirculation in conscious rats. In this way microvascular characteristics could be observed sequentially after diabetes induction without confounding effects of anesthesia. We were interested in the direct effects of hyperglycemia on the microcirculation in a situation in which no insulin was administered. Using this model, also vascular reactivity changes could be studied in conscious animals. Attention was paid to reactivity to both endothelium-dependent and endotheliumindependent vasoactive substances.

In part two increased vascular permeability and albuminuria, two established features of diabetic angiopathy are studied. We were especially interested in the effectiveness of the ACE-inhibitor perindoprilat as well as aminoguanidine in reducing or preventing these vascular disturbances, which might give an indication of the role of the renin-angiotensin system as well as AGE-formation in the development of increased vascular permeability. By measuring effects on both increased permeability and albuminuria we tried at the same time to address the question whether these features of diabetic vascular dysfunction share a common etiologic mechanism and can be influenced simultaneously. In the third part the question is addressed whether diabetes can alter mechanical properties of the arterial wall. The hypothesis that (experimental) diabetes might influence arterial wall properties originated from the observations that vessel wall matrix proteins can be modified markedly by hyperglycemia. The last experimental chapter deals with the effects of aminoguanidine on mechanical properties of the arterial wall in diabetes. 


\section{REFERENCES}

1. Klein R, Davis MD, Moss SE, Klein BEK, Demets DL: The Wisconsin epidemiologic study of diabetic retinopathy: a comparison of retinopathy in younger and older onset diabetic persons. In: Comparison of type I and type II diabetes. Vranic M, Hollenberg C., Steiner G, Eds. New York, Plenum 1985, pp 321-325

2. Kornerup $\mathrm{T}$ : Studies in diabetic retinopathy: an investigation of 1,000 cases of diabetes. Acta Med Scand 1955; 153: 81-101

3. Blankenship GW, Skyler JS: Diabetic retinopathy: a general survey. Diabetes Care 1978; 1: $127-131$

4. Ward JD: Diabetic retinopathy: a physician's view. Eye 1990; 4: 169-173

5. Kohner EM, Dollery CT: Diabetic retinopathy. In: Complications of diabetes. Keen H, Jarrett J, Eds. London, Yearbook Medical, 1975, pp 7-98

6. Kohner EM: Diabetic retinopathy. In: Prevention and treatment of diabetic late complications. Mogensen CE and Standl E, Eds. De Gruyter, Berlin 1989, pp 75-91

7. Merimee TJ: Diabetic retinopathy. A synthesis of perspectives. N Engl J Med 1990; 322 : 978-983

8. Dornan TL, Ting A, McPherson CK, et al: Genetic susceptibility to the development of retinopathy in insulin-dependent diabetics. Diabetes 1982; 31: 226-231

9. Groop LC, Koskimies HT, Groop PH, et al: Risk factors and markers associated with proliferative retinopathy in patients with insulin-dependent diabetes. Diabetes 1986; 35: 1397-1403

10. Klein R, Klein BEK, Moss SE, David MD, DeMetz DL: The Wisconsin epidemiologic study of diabetic retinopathy. II. Prevalence and risk of diabetic retinopathy when age at diagnosis is less than 30 years. Arch Opthalmol 1984; 102: 520-526

11. Ishihara M, Yukimura I, Aizawa T, Yamada T, Ohto K, Yoshizawa K: High blood pressure as a risk factor in retinopathy development in NIDDM patients. Diabetes Care 1987; 10: 20-25

12. Klein R, Klein BEK, Davis MD: Is cigarette smoking associated with diabetic retinopathy? Am J Epidemiol 1983; 118: 228-233

13. Muelhauser I, Sawicki P, Berger M: Cigarette smoking as a risk factor for macroproteinuria and proliferative retinopathy in type I (insulin-dependent) diabetes. Diabetologia 1986; 29: 500-502

14. Murphy RP, Nanada M, Enger C, Vitale S, Patz A: The relationship of puberty to diabetic retinopathy. Arch Ophthalmol 1990; 108: 215-218

15. Danser AHJ, Deinum J, Derkx FHM, Schalekamp MHD, de Jong PTVM: Components of the renin-angiotensin system in vitreous fluid from eyes with and without diabetic retinopathy. In: Current advances in ACE inhibition, McGregor GA and Sever IS, Eds, Churchill Livingstone, London 1989, pp 195-197

16. Luetscher JA, Kraemer FB, Wilson DM, Schwartz HC, Bryer-Ash M: Increased plasma inactive renin in diabetes mellitus. $N$ Engl J Med 1985; 312: 1412-1417

17. Diabetic Retinopathy Study Research Group: Photocoagulation treatment of diabetic retinopathy. Ophthalmology 1981; 88: 583-600

18. British Multicentre Study Group: Photocoagulation for diabetic maculopathy. A randomised controlled clinical trial using the Xenon arc. Diabetes 1983; 32: 1010-1016

19. British Multicentre Study Group: Photocoagulation for proliferative diabetic retinopathy: a randomised controlled clinical trial using the Xenon arc. Diabetologia $1984 ; 26$ : 109-115 
20. Bojestig M, Amqvist HJ, Hermansson G, Karlberg BE, Ludvigsson J: Declining incidence of nephropathy in insulin-dependent diabetes mellitus. N Engl J Med 1994; 330: 15-18

21. Mogensen CE, Andersen MJF: Increased kidney size and glomerular filtration rate in early juvenile diabetes. Diabetes $1973 ; 22: 706-712$

22. Mogensen CE, Gammelgaard J, Frandsen M, Parving $\mathrm{HH}$ : Increased kidney size, glomerular filtration rate and renal plasma flow in short-term insulin-dependent diabetes. Diabetologia 1981; 20: 451-456

23. Morley AR: Renal vascular disease in diabetes mellitus. Histopathology 1988; 12: 343358

24. Hirose K, Tsuchida H, Osterby R, Gundersen HJG: A strong correlation between glomerular filtration rate and filtration surface in diabetic kidney hyperfunction. Lab Invest 1980; 43: 434-437

25. Ellis EN, Steffes MW, Goetz FC, Sutherland DER, Mauer SM: Glomerular filtration surface in type I diabetes mellitus. Kidney Int 1986; 29: 889-894

26. Steffes MW, Osterby R, Chavers B, Mauer MS: Mesangial expansion as a central mechanism for loss of kidney function in diabetic patients. Diabetes 1989; 38: 1077-1081

27. Osterby R: Early phases in the development of diabetic glomerulopathy. Acta Med Scand 1975; 574 (suppl. 1): 13-77

28. Osterby R, Andersen AR, Gundersen, Jorgensen HE, Mogensen CE, Parving HH: Quantative study on glomerular ultrastructure in type 1 diabetes with incipient nephropathy. Diab Nephrop 1983; 3: 95-100

29. Mogensen CE, Andersen MJF: Increased kidney size and glomerular filtration rate in untreated juvenile diabetics. Diabetologia 1975; 11: 221-224

30. Mogensen CE: Renal function changes in diabetes. Diabetes 1976; 25 (suppl. 2): 872-879

31. Mogensen CE, Christensen CK, Vittinghus E: The stages in diabetic nephropathy: with emphasis on the stage of incipient diabetic nephropathy. Diabetes 1983; 32 (suppl. 2): $04-78$

32. Mogensen CE: Microalbuminuria predicts clinical proteinuria and early mortality in maturity-onset diabetes. N Engl J Med 1984; 310: 356-360

33. Borch-Johnsen K, Kreiner S: Proteinuria: A predictor of cardiovascular mortality in insulin-dependent diabetes mellitus. Br Med J 1987; 294: 1651-1654

34. Hansen KW, Christensen CK, Andersen HP, Pedersen M, Christiansen JS, Mogensen $\mathrm{CE}$ : Ambulatory blood pressure in microalbuminuric type 1 diabetic patients. Kidney Int 1992; 41: 847-854

35. Parving $\mathrm{H}-\mathrm{H}$, Andersen AR, Smidt UM: Effects of antihypertensive treatment on kidney function in diabetic nephropathy. Br Med J 1987, 299: 230-233

36. Deckert T, Lauritzen T, Parving H-H, Christiansen JS, The Steno Study Group: Effect of two years of strict metabolic control on kidney function in long-term insulin-dependent diabetes. Diab Nephrop 1983, 2: 6-10

37. Viberti GC, Bilous RW, Mackintosh D, Bending J, Keen H: Long-term correction of hyperglycemia and progression of renal failure in insulin-dependent diabetes. $\mathrm{Br} \mathrm{Med}$ J 1983, 286: 598-602

38. Mathiesen ER, Ronn B, Jensen T, Storm B, Deckert T: Relationship between blood pressure and urinary albumin excretion in development of microalbuminuria. Diabetes 1990; 39: 345-349

39. Krolewski AS, Canessa M, Warram JH et al: Predisposition to hypertension and susceptibility to renal disease in insulin-dependent diabetes mellitus. $N$ Engl J Med 1988; 318: 140-145 
40. Wiseman M, Viberti GC, Mackintosh J, Jarret RF, Keen H: Glycemia, arterial pressure and microalbuminuria in type 1 (insulin-dependent) diabetes mellitus. Diabetologia 1984; 26: 401-405

41. Chase HP, Garg SK, Harris S, Hoops SL, Marshall G: High-normal blood pressure and early diabetic nephropathy. Arch Int Med 1990; 150: 639-641

42. Mangili R, Bending IJ, Scott G, Gupta A, Viberti GC: Increased sodium-lithium countertransport activity in red cells in patients with insulin-dependent diabetes and nephropathy. $N$ Engl J Med 1988; 318: 146-150

43. Viberti GC: Low-protein diet and progression of diabetic kidney disease. Nephrol Dial Transplant 1988; 3: 334-339

44. Wiseman MJ, Bogneth MJ, Dodds R, Keen H, Viberti GC: Changes in renal function in response to protein restricted diet in type I diabetes. Diabetologia 1987; 30: 154-159

45. American Diabetes Association: Nutritional recommendations and principles for individuals with diabetes mellitus: 1986. Diabetes Care 1987; 10: 126-132

46. Selby JV, Fitzsimmons SC, Newman JM, Katz PP, Sepe S, Showstack J: The natural history and epidemiology of diabetic nephropathy. JAMA 1990; 263: 1954-1960

47. Kannel WB, McGee DL: Diabetes and cardiovascular risk factors: the Framingham study. Circulation 1979; 59: 8-13

48. Butler JR, Ostrander JR, Carmen WJ, Lamphiear DE: Mortality from coronary heart disease in the Tecumsch study. Am J Epidemiol 1985; 121: 541-547

49. Donahue RP, Abbott RD, Reed DM, Yano K: Postchallenge glucose concentration and coronary heart disease in men from Japanese ancestry: Honolulu Heart Program. Diabetes 1987; 36: 689-692

50. Scheidt-Nave C, Barrett-Conner E, Wingard DL, Cohn BA, Edelstein SL: Sex differences in fasting glycemia as a risk factor for ischemic heart disease and death. Am J Epidemiol 1991; 133: 565-576

51. Reaven GR: Insulin resistance and compensatory hyperinsulinemia: Role in hypertension, dyslipidemia and coronary heart disease. American Heart Journal 1991; 121 (suppl. 4): $1283-1288$

52. Krolewski AR, Warren JH: Epidemiology of diabetes mellitus. In: Joslin's Diabetes Mellitus. Marble A, Krall LP, Bradley RS, Christlieb AR, Souldner JS, Eds. Philadelphia, Lea and Febiger, pp 12-42

53. Roccella, on behalf of the Working group on hypertension in Diabetes. Statement on hypertension in diabetes mellitus. Arch Intern Med 1987; 146: 830-842

54. Deckert T, Feldt-Rasmussen B, Borch-Johnsen K, Jensen T, Kofoed-Enevoldsen A: Albuminuria reflects widespread vascular damage: the Steno hypothesis. Diabetologia 1989; 32: 219-226

55. Schwartz CJ, Valente AJ, Sprague EA, Kelley JL, Nerem RM: The pathogenesis of atherosclerosis; an overview. Clin Cardiol 1991; 14: I1-16

56. Heesen BJ, Wolffenbuttel BHR, Leurs PB, et al: Lipoprotein(a) levels in relation to diabetic complications in patients with non-insulin dependent diabetes. Eur J Clin Invest 1993; 23: 580-584

57. Bagdade JD, Root RK, Bulger RJ: Impaired leucocyte function in patients with poorly controlled diabetes. Diabetes 1974; 23: 9-15

58. Stehouwer CDA, Stroes ESG, Hackeng EHL, Mulder PGH, den Ottolander GJH: Von Willebrand factor and development of diabetic nephropathy in insulin-dependent diabetes mellitus. Diabetes 1991; 40: 971-976 
59. Mullarkey CJ, Edelstein D, Brownlee M: Free radical generation by early glycosylation products: a mechanism for accelerated atherogenesis in diabetes. Biochem Biophys Res Comm 1990; 713: 932-939

60. Cohen I, Burk D, Fullerton RJ, Veis A, Green D: Non-enzymatic glycation of human blood platelet proteins. Thromb Res 1989; 55: 341-349

61. Pirart J: Diabetes mellitus and its degenerative complications: a prospective study of 4,400 patients observed between 1947 and 1973. Diabete Metab 1977; 3: 97-107

62. Pirart J: Diabetes mellitus and its degenerative complications: a prospective study of 4,400 patients observed between 1947 and 1973. Part 2. Diabete Metab 1977; 3: 173-182

63. Pirart J: Diabetes mellitus and its degenerative complications: a prospective study of 4,400 patients observed between 1947 and 1973. Part 3. Diabete Metab 1977; 3: 245-256

64. Low PA, Tuck RR, Takenchi M: Diabetic neuropathy. In: Dyck PJ, Thomas PK, Abury AK, Eds. Philadelphia 1987, WB Saunders, pp 266-278

65. Dyck PJ, Hansen S, Karnes J, et al: Capillary number and percentage closed in human sural nerve. Proc Natl Acad Si U USA 1985; 82: 2513-2517

66. Raff MC, Ashbury AK, Ischemic mononeuropathy and mononeuropathy multiplex in diabetes mellitus. $N$ Engl J Med 1968; 279: 17-21

67. Low PA, Tuck RR, Dyck PJ, Schmelzer JD, Yao JK: Prevention of some electrophysiologic and biochemical abnormalities with oxygen supplementation in experimental diabetic neuropathy. Proc Natl Acad Sci USA 1984; 81: 6894-6898

68. Vinik AI, Holland MT, LeBeau JM, Liuzzi FJ, Stansberry KB, Colen LB: Diabetic neuropathies. Diabetes Care 1992; 15: 1927-1975

69. McCullock DK, Campbell IW, Prescott RJ, Clarke BF: Effect of alcohol intake on symptomatic peripheral neuropathy in diabetic men. Diabetes Care 1980; 3: 245-247

70. Rabinowe SL, Brown FM, Watts M, Kadrofske MM, Vinik AI: Anti-sympathetic ganglia antibodies and postural blood pressure in IDDM subjects of varying duration and patients at high risk of developing IDDM. Diabetes Care 1989; 12: 1-6

71. Edmonds ME: The diabetic foot: pathophysiology and treatment. Clin Endocrinol Metab 1986; 15: 889-916

72. Lithner F: Epidemiology and economic impact of the diabetic foot - a major health care problem. In: The diabetic foot. Bakker K, Nieuwenhuijzen Kruseman AC, Eds. Amsterdam, Excerpta Medica 1991, pp 9-17

73. Bild DE, Selby JV, Sinnock P, Browner WS, Braveman P, Showstack JA. Lower extremity amputation in people with diabetes -epidemiology and prevention. Diabetes Care 1989; 12: 24-31

74. Most RS, Sinnock P: The epidemiology of lower extremity amputations in diabetic individuals. Diabetes Care 1983; 6: 87-91

75. Osmundson PJ, O'Fallon WM, Zimmerman BR, Kazmier FJ, Langworthy AL, Palumbo PJ: Course of peripheral occlusive disease in diabetes by vascular laboratory assessment. Diabetes Care 1990; 13: 143-152

76. Fagerberg SE: Studies on the pathogenesis of diabetic neuropathy. Acta Med Scand 1956; 154: 145-148

77. Bencosme RA, West RO, Kerr JW, Wilson DL: Diabetic capillary angiopathy in human skeletal muscles. Am J Med 1966; 40: 67-70

78. Aagenaes $\mathrm{O}$, Moe H: Light- and electronmicroscopic studies of skin capillaries of diabetics. Diabetes 1961; 10: 253-255

79. Siperstein MD, Hunger RH, Madison LL: Studies of skeletal muscle capillary basement membranes in normal subjects, diabetic and prediabetic patients. J Clin Invest 1968; 47: 1973-1999 
80. Karam JH, Rosenthal M, O'Donnell J], et al: Discordance of diabetic microangiopathy in identical twins. Diabetes $1976 ; 25: 24-28$

81. Raskin P, Pietri AO, Unger R, Shannon WA: The effect of diabetic control on the width of skeletal muscle basement membrane in patients with type 1 diabetes mellitus. N Engl J Med 1983; 309: 1546-1550

82. Cagliero E, Maiello M, Boeri D, Roy S, Lorenzi M: Increased basement membrane components in human endothelial cells cultured in high glucose. J Clin Invest 1988; 82: 735-738

83. Williamson JR, Kilo C: Capillary basement membranes in diabetes. Diabetes 1983; 32 (suppl. 2): 96-100

84. Nyengaard JR, Rasch R: The impact of experimental diabetes in rats on glomerular capillary number and sizes. Diabetologia 1993; 36: 189-194

85. Yarom R, Zirkin H, Stämmler G, Rose AG: Human coronary microvessels in diabetes and ischaemia. Morphometric study of autopsy material. J Pathol 1992; 166: 265-270

86. Bohlen HG, Hankins KG: Early microvascular pathology during hyperglycemia in bats. Blood Vessels 1983; 20: 213-220

87. Bohlen HG, Niggl BA: Arteriolar anatomical and functional abnormalities in juvenile mice with genetic or streptozotocin-induced diabetes mellitus. Circ Res 1979; 45: 390396

88. Bohlen HG, Hankins KD: Early arteriolar and capillary changes in streptozotocininduced diabetic rats and intraperitoneal hyperglycemic rats. Diabetologia 1982; 22: 344-348

89. Gundersen HJG: Peripheral blood flow and metabolic control in control in juvenile diabetes. Diabetologia 1974; 10: 225-231

90. Christensen NJ: A reversible vascular abnormality associated with diabetic ketosis. Clin Sci 1970; 10: 439-458

91. Gitelson S, Wertheimer-Kaplinski N: Color of the face in diabetes mellitus. Diabetes 1965; 14: 201-208

92. Chazan BI, Balodimos MC, Lavine RL, Koncz L: Capillaries of the nailfold of the toe in diabetes mellitus. Microvasc Res 1970; 2: 504-507

93. Skouborg F, Nielsen AV, Lauritzen $\mathrm{E}$, et al: Diameters of the retinal vessels in diabetic and normal subjects. Diabetes 1969; 18: 292-298

94. Cunha-Vaz JG, Fonseca JR, Abreu JRF, et al: Studies on retinal blood flow II. Diabetic retinopathy. Arch Ophthalmol 1978; 96: 809-811

95. Stefansson E, Lander MB III, Wolbarsht ML: Oxygenation and vasodilatation in relation to diabetic and other proliferative retinopathies. Ophthalmic Surg 1983: 14: 209226

96. Zatz R, Brenner BM: Pathogenesis of diabetic microangiopathy. The hemodynamic view. Am J Med 1986; 80: 443-453

97. Parving H-H, Viberti GC, Keen $\mathrm{H}$, Christiansen JS, Lassen NA. Hemodynamic factors in the genesis of diabetic angiopathy. Metabolism 1983; 32: 943-949

98. Brody MJ, Dixon RL: Vascular reactivity in experimental diabetes mellitus. Circ Res 1964; 14: 494-501

99. Abebe W, Harris KH, MacLeod KM: Enhanced contractile responses of arteries from diabetic rats to $\alpha 1$-adrenoceptor stimulation in the absence and presence of extracellular calcium. / Cardiovasc Pharmacol 1990; 16: 239-248

100. Abebe W, MacLeod KM: Protein kinase C-mediated contractile responses of arteries from diabetic rats. Br J Pharmacol 1990; 101: $465-471$ 
101. Abebe W, MacLeod KM: Augmented inositol phosphate production in mesenteric arteries from diabetic rats. Eur J Pharmacol 1990; 225: 29-36

102. Morff RJ: Microvascular reactivity at different arteriolar levels and different durations of streptozotocin-induced diabetes. Diabetes 1990; 39: 354-360.

103. Friedman JJ: Vascular sensitivity and reactivity to norepinephrine in diabetes mellitus. Am J Physiol 1989; 256: H1134-1138

104. Ramanadham S, Lyness WH, Tenner TE: Alterations in aortic and tail reactivity to agonists after streptozotocin treatment. Can J Physiol Pharmacol 1984; 62: 418-423

105. Sullivan S, Sparks HV: Diminished contractile responses of aortas from diabetic rabbits. Am J Physiol 1979; 236: H301-306

106. Eichler HG, Blaschke TF, Kraemer FB, Ford GA, Blöchl-Daum B, Hoffman BB: Responsiveness of superficial hand veins to $\alpha$-adrenoceptor agonists in insulindependent diabetic patients. Clin Sci 1992; 82: 163-168

107. Christ GJ, Schwartz CB, Stone BA, et al: Kinetic characteristics of $\alpha 1$-adrenergic contractions in human corpus cavernosum smooth muscle. Am J Physiol 1992; 263: H15-19

108. Christlieb AR, Janka H-U, Kraus B, et al: Vascular reactivity to angiotensin II and to norepinephrine in diabetic subjects. Diabetes 1976; 4: 268-274

109. Fortes ZB, Leme JG, Scivoletto R: Vascular reactivity in diabetes mellitus: role of the endothelial cell. Br J Pharmacol 1983; 79: 771-781

110. Tesfamariam B, Jakubowski JA, Cohen RA: Contraction of diabetic rabbit aorta caused by endothelium-derived PGH $_{2}-$ TXA $_{2}$. Am I Physiol 1989; 257: H1326-1333

111. Takiguchi I, Satoh N, Hashimoto $H$, Nakashima M: Changes in vascular reactivity in experimental diabetic rats: comparison with hypothyroid rats. Blood Vessels 1988; 25: 250-260

112. Durante W, Sen AK, Sunahara FA: Impairment of endothelium-dependent relaxation in aortae from spontaneously diabetic rats. Br J Pharmacol 1988; 94: 463-468

113. Kamata K, Miyata N, Kasuya Y. Impairment of endothelium-dependent relaxation and changes in levels of cyclic GMP in aortae from streptozotocin-induced diabetic rats. Br I Pharmacol 1989; 97: 617-618

114. Saenz de Tejada I, Goldstein I, Azadzoi K, Krane RJ, Cohen RA: Impaired neurogenic and endothelium-mediated relaxation of penile smooth muscle from diabetic men with impotence. $N$ Engl J Med 1989; 320: 1025-1030

115. Smits P, Kapma JA, Jacobs MC, Lutterman J, Thien T: Endothelium-dependent vascular relaxation in patients with type 1 diabetes. Diabetes 1993; 42: 148-153

116. Calver A, Collier J, Vallance P: Inhibition and stimulation of nitric oxide synthesis in the human forearm arterial bed of patients with insulin-dependent diabetes. J Clin Invest 1992; 90: 2548-2554

117. Kuhn FE, Mohler ER, Satler LF, Reagan K, Lu DY, Rackley CE: Effects of high-density lipoprotein on acetylcholine-induced coronary vasoreactivity. Am J Cardiol 1991; 68: 1425-1430

118. Galle J, Bassenge E: Einfluß der "low-density"-lipoproteine (LDL) auf die vasomotorik. Z Kardiol 1991; 80 (suppl. 9): 15-20

119. Parving $\mathrm{H}-\mathrm{H}$, Noer I, Deckert $\mathrm{T}$, et al: The effect of metabolic regulation on microvascular permeability to small and large molecules in short-term juvenile diabetics. Diabetologia 1976; 12: 161-166

120. O'Hare JA, Twomey B, O'Sullivan DJ: Poor metabolic control, hypertension and microangiopathy independently increase the transcapillary escape rate of albumin in diabetes. Diabetologin 1983; 25: 260-263 
121. Bollinger A, Frey J, Jäger K, Furrer J, Seglias J, Siegenthaler W: Patterns of diffusion through skin capillaries in patients with long-term diabetes. N Engl J Med 1982; 307: 1305-1310

122. Feldt-Rasmussen B: Increased transcapillary escape rate of albumin in type 1 (insulindependent) diabetic patients with microalbuminuria. Diabetologia 1986; 29: 282-286

123. Kilzer P, Chang K, Marvel J, et al: Albumin permeation of new vessels is increased in diabetic rats. Diabetes $1985 ; 34: 333-336$

124. Williamson JR, Chang $K$, Tilton RG, et al: Increased vascular permeability in spontaneously diabetic $B B / W$ rats and in rats with mild versus severe streptozotocininduced diabetes: prevention by aldose reductase inhibitors and castration. Diabetes 1987; 36: 813-821

125. Tilton RG, Chang K, Pugliese G, et al: Prevention of hemodynamic and vascular albumin filtration changes in diabetic rats by aldose reductase inhibitors. Diabetes 1989; 38: 1258-1270

126. Corbett JA, Tilton RG, Chang $K$, et al: Aminoguanidine, a novel inhibitor of nitric oxide formation, prevents diabetic vascular dysfunction. Diabetes 1992; 41: 552-556

127. Tilton RG, Chang K, Hasan KS, et al: Prevention of diabetic vascular dysfunction by guanidines. Inhibition of nitric oxide synthase versus advanced glycosylation endproduct formation. Diabetes 1993; 42: 221-232

128. Tucker BJ: Early onset of increased transcapillary escape rate in awake diabetic rats. Diabetes 1990; 39: 919-922

129. Zatz R, Meyer TW, Rennke HG, Brenner BM: Predominance of hemodynamic rather than metabolic factors in the pathogenesis of diabetic glomerulopathy. Proc Natl Acad Sci USA 1985; 82: 5963-5967

130. Sandeman DD, Shore AC, Tooke JE: Relation of skin capillary pressure in patients with insulin-dependent diabetes mellitus to complications and metabolic control. $N$ Engl J Med 1992; 327: 760-764

131. Spiro RG: Pathogenesis of diabetic glomerulopathy: a biochemical view. In: The Kidney and Hypertension in diabetes. Mogensen CE, Ed. Boston, Martinus Nijhoff Publishing, 1988.

132. Shimomura H, Spiro RG: Studies on the macromolecular components of human glomerular basement membrane and alterations in diabetes: decreased levels of heparan sulphate and laminin. Diabetes 1987; 36: 374-381

133. Van den Born J, Van den Heuvel LPWJ, Bakker MAH, et al: A monoclonal antibody against GBM heparan sulphate induces an acute selective proteinuria in rats. Kidney Int 1992; 41: 115-123

134. Microalbuminuria. Implications for micro- and macrovascular disease. Diabetes Care 1992; 15: 1181-1191

135. Simon A, Levenson A: Use of arterial compliance for evaluation of hypertension. Am J Hypertension 1990; 3: 97-105

136. Kannel WB, Castelli WP, McNamara PM: Role of blood pressure in the development of congestive heart failure. $N$ Engl J Med 1972; 287: 781-787

137. Cohn JN: Blood pressure and cardiac performance. Am J Med 1973; 55: 351-361

138. Thordarson H, Thorgeirsson $G$, Helgason $T$ : Aortic stiffness in insulin-dependent diabetics; an echocardiographic study. Diabetic Med 1986; 3: 449-454

139. Oxlund H, Andreassen TT, Heickendorff L: Increased aortic stiffness in patients with type 1 diabetes mellitus. Diabetologia 1989; 32: 748-752

140. Patel MB, Zhang PL, Patel AC, Patel KP: Altered pressure-volume relation of right atrium and venoatrial junction in diabetic rats. Am J Physiol 1992; 263: H1017-1020 
141. Dahl-Jörgensen $K$, Brinchmann-Hansen $O$, Hanssen KF, et al: Effect of near normoglycaemia for two years on progression of early diabetic retinopathy, nephropathy, and neuropathy: the Oslo study. Br Med J 1986; 293: 1195-1199

142. Lauritzen T, Frost-Larsen K, Larsen HW, Deckert T, and the Steno Study Group: Effect of 1 year near normal blood glucose levels on retinopathy in IDDM. Lancet 1983; 1: 200-204.

143. Dahl-Jörgensen K, Brinchmann-Hansen O, Hanssen KF, Sandvik L, Aagenaes O, Aker diabetes group. Rapid tightening of blood glucose control leads to transient deterioration of retinopathy in insulin dependent diabetes mellitus: the Oslo study. $\mathrm{Br} \mathrm{Med}$ J 1985; 290: 811-815

144. Lauritzen T, Frost-Larsen K, Larsen HW, Deckert T, the Steno Study Group: two-year experience with continuous subcutaneous insulin infusion in relation to retinopathy and neuropathy. Diabetes 1985; 34 (suppl. 3): 74-79

145. Friberg TR, Rosenstock J, Sanborn G, Vaghefi A, Raskin P: The effect of long-term near-normoglycemic control on mild diabetic retinopathy. Ophthalmology 1985; 92: 1051-1058

146. Rosenstock J, Friberg TR, Raskin P: Effect of glycemic control on microvascular complications in patients with type I diabetes mellitus. Am J Med 1986; 81: 1012-1017

147. Viberti GC, Pickup JC, Phil D, Jarrett RJ, Keen H: Effect of control of blood glucose on urinary excretion of albumin and $B 2$ microglobulin in insulin-dependent diabetes. N Engl J Med 1979; 300: 638-641

148. Viberti GC, Mackintosh D, Bilous RW, Pickup JC, Keen H: Proteinuria in diabetes mellitus: role of spontaneous and experimental variation of glycemia. Kidney Int 1982; 21: $714-720$

149. The Kroc Collaborative Study Group: Blood glucose control and the evolution of diabetic retinopathy and albuminuria. N Engl J Med 1984; 311: 365-372

150. Holman RR: Prevention of deterioration of renal and sensory nerve function by more intensive management of insulin dependent diabetic patients. Lancet 1983; 1(8318): 204-208

151. Viberti GC, Bilous RW, Mackintosh D, Bending JJ, Keen H: Long term correction of hyperglycaemia and progression of renal failure in IDDM. Br Med J 1983; 286: 598-602

152. Ehle AL, Raskin P: Increased nerve conduction in diabetics after a year of improved glucoregulation. J Neurol Sci 1986; 74: 191-197

153. Jakobsen J, Christiansen JS, Kristoffersen I, et al: Autonomic and somatosensory nerve function after two years of subcutaneous continuous insulin infusion in type 1 diabetes. Diabetes 1988; 37: 452-455

154. Pietri A, Ehle AL, Raskin P: Changes in nerve conduction velocity after six weeks of glucoregulation with portable insulin infusion pumps. Diabetes 1980; 29: 668-671

155. The Diabetes Control and Complications Trial Research Group: The effect of intensive treatment of diabetes on the development and progression of long-term complications in insulin-dependent diabetes mellitus. $N$ Engl J Med 1993; 329: 977-986

156. Wolffenbuttel BHR, Huijberts MSP, Heesen BJ, Leurs PB, Nieuwenhuijzen Kruseman AC: Goede instelling van diabetes verkleint de kans op diabetische complicaties. Ned Tijdschr Geneeskd 1993; 137: 2179-2183

157. Cerami A, Vlassara $\mathrm{H}$, Brownlee $\mathrm{M}$ : Role of advanced glycosylation products in complications of diabetes. Diabetes Care 1988; 11 (suppl. 1): 73-79

158. Brownlee $\mathrm{M}$ : Glycation products and the pathogenesis of diabetic complications. Diabetes Care 1992; 15: 1835-1843 
159. Duell PB, Oram JF, Bierman EL: Non-enzymatic glycosylation of HDL and impaired HDL-receptor-mediated cholesterol efflux. Diabetes 1991; 40: 377-384

160. Vlassara H, Brownlee M, Monogue KR, Dinarello CA, Pasagian A: Cachectin/TNF and IL-1 induced by glucose-modifed proteins: role in normal tissue remodeling. Science 1988; 240: 1546-1548

161. Hasegawa G, Nakano K, Sawada M, et al: Possible role of tumor necrosis factor and interleukin-1 in the development of diabetic nephropathy. Kidney Int 1991; 40: 10071012

162. Tsilibary EC, Charonis AS, Leger LA, Wohlhueter RM, Furcht RT: The effect of nonenzymatic glycosylation on the binding of the main noncollagenous $\mathrm{NCl}$ domain to type IV collagen. J Biol Chem 1988; 263: 4302-4308

163. Charonis AS, Tsilibary EC. Structural and functional changes of laminin and type IV collagen after nonenzymatic glycation. Diabetes 1992; 41 (suppl. 2): 49-51

164. Bucala R, Tracey KJ, Cerami A. Advanced glycosylation endproducts quench nitric oxide and mediate defective endothelium-dependent vasodilatation in experimental diabetes. I Clin Invest 1991; 87: 432-438

165. Vlassara H, Fuh H, Makita Z, Krungkai S, Cerami A, Bucala R: Exogenous advanced glycosylation endproducts induce complex vascular dysfunction in normal animals: A model for diabetic and aging complications. Proc Natl Acad Sci 1992; 89: 12043-12047

166. Edelstein D, Brownlee M: Mechanistic studies of advanced glycosylation endproduct inhibition by aminoguanidine. Diabetes 1992; 41: 26-29

167. Brownlee $M$, Vlassara $H$, Kooney A, Ulrich P, Cerami A: Aminoguanidine prevents diabetes-induced arterial wall protein cross-linking. Scilnce 1986; 232: 1h29-1632

168. Hammes H-P, Martin S, Federlin K, Geisen K, Brownlee M: Aminoguanidine treatment inhibits the development of experimental diabetic retinopathy. Proc Natl Acad Sci USA 1991; 88: 11555-11558

169. Soulis-Liparota T, Cooper M, Papazoglou D, Clarke B, Jerums G: Retardation by aminoguanidine of development of albuminuria, mesangial expansion, and tissue fluorescence in streptozotocin-induced diabetic rat. Diabetes 1991; 40: 1328-1334

170. Edelstein D, Brownlee M: Aminoguanidine ameliorates albuminuria in diabetic hypertensive rats. Diabetologia 1992; 35: 96-97

171. Ellis EN, Good BH: Prevention of glomerular basement membrane thickening by aminoguanidine in experimental diabetes mellitus. Metabolism 1991; 40: 1016-119

172. Kihara M, Schmelzer JD, Poduslo JF, Curran GL, Nickander KK, Low PA: Aminogiuanidine effects on nerve blood flow, vascular permeability, electrophysiology and oxygen free radicals. Proc Natl Acad Sci USA 1991; 88: 6107-6111

173. Cameron NE, Cotter MA, Dines K, Love A: Effects of aminoguanidine on peripheral nerve function and polyol pathway metabolites in streptozotocin-diabetic rats. Diabetologia 1992; 35: 946-950

174. Yagihashi S, Kamijo M, Baba M, Yagihashi N, Nagai K: Effect of aminoguanidine on functional and structural abnormalities in peripheral nerve of STZ-induced diabetic rats. Diabetes 1992; 41: 47-52

175. Oxlund $\mathrm{H}$, Andreassen TT: Aminoguanidine treatment reduces the increase in collagen stability of rats with experimental diabetes mellitus. Diabetologia 1992; 35: 19 25

176. Orosz SE, Townsend SF, Tornheim PA, Brownscheidle CM: Localization of aldose reductase and sorbitol dehydrogenase in the nervous system of normal and diabetic rats. Acta Diabetol Lat 1981; 18: 373-381 
177. Kennedy A, Frank RN, Varma SD: Aldose reductase in retinal and cerebral microvessels and cultured vascular cells. Invest Ophthalmol Vis Sci 1983; 24: 1250-1254

178. Corder CN, Braughler JM, Culp PA: Quantitative histochemistry of the sorbitol pathway in glomeruli and small arteries of human diabetic kidney. Folia Histochem Cytochem 1979; 17: 137-146

179. Cheng HM, Gonzalez RG: The effect of high glucose and oxidative stress on lens metabolism, aldose reductase, and senile cataractogenesis. Metabolism 1986; 35 (suppl. 1): $10-14$

180. Berridge MJ: Intracellular signalling through inositol trisphosphate and diacylglycerol. Biol Chem Hoppe Seylet 1986; 367: 447-456

181. Williamson JR, Chang K, Frangos M, et al: Hyperglycemic "pseudohypoxia" and diabetic complications. Diabetes 1993; 42: 801-813

182. Williamson $\mathrm{J}$, Chang $\mathrm{K}$, Rowold $\mathrm{E}$ et al : Diabetes-induced changes in vascular permeability and changes in granulation tissue levels of sorbitol, myo-inositol, chiroinositol, and scyllo-inositol are prevented by sorbinil. Metabolism 1986; 35: 41-45

183. Pugliese G, Tilton RG, Speedy A, et al: Modulation of hemodynamic and vascular filtration changes in diabetic rats by dietary myo-inositol. Diabetes 1990; 39: 312-322

184. Cohen MP, Dasmahapatra A, Shapiro E: Reduced glomerular sodium/potassium adenosine triphosphatase activity in acute streptozotocin diabetes and its prevention by sorbinil. Diabetes 1985; 35: 1071-1074

185. Goldfarb S, Ziyadeh FN, Kern EFO, Simmons DA: Effects of polyol-pathway inhibition and dietary myo-inositol on glomerular hemodynamic function in experimental diabetes in rats. Diabetes $1991 ; 40: 465-471$

186. Chang WP, Dimitriadis E, Allen T, Dunlop ME, Cooper M, Larkins RG: The effect of aldose reductase inhibitors on glomerular prostangladin production and urinary albumin excretion in experimental diabetes mellitus. Diabetologia 1991; 34: 225-231

187. Griffin BW, McNatt LG, Chandler ML, York BM: Effects of two new aldose reductase inhibitors, AL-1567 and AL-1576, in diabetic rats. Metabolism 1987; 36: 486-490

188. Stribling D, Mirrlees ZDJ, Harrison HE, Earl DCN: Properties of ICI 128,436, a novel aldose reductase inhibitor, and its effects on diabetic complications in the rat. Metabolism 1985; 34: 336-344

189. Greene DA, Lattimer S: Action of sorbinil in diabetic peripheral nerve. Relationship of polyol (sorbitol) pathway inhibition to a myo-inositol mediated defect in sodiumpotassium ATP-ase activity. Diabetes $1984 ; 33: 712-716$

190. Engerman RL, Kern TS: Aldose reductase fails to prevent retinopathy in diabetic and galactosemic dogs. Diabetes 1993; 42: 820-825

191. The sorbinil retinopathy trial research group: A randomized trial of sorbinil, an aldose reductase inhibitor, in diabetic retinopathy. Arch Ophthalmol 1990; 108: 1234-1244

192. Pedersen MM, Christiansen JS, Mogensen CE: Reduction of glomerular hyperfiltration in normoalbuminuric IDDM patients by $6 \mathrm{mo}$ of aldose reductase inhibition. Diabetes 1991; 40: 527-531

193. Dzau VJ: Circulating versus local renin-angiotensin system in cardiovascular homeostasis. Circulation 1988; 77 (suppl. 1): I4-13

194. Campbell DJ: Circulating and tissue angiotensin systems. / Clin Inoest 1987; 79: 1-6

195. Ganten D, Hermann K, Bayer C, Unger T, Lang RE: Angiotensin synthesis in the brain and increased tumover in hypertensive rats. Science 1983; 221: 869-871

196. Lindpaintner K, Ganten D: The cardiac renin-angiotensin system. An appraisal of present experimental and clinical evidence. Circ Res 1991; 68: 905-921 
197. Naruse K, Inagami M: Markedly elevated specific renin in the adrenal in genetically hypertensive rats. Proc Natl Acad Sci USA 1982; 79: 3295-3297

198. Aguilera G, Schirar A, Baukal A, Catt KJ: Circulating angiotensin II and adrenal receptors after nephrectomy. Nature 1981; 289: 507-509

199. Dzau VJ, Pratt RE: Renin-angiotensin system: biology, physiology and pharmacology. In: Handbook of experimental cardiology. Haber E, Morgan H, Katz A, Fozzard H, Eds. New York, Raven Press 1986, pp 1631-1661

200. Rosenthal JH, Pfeiffe B, Michailov ML, Pschorr J, Jacob ICM, Dehiheim H: Investigation of components of the renin angiotensin system in rat vascular tissue. Hypertension 1984; 6: 383-390

201. Dzau VJ, Ellison K, McGowan D, Gross KW, Ouellette A: Hybridization studies with a renin cDNA probe: evidence for widespread expression of renin in the mouse. $J$ Hypertension 1984; 2: 235-237

202. Kunapuli SP, Benedict CR, Kumar A: Tissue specific hormonal regulation of the rat angiotensinogen gene expression. Arch Biophys Biochem 1987; 254: 642-646

203. Ohkubo H, Nakayama K, Tanaka T, Nakanishi S: Tissue distribution of rat angiotensinogen mRNA and structural analysis of heterogeneity. J Biol Chem 1986; 261:319-323

204. Schelling P, Fischer H, Ganten D: Angiotensin and cell growth: a link to cardiovascular hypertrophy? J Hypertension 1991; 9: 3-15

205. Geisterfer AAT, Peach MJ, Owens GK: Angiotensin II induces hypertrophy not hyperplasia, of cultured rat aortic smooth muscle cells to angiotensin II. Circ Res 1988; 62: $749-756$

206. Powell JS, Clozel JP, Mueller RKM, et al: Inhibitors of angiotensin-converting enzyme prevent myointimal proliferation after vascular injury. Science 1989; 245: 186-188

207. Fernandez LA, Twickler J, Mead A: Neovascularization produced by angiotensin II. J Lab Clin Med 1985; 105: 141-145

208. Christlieb AR: Nephropathy, the renin system and hypertensive vascular disease in diabetes mellitus. Cardiovasc Med 1978; 2: 417-431

209. Fernadaz-Cruz A, Noth RH, Lassman MN, Hollis JB, Mulrow PJ: Low plasma renin activity in normotensive patients with diabetes mellitus: relationship to neuropathy. Hypertension 1981; 3: 87-92

210. Chatel R de, Wiedmann P, Flammer J, et al: Sodium, renin, aldosterone, catecholamines and blood pressure in diabetes mellitus. Kidney Int 1977; 12: 412-421

211. O'Hare JA, Ferris JB, Brady D, Twomey B, O'Sullivan DJ: Exchangeable sodium and renin in hypertensive diabetic patients with and without nephropathy. Hypertension 1985; 7(suppl 2): 43-48

212. Burden AC, Thurston H: Plasma renin activity in diabetes mellitus. Clin Sci 1979; 56: 255-259

213. Drury PL, Bodansky HJ: The relationship of the renin-angiotensin system in Type I diabetes to microvascular disease. Hypertension 1985; 7 (suppl. 2): 84-89

214. Cassis L: Downregulation of the renin-angiotensin system in streptozotocin diabetic rats. Am J Physiol 1992; 262: E105-109

215. Everett AD, Scott J, Wilfong $\mathrm{N}$, et al: Renin and angiotensin expression during the evolution of diabetes. Hypertension 1992; 19: 70-78

216. Franken AAM, Derkx FHM, Man in 't Veld AJ, et al: High plasma prorenin in diabetes mellitus and its correlation with some complications. / Clin Endocrinol Metab 1990; 71: 1008-1015 
217. Danser AHJ, van den Dorpel MA, Deinum J, et al: Renin, prorenin and immunoreactive renin in vitreous fluid from eyes with and without diabetic retinopathy. J Clin Endocrinol Metab 1989; 68: 160-167

218. Passa P, Leblanc $H$, Marre M: Effects of enalapril in insulin-dependent diabetic subjects with mild to moderate hypertension. Diabetes Care 1987: 10: 200-204

219. Taguma Y, Kilamot I, Futaki G, et al: Effect of captopril on heavy proteinuria in azotemic diabetics. $N$ Engl J Med 1985; 313: 1617-1620

220. Zatz R, Dunn BR, Meyer TW, Anderson S, Rennke HG, Brenner BM: Prevention of diabetic glomerulopathy by pharmacological amelioration of glomerular capillary hypertension. J Clin Inve'st 1986; 77: 1925-1930

221. Ferriere $\mathrm{M}$, Lachkar $\mathrm{H}$, Richard $\mathrm{JL}$, et al: Captopril and insulin sensitivity. Ann Intern Med 1985; 102: 134-135

222. Saltvedt E, Andreassen P, Dahl K, et al: An improved serum lipid profile in hypertensives during captopril treatment. Postgrad Med J 1986; 62(suppl. 1): 62

223. Marre M, Chatellier $G$, Leblanc $H$, et al: Prevention of diabetic nephropathy with enalapril in normotensive diabetics with microalbuminuria. Br Med J 1988; 297: 10921095

224. Anderson S, Rennke HG, Garcia DL, Brenner BM: Short- and long-term effects of antihypertensive therapy in the diabetic rat. Kidney Int 1989; 36: 526-536

225. Björck S, Mulec ZH, Johnsen SA, Nyberg G, Aurell M: Contrasting effects of enalapril and metoprolol on proteinuria in diabetic nephropathy. Br Med J 1990; 300: 904-906

226. Mimran A, Insue A, Ribstein J, Bringer J, Monnier L: Comparative effect of captopril and nifedipine in normotensive patients with incipient diabetic nephropathy. Diabetes Care 1988; 11: 850-853

227. Stornello M, Valvo EV, Scapellato L: Persistent albuminuria in normotensive noninsulin dependent (type II) diabetic patients: comparative effects of angiotensinconverting enzyme inhibitors and B-adrenoceptor blockers. Clin Sci 1992; 82: 19-23

228. Melbourne Diabetic Nephropathy Study Group: Comparison between perindoprilat and nifedipine in hypertensive and normotensive diabetic patients with microalbuminuria. Br Med J 1991; 302: 210-216

229. De Zeeuw D, Heeg JE, de Jong PE: The anti-proteinuric effect of angiotensin converting enzyme inhibitors in human renal disease. International Yearbook of Nephrology 1992: 95-113

230. Heeg JE, de Jong PE, van der Hem GK, de Zeeuw D: Angiotensin II does not acutely reverse the reduction of proteinuria by long-term ACE inhibition. Kidney Int 1991; 40: 734-741

231. Morelli E, Loon N, Meyer T, Peyers W, Myers BD: Effects of converting enzyme inhibition on barrier function in diabetic glomerulopathy. Diabetes 1990; 39: 76-82

232. Tomlinson KC, Gardiner SM, Hebden RA, Bennett T: Functional consequences of streptozotocin-induced diabetes mellitus, with particular reference to the cardiovascular system. Pharmacol Rev 1992; 44: 103-150

233. Rakieten N, Rakieten ML, Nadkarni MV: Studies on the diabetogenic action of streptozotocin. Cancer Chemother Rep 1963; 29: 91-94

234. Bell RH, Hye RJ: Animal models of diabetes mellitus: physiology and pathology. $J$ Surg Res 1983; 35: 433-460 


\section{MICROVASCULAR DERANGEMENTS}





\section{CHAPTER 2}

Changes in microvascular diameters and microvascular density following diabetes induction

M.S.P. Huijberts, B.H.R. Wolffenbuttel, F.R.L. Crijns, A.C. Nieuwenhuijzen Kruseman, H. van Essen, H.A.J. Struijker Boudier

(submitted) 



\section{SUMMARY}

Diabetes mellitus is often complicated by the development of vascular lesions. The microcirculation is particularly susceptible to diabetes-induced injury. We used the dorsal microcirculatory chamber, a preparation in conscious rats suited for long-term measurements of striated muscle microvessels, in order to observe the direct effects of diabetes induction with streptozotocin on the microcirculation. 14 Male Wistar Rp rats were used and implanted with a dorsal microcirculatory chamber at the age of 6-7 weeks. After three weeks recovery, rats were divided into a control group $(n=7)$ and a diabetic group $(\mathrm{n}=7)$, in which diabetes was induced by i.p. injection with $70 \mathrm{mg} / \mathrm{kg}$ streptozotocin. Using intravital microscopy, recordings of selected arterioles and venules were made before diabetes induction and then weekly for a period of 6 weeks. Vessel diameters were measured off-line with an image-shearing device. In parallel, photographic pictures were taken of all the preparations; vascular densities of different vessel classes were determined from these slides using a standard grid-counting method. After diabetes induction no effects on diameters of larger A1 and A2 arterioles were observed. However, the smallest A3/A4 arterioles showed a gradual constriction after streptozotocin-administration. In addition, 4 and 6 weeks after diabetes induction an increased density of venules was observed. These results indicate that also in microvascular beds which are not specifically known for diabetes-related damage, vascular alterations develop already shortly after diabetes induction.

\section{INTRODUCTION}

The microcirculation is one of the systems that is very susceptible to diabetesinduced damage. Since the discovery of insulin and the subsequent survival of patients with diabetes it has become clear that this disease has deleterious effects on the microvasculature of various organs. Most vulnerable are the microvascular beds of the retina and the kidney, where severe vascular damage leading to terminal organ dysfunction can develop. However, there are also indications that the microcirculation in general is affected by diabetes. Microcirculatory studies that have been performed in both humans and animals, show evidence for vasodilation leading to increased flow (1-3), increased permeability (4-6), and increased pressure (7). This has led to the hypothesis of hyperperfusion damage induced by diabetes. On the other hand, especially in more advanced stages where microangiopathy is already present, signs of diminished flow have been observed (8-10). In human studies nevertheless, the necessity of giving some kind of anti-hyperglycemic treatment can make it difficult to answer questions concerning the effects of hyperglycemia per se on the microcirculation. The streptozotocin-induced diabetic rat is an 
animal model which does not require insulin for prolonged survival. Morphometric studies regarding the effects of diabetes on the microcirculation in this model are scarce, however.

In this study we wanted to investigate the effects of diabetes induction with streptozotocin on microvascular diameters and microvascular density in vivo, using the dorsal microcirculatory preparation. This model allows us to observe sequentially striated muscle arteriolar and venular diameters and vascular density following diabetes induction with streptozotocin in conscious unrestrained diabetic rats.

\section{MATERIALS AND METHODS}

\section{Animals}

Male Wistar Rp rats (TNO-REPGO, Rijswijk, the Netherlands) were used. Rats were obtained shortly after weaning (60-100 g) and were immediately trained in order to habituate them to sit unstressed in a rodent restrainer minimizing motion without hampering normal respiration, for at least two hours. As soon as rats attained a body weight of 130-140 $\mathrm{g}$ they were implanted with a dorsal microcirculatory chamber. After a period of three weeks allowed for recovery, the quality of microcirculatory preparations was evaluated according to criteria described below. After admission to the study rats were randomized into a control group $(n=7)$ and a diabetic group $(n=7)$. Diabetes was induced by i.p. injection of $70 \mathrm{mg} / \mathrm{kg}$ streptozotocin (Sigma, St. Louis, MO, USA) in citrate buffer ( $\mathrm{pH} 4.5$ ). Rats in the control group received an injection with the vehicle. Development of diabetes was assessed by blood glucose measurements using a hexokinase method.

\section{Implantation of the dorsal microcirculatory chamber}

This model is described in detail elsewhere $(11,12)$. The dorsal microcirculatory chamber consists of two halves of polycarbonate with a tissue culture cover slip (Thermanox, Nunc Inc., Naperville, IL, USA) in the central area where the muscle is exposed. Rats undergo surgery when their body weights are in the range of 130-140 g. Surgery is performed under sterile conditions and antibiotic prophylaxis with amfipenicilline (Gist-Brocades, Delft, The Netherlands) is given perioperatively. Anesthesia was induced with a mixture of ketamine (5 $\mathrm{mg} / \mathrm{kg})$ and xylazine $(1 \mathrm{mg} / \mathrm{kg})$, and subsequently the back of the rat was shaven and depilated with a standard chemical depilating agent.

The dorsal skin was then disinfected with povidone-iodine (Betadine, Dagra, Diemen, The Netherlands). To maintain anesthesia $30 \mathrm{mg} / \mathrm{kg}$ of pentobarbital was injected, and the dorsal skin of the rat was attached to a D-shaped stainless steel frame by means of sutures placed through the skin along the vertebral column. In this way a dorsal skinfold was formed. On the right side of the 
rat a circular area of $11 \mathrm{~mm}$ was excised, and subsequently connective tissue covering the inside of the contralateral cutaneous maximus muscle was removed. Eventual microbleedings were stopped by application of thrombin (Sigma, St. Louis, MO, USA) which was carefully removed afterwards. The right chamber half was then positioned and securing screws were placed through small dermal incisions. The rat, still attached to the D-shaped frame, was then turned on its right side, exposing the left side of the skinfold. Another circular area $(\varnothing 15 \mathrm{~mm})$, exactly opposing the excised part on the right side was demarcated, and in this area the skin was very precisely separated from the cutaneous maximus muscle underlying it. The exposed muscle was immersed in sterile saline and the other chamber half was put in place. Stainless steel nuts were fitted to the securing screws penetrating both sides of the skinfold, excess length of the screws was cut off and finally a drop of glue was applied on top of the nuts. The animal was detached from the frame and provided with an aluminum cap to protect the chamber.

After surgery, the animals were housed in separate cages in rooms with controlled light and temperature, to which they had previously been acclimatized. Each week the preparation was gently cleaned using povidone-iodine and sterile saline under anesthesia. Three weeks were allowed for recovery and evaluation of the preparation. The preparation was included in the study when 1) no bleeding occurred, 2) no signs of inflammation were present, and 3) vasomotion was visible.

\section{Measurement of microvascular diameters}

Following admission to the study, baseline microvascular measurements were made (week 0 ). To this end, rats were placed in the rodent restrainer and positioned in a horizontally mounted Leitz Orthoplan microscope, allowing the rats to sit in their natural position. First, the entire preparation was observed at low magnification (Zeiss Plan objective 2.5x; numeric aperture (NA) 0.08 ) to document the microvasculature and its angioarchitecture. Individual segments of the arteriolar and venular tree were inspected using a Zeiss Plan 10x; NA 0.25 . Small arterioles and venules were grouped according to functional branching order and were classified alphanumerically. Corresponding to this classification, A1 arterioles (80-140 $\mu \mathrm{m})$, are the primary perfusing arterioles, and their branches are designated second order arterioles (A2; resting diameters $40-80 \mu \mathrm{m}$ ). The precapillary arterioles (A3 and A4; resting diameters 10-40 $\mu \mathrm{m})$ primarily serve blood distribution within the microvascular segment. Venules are classified similarly but have slightly larger diameters compared to arterioles of the same order.

Combining all this information, a detailed map of the muscle microcirculation was made and arterioles and venules of different orders were selected for weekly measurements. Individual video recordings of the vessels were made subsequently. Diameters were recorded for at least 1 minute per vessel. Video 
recordings of the selected vessels were repeated every week for a period of 6 weeks. Arteriolar and venular diameters were analyzed off-line with an image shearing device (13).

\section{Determination of microvascular density}

In parallel with the weekly video recordings of selected vessels, photographic pictures were made of each preparation enrolled in the study. Slides (Kodak Ektachrome 64) were taken with a Nikon F-301 camera with a $50 \mathrm{~mm}$ f/1.8 Nikkor lens, a polarizing filter and a Novoflex automatic extension bellow, mounted on a small stage. Rats were placed on the stage and gently restrained by hand. A flash light (Metz Mecablitz 32CT3) was used to transilluminate the microcirculatory preparation. The extension of the bellow resulted in a $2 x$ magnification. A resolution of $10 \mu \mathrm{m}$ was calculated for these slides.

The slides made in week 0 , week 4 , and week 6 were used to determine microvascular diameters according to standard stereological techniques. Microvascular density index (VDI) values were determined by counting the number of intersections with a line grid placed on a projection of the slide. For $\mathrm{A} 1 / \mathrm{A} 2$ arterioles and V1/V2 venules a grid with a depth of $800 \mu \mathrm{m}$ and a total grid length of $314 \mathrm{~mm}$ was used. For smaller vessels $>10 \mu \mathrm{m}$ no discrimination could be made between arterioles and venules. For these vessels a grid with a depth of $110 \mu \mathrm{m}$ and a length of $97 \mathrm{~mm}$ was used.

\section{Statistical analysis}

Data are expressed as mean \pm SEM. Differences between groups were analyzed with an unpaired Student's $t$ test or repeated measures analysis of variance. $p$ values $<0.05$ were considered statistically significant.

\section{RESULTS}

\section{General characteristics}

Baseline body weights were comparable in both groups ( $173 \pm 3 \mathrm{~g}$ in control rats and $178 \pm 5 \mathrm{~g}$ in diabetic rats). Following induction of diabetes, body weight in the diabetic group decreased slightly and then steadily increased but at a much slower rate in comparison with the control group. After 6 weeks body weights were markedly lower in the diabetic group compared to the control group ( $196 \pm 7 \mathrm{~g}$ vs. $270 \pm 4 \mathrm{~g}, p<0.0001$, Fig. 1a). Blood glucose levels were in the $6-8 \mathrm{mmol} / \mathrm{l}$ range before induction of diabetes. After streptozotocin-administration, blood glucose levels in the diabetic group rose to $21.9 \pm 1.2$ $\mathrm{mmol} / \mathrm{l}$. Blood glucose levels in the diabetic group remained in the range of 20-25 mmol/l, while the control group kept levels of 6-8 mmol/l (Fig. 1b, $p<0.0001$ ). 


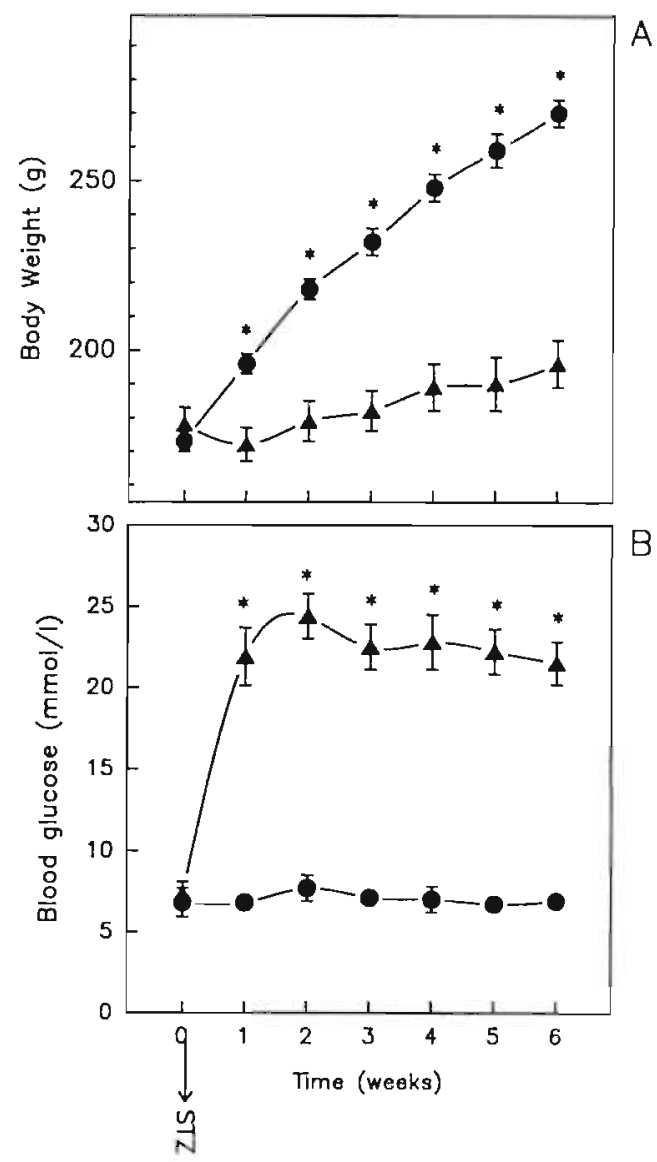

Figure 1: Body weight (panel A) and blood glucose levels (panel B) in control rats (circles) and diabetic rats (triangles) before and after diabetes induction. ${ }^{*} p<0.001$

Microvascular diameters

Arterioles (Fig. 2a). Baseline diameters for A1 arterioles were comparable in both groups (114 $\pm 12 \mu \mathrm{m}$ in the control group ( $\mathrm{n}=7)$, vs. $116 \pm 16 \mu \mathrm{m}$ in the diabetic group $(n=7)$ ). Diameters of $A 2$ arterioles were equally comparable (53 \pm 5 in the control group $(n=11)$, vs. $51 \pm 6$ in the diabetic group $n=11)$. Neither in A1 arterioles nor in A2 arterioles, induction of diabetes had significant effects on vascular diameters (Fig. 2a). In the smaller A3/A4 arterioles however, induction of diabetes gradually decreased vascular diameters (week $0 ; 29$ $\pm 2 \mu \mathrm{m}$ in the control group $(\mathrm{n}=10)$ vs. $26 \pm 3 \mu \mathrm{m}$ in the diabetic group $(\mathrm{n}=10)$. (week 6; $26 \pm 3 \mu \mathrm{m}$ in the control group vs. $17 \pm 2 \mu \mathrm{m}$ in the diabetic group, $p<0.05$, Fig. 2a). 

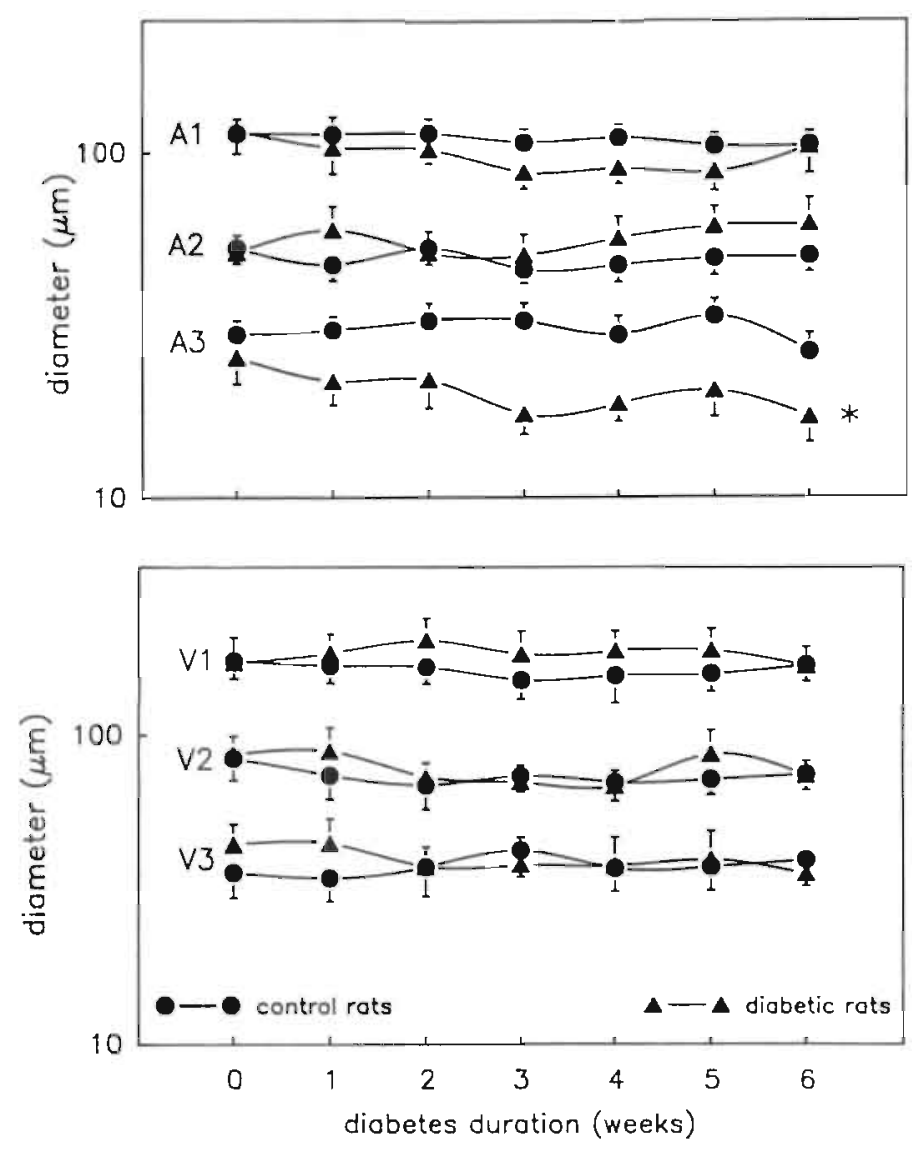

Figure 2: Arteriolar (panel A) and venular (panel B) diameters following diabetes induction with streptozotocin (diabetic rats, triangles) or vehicle injection (control rats, circles). ${ }^{*} p<0.05$

Venul's (Fig. 2b) Baseline diameters in V1 venules were also comparable between the two groups (175 $\pm 18 \mu \mathrm{m}$ in controls $(n=7)$ vs. $172 \pm 20 \mu \mathrm{m}$ in diabetic rats $(n=7)$. Diameters in V2 venules were $84 \pm 10 \mu \mathrm{m}$ in control rats $(n=11)$ and $86 \pm 12 \mu \mathrm{m}$ in diabetic rats $(n=9)$ while V3/V4 venules had a mean diameter of $36 \pm 6 \mu \mathrm{m}(n=8)$ vs. $44 \pm 7 \mu \mathrm{m}(n=11)$. Induction of diabetes had no significant effects on venular diameters in both groups. 


\section{Microvascular density}

Microvascular density index was expressed as the number of intersections with the counting grid. It was determined for larger arterioles (A1/A2, Fig. 3a), larger venules (V1/V2, Fig. 3b) and smaller vessels (A3/A4-V3/V4, Fig. 3c), since arterioles and venules of this size could not be discriminated from each other. All microvascular density indexes were comparable when determined at week 0 . After diabetes induction microvascular density of larger venules (Fig. 3b) increased with $21 \%$ in week $4(p<0.05)$, while in week 6 an increase of $28 \%$ compared to week 0 was found $(p<0.05)$. In the other vessel classes no differences in vascular density compared to week 0 could be found.

Figure 3: Vascular density of A1/A2 arterioles, V1/V2 venules and A3/A4 arterioles and V3/V4 venules in control rats (C) and diabetic rats (D) at baseline (blank bars) and week 4 (hatched bars) and week 6 (crosshatched bars) following diabetes induction. * $p<0.05$
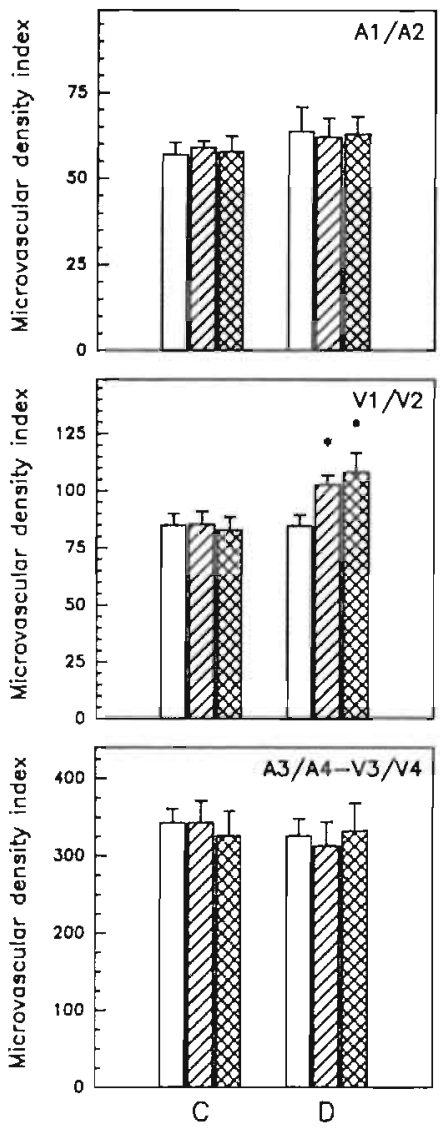


\section{DISCUSSION}

In this study we investigated the effects of streptozotocin-induced diabetes on microvascular diameters and microvascular density of the striated cutaneous maximus muscle. We showed that in the smallest A3/A4 arterioles induction of diabetes with streptozotocin resulted in a gradual decrease in vessel diameter. In addition, an increased density of larger (V1/V2) venules was observed after 4 and 6 weeks of diabetes.

The observed vasoconstriction of striated muscle arterioles is in concordance with reports from experimental studies in cremaster muscle (14), arterioles from bat wings (15) and intrarenal arterioles (16), but in disagreement with studies on intestinal arterioles (17) which showed a marked dilatation following diabetes induction. In cerebral arterioles (17) no effects were observed in larger arterioles. Speculating on the causes and/or consequences of the observed vasoconstriction of this small striated muscle arterioles one can wonder whether this phenomenon is related to specific disturbances at the organ level or a part of a systemic process in which blood flow is redistributed from striated muscle and skin in favor of the kidney, intestine and diaphragm. Such a redistribution of cardiac output has been shown 4 weeks after diabetes induction in rats (18). One would expect however, that larger arterioles would be involved also in this vasoconstrictory response. Larger arterioles are usually considered to be important in the regulation of vascular resistance, and thus flow.

The observed vasoconstriction might be a consequence of altered vascular reactivity in the microvascular bed. Alterations in vascular reactivity have been observed in microvessels from diabetic rats. Most studies direct at impaired responses to vasodilators (19) in parallel with enhanced responses to vasoconstrictors (20). This might alter the balance between contracting and relaxing factors in these vessels in favor of contracting factors. Whether the vasoconstriction of precapillary arterioles affects muscle flow to such an extent that tissue oxygenation is diminished, can be questioned. Nevertheless, the observed vasoconstriction of smaller arterioles could have various adverse effects. A diminished flow to skeletal muscle has been implicated in the genesis of insulin resistance in diabetes (21). Moreover, one can speculate that in situations in which the metabolic demand of the striated muscle is increased, muscle flow might not rise sufficiently, as has been demonstrated in diabetic patients doing exercise tests (22). Adequate adaptation might also become a problem when the local circulation is compromised by the development of occlusive atherosclerotic lesions, as happens very often in diabetic patients (23). The inability to dilate microvessels sufficiently might extend tissue damage in these situations. 
Yet, it should be noted that the observed vasoconstriction of smaller arterioles in diabetic rats is in contrast with various studies in humans in which signs of increased blood flow were found $(1,2)$. It is possible however, that this increased flow is related to the administration of exogenous insulin that has been shown to increase skeletal muscle blood flow (24). In addition, it is our opinion that measurements in rats with marked hyperglycemia and already signs of microangiopathy, such as microalbuminuria and increased vascular permeability should not be compared with data from diabetic patients with fairly regulated diabetes and no signs of microangiopathy.

A second observation in this study was the increased density of V1/V2 venules after 4 and 6 weeks of diabetes. Density of A1/A2 arterioles was not affected by diabetes induction. Combined vascular density of the smallest arterioles and venules, which could not be distinguished from each other was not altered, although it is possible that a reduction of arterioles together with an increase in venular density or vice versa exists. Neovascularization in diabetes is a wellknown phenomenon in advanced stages of diabetic retinopathy where vessel formation is also located on the venular side of the capillary bed. Outside the retina there is little knowledge about vessel growth related to diabetes but the studies that have been performed report increased (25) as well as decreased vessel numbers (26).

Increases in venular density have also been associated with increased fluid filtration across the microvasculature as a consequence of increased microvascular pressure. Increased intracapillary pressure has been demonstrated recently in skin capillaries from insulin-dependent diabetic patients (7). Also a number of angiogenic factors are suggested to be present in the diabetic milieu. Macrophages for example, possess a receptor for Advanced Glycosylation Endproducts (AGEs), which form under hyperglycemic circumstances from the reaction of circulating sugars with long-lived proteins. Upon reaction of AGEs with this receptor, macrophages secrete TNF- $\alpha$, PDGF and IGF- 1 in quantities large enough to stimulate vascular growth (27). In addition, the renin-angiotensin system (RAS) which has also been implicated in vascular growth $(28,29)$, might be (locally) activated in diabetes. High levels of the renin precursor prorenin are found in the plasma of diabetic patients with retinopathy and/or microalbuminuria (30), as well as in vitreous fluid of diabetic patients with proliferative retinopathy (31). Finally, alterations in intracellular sodium concentration, as a result of decreased $\mathrm{Na}^{+} / \mathrm{K}^{+}$-ATPase activity that has been demonstrated under hyperglycemic conditions (32), might also have growth-promoting effects (33).

In conclusion, we observed a gradual decrease in diameter of smaller striated muscle arterioles following diabetes induction with streptozotocin in rats, as well as an increased vascular density of venules. This indicates that also in 
tissues that are not predisposed to diabetes-induced damage, vascular alterations develop that might have adverse consequences on cardiovascular homeostasis in diabetes. 


\section{REFERENCES}

1. Houben AJHM, Schaper NC, Slaaf DW, Tangelder GJ, Nieuwenhuijzen Kruseman AC: Skin blood cell flux in insulin-dependent diabetic subjects in relation to retinopathy or incipient nephropathy. Eur J Clin Invest 1992; 22: 67-72

2. Gundersen HJG: Peripheral blood flow and metabolic control in juvenile diabetes. Diabetologia 1974; 10: 225-231

3. Kohner EM, Hamilton AM, Saunders SJ, Sutcliffe BA, Bulpitt CJ: The retinal blood flow in diabetes. Diabetologia 1975; 11: 27-33

4. Bollinger A, Frey J, Jaeger K, Furrer J, Seglias J, Siegenthaler W: Patterns of diffusion through skin capillaries in patients with long-term diabetes. New Engl J Med 1982; 307: 1305-1310

5. O'Hare JA, Ferriss JB, Twomey B, O'Sullivan DJ: Poor metabolic control, hypertension, and microangiopathy independently increase the transcapillary escape rate of albumin in diabetes. Diabetologia 1983; 25: 260-263

6. Feldt-Rasmussen B: Increased transcapillary escape rate of albumin in Type 1 (insulindependent) diabetic patients with microalbuminuria. Diabetologia $1986 ; 29: 282-286$

7. Sandeman DD, Shore AC, Tooke JE: Relation of skin capillary pressure in patients with insulin-dependent diabetes mellitus to complications and metabolic control. $N$ Engl J Med 1992; 327: 760-764

8. Bresnick GH, De Venecia G, Myers EL, Harris JA, Davies MD: Retinal ischemia in diabetic nephropathy. Arch Ophthalmol 1975; 93: 1300-1310

9. Ditzel J, Sagild U: The degenerative and hemodynamic changes in the bulbar conjunctiva of normotensive diabetic patients. N Engl J Med 1954; 250; 587-594

10. Ditzel J, Sargeant L, Hadley WG: The relationship of abnormal vascular responses to retinopathy in diabetes. Arch Intern Med 1957; 101: 912-920

11. Smith TL, Osborne SW, Hutchins PM: Long-term micro- and macrocirculatory measurements in conscious rats. Microvasc Res 1985; 29: 360-370

12. Le Noble JLML, Smith TL, Hutchins PW, Struijker Boudier HAJ: Microvascular alterations in adult conscious spontaneously hypertensive rats. Hypertension 1990; 15: 415-419

13. Intaglietta $M$, Tompkins WR: Microvascular measurements by video image shearing and splitting. Microvasc Res 1973; 5: 309-312

14. Bohlen HG, Niggl BA: Arteriolar anatomical and functional abnormalities in juvenile mice with genetic or streptozotocin-induced diabetes mellitus. Circ Res 1979; 45:390396

15. Bohlen $\mathrm{HG}$, Hankins KD: Early microvascular pathology during hyperglycemia in bats. Blood Vessels 1983; 20: 213-220

16. Bohlen HG, Hankins KD: Early arteriolar and capillary changes in streptozotocininduced diabetic rats and intraperitoneal hyperglycemic rats. Diabetologia 1982; 22: 344-348

17. Moore SA, Bohlen HG, Miller BG, Evan AP: Cellular and vessel wall morphology of cerebral cortical arterioles after short-term diabetes in adult rats. Blood Vessels 1985; 22: 265-277

18. Hill MA, Larkins RG: Alterations in the distribution of cardiac output in experimental diabetes in rats. Am J Physiol 1989; 257: H571-580

19. Lash JM, Bohlen HG: Structural and functional origins of suppressed acetylcholine vasodilation in diabetic rat intestinal arterioles. Circ Res 1991; 69: 1259-1268 
20. Hill MA, Larkins RG: Altered microvascular reactivity in streptozotocin-induced diabetes in rats. Am J Physiol 1989; 257: H1438-1445

21. Baron AD, Brechtel-Hook G, Johnson A, Hardin D: Skeletal muscle blood flow. A possible link between insulin resistance and blood pressure. Hypertension 1993; 21: 129-135

22. Young JL, Pendergast DR, Steinbach J: Oxygen transport and peripheral microcirculation in long-term diabetes. Proc Soc Exp Biol Med 1991; 196: 61-68

23. Singer DE, Nathan DM, Anderson KM, Wilson PWF, Evans JC: Association of HbA1c with prevalent cardiovascular disease in the original cohort of the Framingham Heart Study. Diabetes 1992; 41: 202-209

24. Anderson EA, Mark AL: The vasodilator action of insulin. Implications for the insulin hypothesis of hypertension. Hypertension 1993; 21: 136-141

25. Nyengaard JR, Rasch R: The impact of experimental diabetes mellitus in rats on glomerular capillary number and sizes. Diabetologia 1993; 36; 189-194

26. Yarom R, Zirkin H, Stämmler G, Rose AG: Human coronary microvessels in diabetes and ischaemia. Morphometric study of autopsy material. J Pathol 1992; 166: 265-270

27. Vlassara H, Brownlee M, Monogue K, Dinarello CA, Pasagian A: Cachectin/TNF and 几-1 induced by glucose modified proteins: role in normal tissue remodeling. Science 1988; 240: 1546-1548

28. Daemen MJAP, Lombardi DM, Bosman FT, Schwartz SM: Angiotensin II induces smooth muscle cell proliferation in the normal and injured rat arterial wall. Circ Res $1991 ; 68: 450-456$

29. Le Noble FAC, Hekking JWM, Van Straaten HWM, Slaaf DW, Struijker Boudier HAJ: Angiotensin II stimulates angiogenesis in the chorio-allantoic membrane of the chick embryo. Eur J Pharmacol 1991; 195: 305-306

30. Franken AAM, Derkx FH, Blankestijn PJ, Janssen JA, Mannesse CK, Hop W: Plasma prorenin as an early marker of microvascular disease in patients with diabetes mellitus. Diabete Metab 1992; 18: 137-143

31. Danser AHJ, Van den Dorpel MHA, Deinum J, et al: Renin, prorenin, and immunoreactive renin in vitreous fluid from eyes with and without diabetic retinopathy. J Clin Endocrinol Metab 1989; 68: 160-167

32. Simmons DA, Winegrad AI. Mechanism of glucose-induced $\mathrm{Na}^{+} / \mathrm{K}^{+}-$ATPase inhibition in aortic wall of rabbits. Diabetologia 1989; 32: 402-408

33. Kent RL, Hoober JK, Cooper IV J: Load responsiveness of protein synthesis and adult mammalian myocardium: role of cardiac deformation linked to sodium influx. Circ Res 1989; 64: 74-85 


\section{CHAPTER 3}

In vivo arteriolar reactivity in experimental diabetes

M.S.P. Huijberts, F.R.L. Crijns, B.H.R. Wolffenbuttel, A.C. Nieuwenhuijzen Kruseman, H. van Essen, H.A.J. Struijker Boudier

(submitted) 



\section{SUMMARY}

The effects of the endothelium-dependent vasodilator acetylcholine (Ach), and the potassium-channel opener BRL 38227 (BRL), and the vasoconstricting effects of the $\alpha 1$-adrenoceptor agonist phenylephrine (PHE) and angiotensin II (ANG-II) on blood pressure and striated muscle arteriolar diameter were studied six weeks after diabetes induction $(70 \mathrm{mg} / \mathrm{kg}$ streptozotocin i.p.), in conscious diabetic $(n=18)$ and non-diabetic control rats $(n=20)$. Animals were infused i.v. with Ach $\left(3,10\right.$ and $\left.30 \mu \mathrm{g} \cdot \mathrm{kg}^{-1} \cdot \mathrm{min}^{-1}\right)$, and thereafter received an injection of $30 \mu \mathrm{g} / \mathrm{kg}$ BRL. In a separate set of experiments, rats were infused i.v. with PHE (1,3, and $\left.10 \mu \mathrm{g} \cdot \mathrm{kg}^{-1} \cdot \mathrm{min}^{-1}\right)$ and ANG-II $\left(0.1\right.$ and $\left.0.3 \mu \mathrm{g} \cdot \mathrm{kg}^{-1} \cdot \mathrm{min}^{-1}\right)$. Changes in arteriolar diameters were measured in the cutaneous maximus muscle, using the dorsal microcirculatory chamber model. Body weights were lower in the diabetic group compared to the control group ( $200 \pm 6 \mathrm{~g}$ vs. 277 $\pm 6 \mathrm{~g}, p<0.001)$, while blood glucose levels were markedly elevated $(24.5 \pm 0.7$ $\mathrm{mM}$ vs. $7.4 \pm 0.4 \mathrm{mM}, p<0.001)$. Baseline MAP was slightly lower in diabetic compared to control rats (112 $\pm 4 \mathrm{mmHg}$ vs. $120 \pm 4 \mathrm{mmHg}, p=0.06)$. The decrease in MAP following Ach infusion was approximately $30 \%$ lower in diabetic rats $(p<0.02)$. Arteriolar responses to Ach were also markedly lower in diabetic rats; the effect was most pronounced in A2 arterioles $(p<0.001)$. Systemic and arteriolar responses to BRL were also both decreased in diabetic rats. The increase in blood pressure after PHE was greater in control rats than in diabetic rats $(p<0.02)$, but PHE caused a stronger arteriolar constriction in diabetic animals compared to control animals. ANG-II had no effect on vessel diameters in control animals, whereas the highest dose induced a marked vasoconstriction in diabetic rats. Thus, vascular relaxation is impaired in skeletal muscle arterioles from conscious diabetic rats, while constriction to both angiotensin II and PHE is increased. Systemic responses to these vasopressor agents, however, are unchanged or even decreased. These findings point to significant functional disturbances of endothelium-dependent and endotheliumindependent vasoregulatory mechanisms in experimental diabetes.

\section{INTRODUCTION}

Alterations in vascular reactivity may play a role in the development of diabetic angiopathy. Several studies describe a decreased endothelium-dependent vasodilation but an unaffected response to endothelium-independent vasodilators (1-4). Other authors did not find any difference in endotheliumdependent nor endothelium-independent relaxation (5-8). In these in vitro studies, several factors such as differences in animals, gender, vessel type studied, method of induction of diabetes, use of precontracting agent and additives to the bathing medium (9) may explain the inconsistent findings. In a 
comprehensive review, Tomlinson et al. (10) have focused on the unphysiologic glucose-concentration ( $10 \mathrm{mM})$ of the bathing medium that was used in most of these studies, to assess vessel properties in both diabetic and non-diabetic animals. Recently, Heesen et al. (11) confirmed the importance of glucose concentration of the bathing medium in assessing the vasodilatory responses of aortic rings. A few studies on vascular reactivity in diabetic humans have reported impairment of vasodilation (12).

Alterations in responsiveness to vasopressor substances have been described in various pathological conditions, such as hypertension $(13,14)$ and acute and chronic ischemia (15). The results of studies in diabetes regarding this subject are controversial; increased $(16,17)$, as well as decreased (18) and unchanged (19) reactivity to various vasopressor agents has been reported in studies performed in humans (19), in anesthetized and conscious rats $(17,18)$, isolated rat hindquarters (20), and microcirculatory preparations in anesthetized animals (21). In the few microcirculatory studies performed so far mainly open cremaster muscle preparations were used. However, the surgical procedure in this model may significantly alter normal hemodynamics within the vascular bed (22).

We studied the reactivity to vasodilating and vasoconstricting agents of skeletal muscle arterioles in vivo, using the so-called dorsal microcirculatory chamber model. In this model, the vascular supply of the skeletal muscle used is left entirely intact, and no anesthesia is required during measurements. Simultaneous recordings of blood pressure and heart rate can be made to evaluate systemic effects. To study endothelium-independent relaxation acetylcholine was used. Endothelium-independent relaxation was induced by administration of the potassium-channel opener BRL 38227, since it has been suggested that sensitivity to the often used nitrovasodilators might be influenced by alterations in endothelium-dependent vasodilation (23), and because BRL 38227 is one of the most potent vasodilators. The $\alpha 1$-adrenoceptor agonist phenylephrine and angiotensin II were used as vasoconstricting agents.

\section{MATERIALS AND METHODS}

\section{Animals}

Male Wistar Rp rats (TNO-REPGO, Rijswijk, The Netherlands) were used. Rats were housed in controlled rooms and had free access to food and water. Three weeks after implantation of the dorsal microcirculatory chamber, they were randomized in a control group $(n=20)$, and a diabetic group $(n=18)$. Diabetes was induced by i.p. injection of $70 \mathrm{mg} / \mathrm{kg}$ streptozotocin (Upjohn, Kalamazoo, USA) in citrate buffer ( $\mathrm{pH} 4.5$ ). Rats in the control group received citrate buffer only. Development of diabetes was assessed by blood glucose measurements (hexokinase-method). 


\section{Dorsal microcirculatory chamber preparation}

This model is described in detail elsewhere $(24,25)$. In 6-7 weeks old rats under ketamine-xylazine/pentobarbital anesthesia, the cutaneous maximus muscle on the back was separated from the covering skin and placed in a thermoneutral polycarbonate chamber. After surgery, the animals were housed in separate cages in rooms with controlled light and temperature, to which they had previously been acclimatized. Three weeks were allowed for recovery and evaluation of the preparation. The preparation was included in the study when 1) no bleeding occurred, 2) no signs of inflammation were present, and 3) vasomotion was visible. After admission to the study, the rats were randomized in a control and a diabetes group as described above. Rats were studied 6 weeks after randomization. In the meantime the animals were trained 3 times a week to sit unstressed in a rodent restrainer, which minimizes motion but does not impede normal respiration.

\section{Assessment of arteriolar reactivity}

One day prior to the start of the experiments, a venous and an arterial catheter for drug-injection and recording of mean arterial pressure (MAP) were implanted under ether anesthesia. On the experimental day, the rats were placed in a rodent restrainer for in vivo microscopy. Video recordings were made of the entire preparation at low magnification (Zeiss Plan objective 2.5x; NA 0.08) to document the microvasculature and its angioarchitecture. Recordings were subsequently made of individual segments of the arteriolar tree using a Zeiss Plan 10x; NA 0.25. Small arterioles were grouped according to functional branching order and were classified alphanumerically. According to this classification, A1 arterioles $(80-140 \mu \mathrm{m})$ are the primary perfusing arterioles, and their branches are designated second order arterioles (A2; resting diameters $40-80 \mu \mathrm{m}$ ). The precapillary arterioles (A3 and A4; resting diameters 10-40 $\mu \mathrm{m})$ primarily serve blood distribution within the microvascular segment.

Video recordings were made from arterioles of each functional class. First, baseline recordings were made of each selected arteriole. The first group of rats was then infused with increasing doses of acetylcholine (Ach) (3, 10 and 30 $\mu \mathrm{g} . \mathrm{kg}^{-1} \cdot \mathrm{min}^{-1}$, Dispersa AG, Winterthur, Switzerland). After establishing a steady state, diameter recordings were made for each dose. Following a washout period of $30 \mathrm{~min}$, new baseline recordings were made of each selected arteriole. Subsequently, the potassium channel opener BRL 38227 was administered in a bolus injection of $30 \mu \mathrm{g} \cdot \mathrm{kg}^{-1}$ dissolved in $0.9 \%$ saline. Video recordings were made after 5-10 min. In the second series of animals, rats were infused intravenously with increasing doses of phenylephrine (PHE) (1, 3 and $10 \mu \mathrm{g} \cdot \mathrm{kg}^{-1} \cdot \mathrm{min}^{-1}$, Sigma, St. Louis, MO, USA). After establishing a steady state, diameter recordings were made for each dose. Following a wash-out period of $30 \mathrm{~min}$, new baseline recordings were made of each selected arteriole. Subse- 
quently, angiotensin II (ANG-II) (Sigma) was administered in doses of 0.1 and $0.3 \mu \mathrm{g} \cdot \mathrm{kg}^{-1} \cdot \mathrm{min}^{-1}$. Video recordings were made after 5-10 min. Arteriolar diameters were analyzed off-line with an image shearing device (21). The effects were calculated as the difference from the baseline value. In additional experiments it was verified that infusion of saline did not have any significant effects on neither mean arterial pressure nor arteriolar diameters.

\section{Mean arterial blood pressure}

Mean arterial blood pressure (MAP) was monitored continuously during the experiment. To this end the arterial catheter was connected to a low volume displacement pressure transducer (CP-01, Century Technology Company, Inglewood, CA, USA). The signal was recorded on a Grass $7 \mathrm{D}$ polygraph (Grass Instruments, Quincy, Mass., USA). Low-pass filtering of the signal yielded MAP.

\section{Statistical analysis}

Data are expressed as mean \pm SEM. Differences between groups were analyzed with an unpaired Student's $t$ test or analysis of variance (ANOVA). $p$-values $<0.05$ were considered statistically significant.

\section{RESULTS}

General characteristics

Body weights were lower in the diabetic animals compared to the control animals ( $200 \pm 6 \mathrm{~g}$ vs. $277 \pm 6 \mathrm{~g}, p<0.001)$. Blood glucose levels were markedly elevated in diabetic rats compared to control rats $(24.5 \pm 0.7 \mathrm{mM}$ vs. $7.4 \pm 0.4$ $\mathrm{mM}, p<0.001)$. Baseline MAP was slightly but non-significantly lower in diabetic rats compared to control rats $(112 \pm 4 \mathrm{mmHg}$ vs. $120 \pm 4 \mathrm{mmHg}$, $p=0.06$ ).

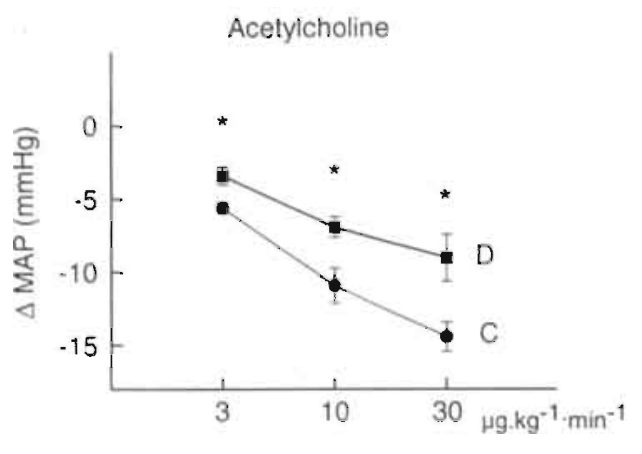

Figure 1: Decrease in mean arterial pressure ( $\triangle \mathrm{MAP})$ in control $(\mathrm{C})$ and diabetic (D) rats following infusion of increasing doses of acetylcholine.

* $p<0.02$ vs controls 
Vasodilator effects

Infusion of increasing doses of Ach resulted in a gradual decrease in mean arterial pressure, reaching a maximum of $14 \pm 1 \mathrm{mmHg}$ decrease in MAP in the control group vs. $9 \pm 1 \mathrm{mmHg}$ in the diabetic group for the highest dose of Ach (Fig. 1). The decrease in MAP induced by the different doses of Ach was significantly lower in diabetic rats compared to control rats for all doses $(p<0.02$, Fig. 1). Baseline arteriolar diameters were not significantly different in diabetic rats compared to control rats, although A3/A4 arterioles tended to be smaller in the diabetic group (Table 1).

Table 1. Baseline arteriolar diameters before the start of the vasodilator experiments

\begin{tabular}{lllll}
\hline & & $\begin{array}{l}\text { Diameter } \\
\text { before Ach }\end{array}$ & $\begin{array}{l}\text { Diameter } \\
\text { before BRL 38227 }\end{array}$ \\
A1 & $C$ & 11 & $119 \pm 8 \mu \mathrm{m}$ & $117 \pm 6 \mu \mathrm{m}$ \\
A2 & $D$ & 11 & $111 \pm 6 \mu \mathrm{m}$ & $113 \pm 5 \mu \mathrm{m}$ \\
& $C$ & 22 & $69 \pm 3 \mu \mathrm{m}$ & $68 \pm 3 \mu \mathrm{m}$ \\
A3/A4 & $D$ & 22 & $63 \pm 3 \mu \mathrm{m}$ & $64 \pm 3 \mu \mathrm{m}$ \\
& $D$ & 30 & $28 \pm 2 \mu \mathrm{m}$ & $32 \pm 2 \mu \mathrm{m}$ \\
& $D$ & 28 & $24 \pm 1 \mu \mathrm{m}$ & $25 \pm 2 \mu \mathrm{m}^{*}$ \\
\hline
\end{tabular}

Baseline diameters of $\mathrm{A} 1, \mathrm{~A} 2$, and $\mathrm{A} 3 / \mathrm{A} 4$ arterioles from control (C) and diabetic (D) rats before administration of acetylcholine (Ach) and BRL 38227.

* Significantly different from control rats, $p<0.05$.

Infusion of Ach resulted in a marked increase in arteriolar diameters in the control group which was most prominent in the A2 arterioles ( $+28 \pm 4 \%$ for the highest dose of Ach, Fig. 2). In the arterioles from diabetic rats, however, Ach infusion had only minor effects on vessel diameters, especially in A2 and A3/A4 arterioles.

Injection of the potassium-channel opener BRL 38227 resulted in a decrease in MAP in both groups, which was again smaller in diabetic rats $(-11 \pm 2 \mathrm{mmHg}$ vs. $-20 \pm 3 \mathrm{mmHg}, p<0.05$ ). Baseline values were comparable to values before infusion of Ach, only in the A3/A4 vessels diameters were now significantly smaller in diabetic rats (Table 1). BRL caused a marked dilation of especially the smaller arterioles (Fig. 2). The responses in diabetic rats were significantly lower than in control rats in A2 and A3/A4 arterioles (Fig. 2). 

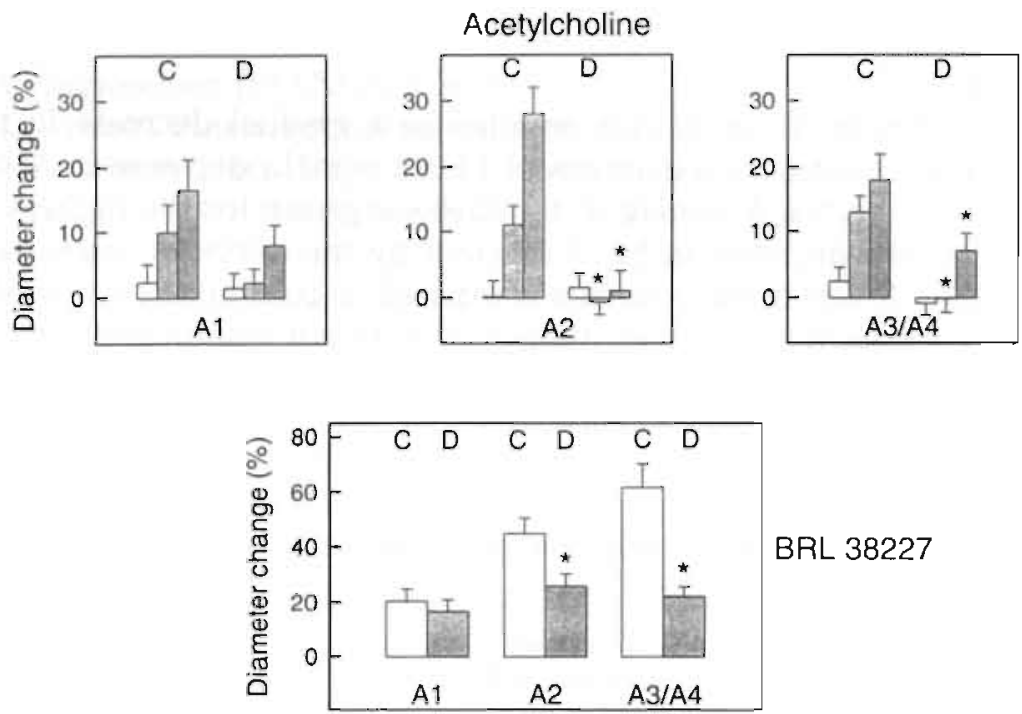

Figure 2: Effects of infusion of 3 (blank bars), 10 (diagonally-hatched bars) and 30 (cross-hatched bars) $\mu \mathrm{g} \cdot \mathrm{kg}^{-1} \cdot \mathrm{min}^{-1}$ acetylcholine and of the potassium channel opener BRL 38227 (30 $\mu \mathrm{g} . \mathrm{kg}^{-1}$ ) on the diameters of A1, A2, and A3/A4 arterioles from diabetic (D) and non-diabetic control rats (C). ${ }^{*} p<0.05$ vs controls

Table 2. Baseline arteriolar diameters before the start of the vasoconstrictor studies

\begin{tabular}{lllll}
\hline & & & $\begin{array}{l}\text { Diameter } \\
\text { before Phe }\end{array}$ & $\begin{array}{l}\text { Diameter } \\
\text { before AII }\end{array}$ \\
A1 & $C$ & 10 & $108 \pm 6 \mu \mathrm{m}$ & $109 \pm 6 \mu \mathrm{m}$ \\
& $D$ & 10 & $113 \pm 6 \mu \mathrm{m}$ & $113 \pm 7 \mu \mathrm{m}$ \\
A2 & $C$ & 18 & $64 \pm 3 \mu \mathrm{m}$ & $62 \pm 3 \mu \mathrm{m}$ \\
& $D$ & 15 & $58 \pm 4 \mu \mathrm{m}$ & $58 \pm 4 \mu \mathrm{m}$ \\
A3 A4 & $C$ & 24 & $25 \pm 2 \mu \mathrm{m}$ & $25 \pm 2 \mu \mathrm{m}$ \\
& $D$ & 19 & $21 \pm 2 \mu \mathrm{m}$ & $21 \pm 2 \mu \mathrm{m}$ \\
\hline
\end{tabular}

Baseline diameters of A1, A2, and A3/A4 arterioles from control (C) and diabetic (D) rats before administration of phenylephrine (Phe) and angiotensin II (AII). 


\section{Vasoconstrictor effects}

Effects of phenylephrine and angiotensin II on MAP are shown in Figure 3. PHE infusion had a dose-dependent effect on MAP in both groups. The blood pressure increase in diabetic rats was significantly less than in control rats $(p<0.05)$. ANG-II also raised blood pressure dose-dependently. The increase in MAP induced by ANG-II infusion tended to be lower in diabetic rats, but this difference was not statistically significant.

Resting diameters before phenylephrine and angiotensin II infusion were comparable in control and in diabetic animals (Table 2).

Figure 3: Increase in mean arterial pressure $(\triangle \mathrm{MAP})$ in control (C) and diabetic (D) rats following increasing doses of phenylephrine and angiotensin $\amalg .{ }^{*} p<0.05$ vs controls
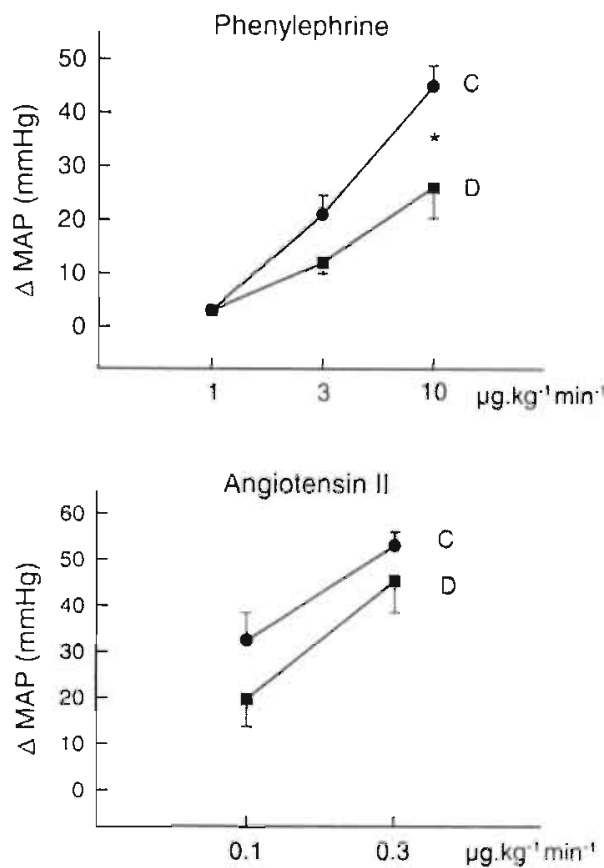

Phenylephrine infusion resulted in a very slight vasoconstriction in the control animals, mainly in A1 and A2 arterioles, whereas no significant effect was observed in A3/A4 arterioles. Vasoconstrictor responses were much stronger in the diabetic animals (A1: $-21 \pm 4, \mathrm{~A} 2:-18 \pm 3$, A3/A4: $-19 \pm 3 \%$, Fig. 4). Angiotensin II infusion, especially in the dose of $0.3 \mu \mathrm{g} \cdot \mathrm{kg}^{-1} \cdot \mathrm{min}^{-1}$, also evoked minor vasoconstrictive response in the vessels of the control group, compared to a marked vasoconstriction induced in all vessels of diabetic animals. 

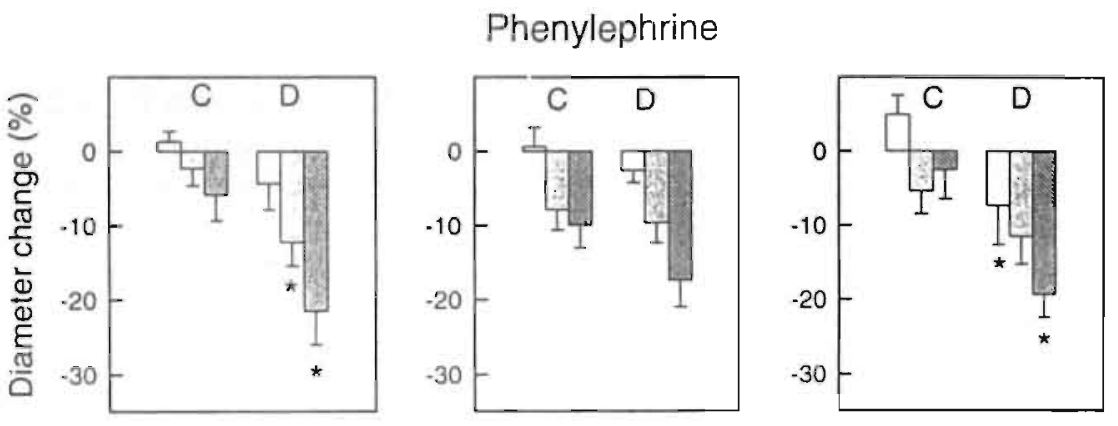

\section{Angiotensin II}
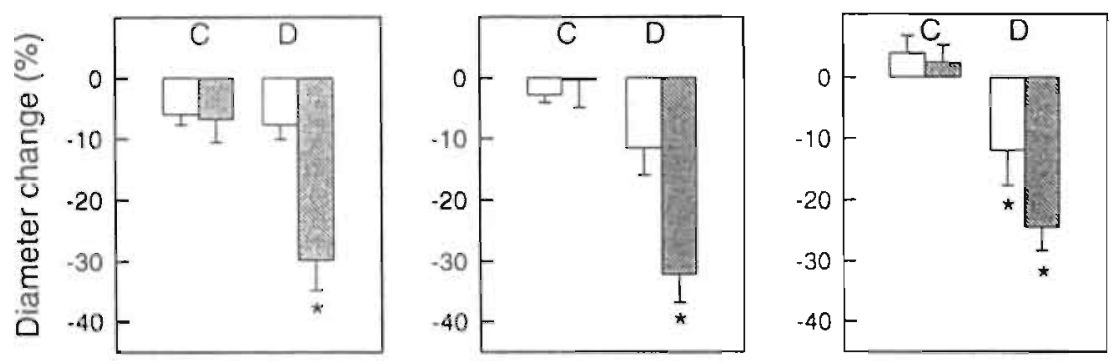

Figure 4: Effects of infusion of 1 (blank bars), 3 (diagonally-hatched bars) and 10 (crosshatched bars) $\mu \mathrm{g} \cdot \mathrm{kg}^{-1} \cdot \mathrm{min}^{-1}$ of phenylephrine, and of 0.1 (blank bars) and 0.3 (cross-hatched bars) $\mu \mathrm{g} \cdot \mathrm{kg}^{-1} \cdot \mathrm{min}^{-1}$ of angiotensin II on diameters of $\mathrm{A} 1, \mathrm{~A} 2$, and $\mathrm{A} 3 / \mathrm{A} 4$ arterioles from diabetic (D) and non-diabetic control rats $(C) .{ }^{*} p<0.05$ vs controls

\section{DISCUSSION}

In this study we demonstrated a marked defect in both endothelium-dependent and endothelium-independent vasodilation in streptozotocin-induced diabetic rats. Acetylcholine infusion in diabetic rats had only very small effects on arteriolar diameters in this striated muscle preparation, while in the control group a $15-30 \%$ increase in vascular diameter was observed. Mean arterial blood pressure dropped to a lesser extent in diabetic rats compared to control rats, which indicates that the defective vasodilation is probably not restricted to this microvascular bed alone. The potassium-channel opener BRL 38227 had very strong vasodilatory effects on the smaller striated muscle arterioles in control rats, which is in concordance with a previous study from our group showing that BRL 38227 preferentially dilated small arterioles in conscious spontaneously hypertensive rats (26). In diabetic rats, responses to BRL were much weaker than in control rats, although increases in arteriolar diameter up 
to $25 \%$ were observed, implying that probably no major structural alterations which impede vascular relaxation are present.

The impairment of acetylcholine-induced vasodilation is in agreement with a report from Lash et al. (27), who described a defective endothelium-dependent dilation of intestinal arterioles. Mayhan (28) reported comparable findings with respect to cerebral arterioles. However, both studies conclude on the basis of unaffected responses to nitrovasodilators that specific endothelium-related alterations are present in diabetic rats. A diminished nitric oxide production by endothelial cells would nevertheless lead to a supersensitivity to organic nitrates (23), suggesting that comparable responses to nitrovasodilators in control and diabetic rats in fact indicate a defective response in the diabetic group. Our study shows that arteriolar responses of striated muscle arterioles to an endothelium-independent vasodilator are indeed disturbed as well. Very recently, similar alterations in endothelium-independent relaxation have been demonstrated in both insulin-dependent (29) and non insulin-dependent (12) diabetic patients.

Several mechanisms have been proposed to be involved in the defective vascular relaxation in diabetes. Tesfamariam et al. (30) have shown that the endothelium of aortic rings from diabetic rabbits exposed to high glucose concentrations produces increased levels of vasoconstrictor prostanoids. Accumulation of oxygen-derived free radicals, such as superoxide anion, which can rapidly inactivate nitric oxide (NO), has also been suggested to play a role (31). Recently, Bucala et al. (32) have shown that Advanced Glycosylation Endproducts (AGEs) in the vascular wall, which are formed under conditions of hyperglycemia, can react with $\mathrm{NO}$ and thereby abolish its vasorelaxant effects.

The diminished response to acetylcholine and the endothelium-independent potassium channel opener BRL 38227 suggests, however, that vascular relaxation in (experimental) diabetes is not impaired uniquely as the result of a specific endothelial defect or a disturbance related to nitric oxide inactivation. Kamata et al. (33) also observed a diminished response to the potassium channel opener cromakalim in aortic strips from diabetic rats. Functional changes in potassium channels could explain the diminished arteriolar response to acetylcholine, since it has been shown that potassium channel blockers attenuate the vasodilator effect of acetylcholine in isolated perfused mesenteric arteries of the rat (34). Still, defects in potassium channels alone cannot explain the diminished reactivity to nitrovasodilators that has been observed in various studies $(29,32)$. Therefore, we suggest that vasorelaxation in diabetes is impaired as the result of disturbances at a more basal level, such as alterations in cellular calcium homeostasis. This remains however to be elucidated in suitable in vivo models or in vitro studies in which attention is paid to the modulation of vasorelaxation by ambient glucose levels. 
In addition to the observed disturbance in vasorelaxation, reactivity to the $\alpha 1$ adrenoceptor agonist phenylephrine and angiotensin II was increased in diabetic rats. While responses of arterioles from diabetic rats to phenylephrine were merely enhanced compared to control rats, strong vasoconstrictory responses to angiotensin II were observed in arterioles from diabetic rats, while control vessels did not show any reaction upon angiotensin II infusion. These findings are in concordance with in vitro studies (35) and studies in anesthetized rats $(16,17)$, showing also an enhanced reactivity of microvessels from diabetic rats to vasoconstrictor substances. Hyperreactivity to vasoconstrictors such as noradrenaline and angiotensin II has also been demonstrated in diabetic patients $(18,36,37)$.

Phenylephrine as well as angiotensin II induce vascular smooth muscle contraction by stimulation of the same second messenger systems. Both the $\alpha 1$ adrenoceptor and the AT1-receptor are coupled to phospholipase $C$ through a pertussis toxin-sensitive G-protein. Phospholipase $C$ hydrolyzes phosphatidylinositol 4,5-bisphosphate resulting in the generation of inositol 1,4,5trisphosphate $\left(\mathrm{IP}_{3}\right)$ and 1,2-diacylglycerol (DAG). $\mathrm{IP}_{3}$ is involved in the release of $\mathrm{Ca}^{2+}$ from intracellular stores while DAG activates protein kinase $\mathrm{C}$. Increased PKC activation in diabetes has been shown recently $(38,39)$ and is thought to be related to elevated glucose concentrations, since PKC activity in cultured rat vascular smooth muscle cells responded rapidly to variations in extracellular glucose concentration (40). It has also been shown that an inhibitor of PKC, staurosporin, could correct the hyperresponsiveness of diabetic vessels (41). In addition, augmented inositol phosphate production induced by stimulation with noradrenaline has been demonstrated in mesenteric arteries from diabetic rats (42). Both increased PKC activation and augmented inositol phosphate production might lead to enhanced responses of arterioles from diabetic rats to phenylephrine and angiotensin II.

Alterations in transcellular cation exchange might also play a role in the observed hyperreactivity to vasoconstrictors in arterioles from diabetic rats, as has been suggested by Simmons and Winegrad (43). They showed that in aortic intima-media preparations elevation of the glucose concentration of the medium resulted in a decreased $\mathrm{Na}^{+} / \mathrm{K}^{+}$-ATPase activity (44), independent of insulin concentration (45). Moreover, elevated activity of the $\mathrm{Na}^{+} / \mathrm{Li}^{+}$exchanger, which has been suggested to represent a mode of operation of the $\mathrm{Na}^{+} / \mathrm{H}^{+}$ antiporter $(46,47)$, has been shown in erythrocytes and platelets from diabetic patients $(48,49)$. A decrease of the activity of the enzyme $\mathrm{Na}^{+} / \mathrm{K}^{+}$-ATPase may lead to an elevation of intracellular $\mathrm{Na}^{+}(50)$. Elevation of $\mathrm{Na}^{+} / \mathrm{H}^{+}$exchange has been shown in platelets derived from patients with diabetes mellitus (48). The resulting increase of intracellular $\mathrm{Na}^{+}$causes depolarization of vascular smooth muscle cells, resulting in an activation of $\mathrm{Ca}^{2+}$ conductance or voltage-depen- 
dent $\mathrm{Na}^{+} / \mathrm{Ca}^{2+}$ exchange and an increase in cytosolic free $\mathrm{Ca}^{2+}(50)$ as biochemical basis for the hyperresponsiveness to vasoconstrictor agents.

Surprisingly, the stronger peripheral vasoconstrictive effect in diabetic animals is not paralleled by an equal rise in mean arterial blood pressure. A depression of systemic responses to phenylephrine and angiotensin II has also been described by Jackson and Carrier who studied conscious diabetic rats (18). Their suggestion that diabetic rats might show a decreased peripheral vasopressor response is in contradiction with our findings. One explanation for this observed difference in systemic and microcirculatory reactions to vasopressor agents might be that larger-sized arterioles, in which reactivity was not found to be significantly altered, are more important in regulating resistance than the smaller arterioles. Many studies though emphasize the importance of smaller arterioles in regulating peripheral resistance (51). The blunted systemic response to the vasopressor agents in spite of increased peripheral vasoconstriction might also be caused by hypersensitivity of mechanisms for short-term regulation of blood pressure, such as the baroreceptor reflex. However, regional variations in arteriolar responsiveness might also exist, as suggested recently in a study in pig arteries (52). A diminished renal arteriolar reactivity to angiotensin II has been shown in diabetic rats (53). In diabetic patients who showed an increased hypertensive response to angiotensin II, a simultaneous decreased reactivity of retinal blood vessels to this agent was demonstrated (54).

In conclusion, we observed in this study a diminished response of striated muscle arterioles from streptozotocin-induced diabetic rats to the endotheliumdependent vasodilator acetylcholine and the endothelium-independent potassium channel opener BRL 38227, and enhanced reactivity to phenylephrine and angiotensin II. In contrast, a blunted systemic response to phenylephrine and an apparently unchanged systemic response to angiotensin II were observed, indicating regional variations in vasopressor responsiveness. This indicates diabetes-induced defects in basal processes involved in vasoreactivity. Regional differences in vascular reactivity could result in a redistribution of blood flow to regions susceptible to hyperperfusion damage, such as the retina and the kidney), and in this way extend diabetes-induced vascular damage. 


\section{REFERENCES}

1. Abiru T, Watanabe Y, Kamata K, Miyata N, Kasuya Y: Decrease in endotheliumdependent relaxation and levels of cyclic nucleotides in aorta from rabbits with alloxan-induced diabetes. Res Comm Chem Pathol Pharmacol 1990; 68: 13-25

2. Durante $W$, Sen AK, Sunahara FA: Impairment of endothelium-dependent relaxation in aortae from spontaneously diabetic rats. Br J Pharmacol 1988; 4: 463-468

3. Kamata K, Miyata N, Kasuyac Y: Impairment of endothelium-dependent relaxation and changes in levels of cyclic GMP in aorta from streptozotocin-induced diabetic rats. Br J Pharmacol 1989; 97: 614-618

4. Pieper GM, Gross GJ: Oxygen free radicals abolish endothelium-dependent relaxation in diabetic rat aorta. Am J Physiol 1988; 255: H825-833

5. Fortes ZB, Leme JG, Scivoletto R: Vascular reactivity in diabetes mellitus: role of the endothelial cell. Br J Pharmacol 1983; 79: 771-781

6. Harris $\mathrm{KH}$, McLeod KM: Influence of the endothelium on contractile responses of arteries from diabetic rats. Eur J Pharmacol 1988; 153: 55-64

7. Mulhern M, Docherty JR: Effects of experimental diabetes on the responsiveness of rat aorta. Br I Pharmacol 1989; 97: 1007-1012

8. Wakabayashi I, Hatake K, Kimura N, Kakishita E, Nagai K: Modulation of vascular tonus by the endothelium in experimental diabetes. Life Sci 1987; 40: 643-648

9. Pieper GM, Gross GJ: Endothelial dysfunction in diabetes. In: Cardiovascular significance of endothelium-derived vasoactive factors. Rubanyi GM, Ed. Mount Kisco, Futura Publishing Company Inc, 1991, pp 223-249

10. Tomlinson KC, Gardiner SM, Hebden RA, Bennett T: Functional consequences of streptozotocin-induced diabetes mellitus, with particular reference to the cardiovascular system. Pharmacol Rev 1992; 44: 103-150

11. Heesen BJ, Ido Y, Wolffenbuttel BHR, Williamson JR: Acetylcholine induced relaxation of isolated aortas is modulated by ambient glucose, l-arginine and myo-inositol. Diabetes 1992; 41 (suppl.1): 480

12. McVeigh GE, Brennan GM, Johnston GD, et al: Impaired endothelium-dependent and independent vasodilation in patients with Type 2 (non-insulin-dependent) diabetes mellitus. Diabetologia 1992; 35: 771-776

13. Lais LT, Brody MJ: Vasoconstrictor hyperresponsiveness: an early pathogenic mechanism in the spontaneously hypertensive rat. Eur J Pharmacol 1978; 47: 177-189

14. Schiffrin EL: Reactivity of small blood vessels in hypertension: Relation with structural changes. Hypertension 1992; 19 (suppl. 2): 1-9

15. Nelissen-Vrancken HJMG, Leenders PJA, Struijker-Boudier HAJ, Smits JFM: Increased responsiveness of the vascular bed to angiotensin I, angiotensin II and phenylephrine in acute and chronic ischemic hindlimbs in rats. J Vasc Res 1992; 29: 359-366

16. Hill MA, Larkins RG: Altered microvascular reactivity in streptozotocin-induced diabetes in rats. Am J Physiol 1989; 257: H1438-1445

17. Morff RJ: Microvascular reactivity at different arteriolar levels and different durations of streptozotocin-induced diabetes. Diabetes 1990; 39: 354-360

18. Jackson CV, Carrier GO: Influence of short-term experimental diabetes on blood pressure and heart rate in response to norepinephrine and angiotensin $I$ in the conscious rat. J Cardiovasc Pharmacol 1983; 5: 260-265

19. Christlieb AR, Janka HU, Kraus B, et al: Vascular reactivity to angiotensin $I$ and to norepinephrine in diabetes mellitus. Diabetes 1976; $25: 268-274$

20. Friedman JJ: Vascular sensitivity and reactivity to norepinephrine in diabetes mellitus. Am J Physiol 1989; 256: H1134-1138 
21. Intaglietta $\mathrm{M}$, Tompkins WR: Microvascular measurements by video image shearing and splitting. Microvasc Res 1973; 5: 309-312

22. Hill MA, Simpson BE, Meininger GA: Altered cremaster muscle hemodynamics due to disruption of deferential feed vessels. Microvasc Res 1990; 39: 349-363

23. Moncada S, Rees DD, Schulz R, Palmer RM: Development and mechanism of a specific supersensitivity to nitrovasodilators after inhibition of vascular nitric oxide synthesis in vivo. Proc Natl Acad Sci USA 1991; 88: 2166-2171

24. Le Noble JLML, Smith TL, Hutchins PW, Struijker Boudier HAJ: Microvascular alterations in adult conscious spontaneously hypertensive rats. Hypertension 1990; 15: 415-419

25. Smith TL, Osborne SW, Hutchins PM. Long-term micro- and macrocirculatory measurements in conscious rats. Microvasc Res 1985; 29: 360-370

26. Struijker Boudier HAJ, Messing MWJ, Van Essen H: Preferential small arteriolar vasodilation by the potassium channel opener, BRL 38227, in conscious spontaneously hypertensive rats. Eur I Pharmacol 1992; 218: 191-193

27. Lash JM, Bohlen HG: Structural and functional origins of suppressed acetylcholine vasodilation in diabetic rat intestinal arterioles. Circ Res 1991; 69: 1259-1268

28. Mayhan WG: Impairment of endothelium-dependent dilatation of cerebral arterioles during diabetes mellitus. Am I Physiol 1989; 256: H621-625

29. Calver A, Collier J, Vallance P: Inhibition and stimulation of nitric oxide synthesis in the human forearm arterial bed of patients with insulin-dependent diabetes. J Clin Invest 1992; 90: 2548-2554

30. Tesfamariam B, Brown ML, Deykin D, Cohen RA: Elevated glucose promotes generation of endothelium-derived vasoconstrictor prostanoids in rabbit aorta. J Clin Inve'st 1990; 85: 929-932

31. Hattori $Y$, Kawasaki H, Abe K, Kanno K: Superoxide dismutase recovers altered endothelium-dependent relaxation in diabetic rat aorta. Am J Physiol 1991; 261: H10861094

32. Bucala R, Tracey KJ, Cerami A: Advanced glycosylation products quench nitric oxide and mediate defective endothelium-dependent vasodilatation in experimental diabetes. J Clin Invest 1991; 87: 432-438

33. Kamata K, Miyata N, Kasuya K: Functional changes in potassium channels in aortas from rats with streptozotocin-induced diabetes. Eur J Pharmacol 1989; 166: 319-323

34. Adeagbo ASO, Malik KA: Endothelium-dependent and BRL 34915-induced vasodilatation in rat isolated perfused mesenteric arteries: role of $\mathrm{G}$-proteins, $\mathrm{K}^{+}$and calcium channels. Br J Pharmacol 1990; 100: 427-434

35. MacLeod KM: The effect of insulin treatment on changes in vascular reactivity in chronic experimental diabetes. Diabetes 1985; 34: 1160-1167

36. Drury PL, Smith GM, Ferriss JB: Increased vasopressor responsiveness to angiotensin II in type 1 (insulin-dependent) diabetic patients without complications. Diabetologia 1984; 27: 174-179

37. Tuck M, Corry D, Trujillo A: Salt-sensitive blood pressure and exaggerated vascular reactivity in the hypertension of diabetes mellitus. Am J Med 1990; 68: 210-216

38. Craven PA, DeRubertis F: Protein kinase C is activated in glomeruli from streptozotocin-induced diabetic rats: possible mediation by glucose. J Clin Invest 1989; 83: 16671675

39. Lee TS, Saltsman KA, Ohashi H, King GL: Activation of protein kinase C by elevation of glucose concentration: proposal for a mechanism in the development of diabetic vascular complications. Proc Natl Acad Sci USA 1989; 86: 5141-5145 
40. Williams B, Schrier RW: Characterization of glucose-induced in situ protein kinase C activity in cultured vascular smooth muscle cells. Diabetes 1992; 41: 1464-1472

41. Abebe W, MacLeod KM: Protein kinase C-mediated contractile responses of arteries from diabetic rats. Br J Pharmacol 1990; 101: 465-471

42. Abebe W, MacLeod KM: Augmented inositol phosphate production in mesenteric arteries from diabetic rats. Eur J Pharmacol 1992; 225: 29-36

43. Simmons DA, Winegrad AI: Mechanisms in rabbit aorta for hyperglycaemia-induced alterations in angiotensin II and norepinephrine effects. Diabetologia 1992; 35: 725-729

44. Simmons DA, Winegrad AI: Mechanism of glucose-induced $\mathrm{Na}^{+} / \mathrm{K}^{+}$-ATPase inhibition in aortic wall of rabbits. Diabetologia 1989; 32: 402-408

45. Simmons DA, Winegrad AI: Insulin does not regulate vascular smooth muscle $\mathrm{Na}^{+} / \mathrm{K}^{+}$-ATPase activity in rabbit aorta. Diabetologia 1993; 36: 212-217

46. Canessa $\mathrm{M}$, Brugnara $\mathrm{C}$, Escobales $\mathrm{N}$ : The $\mathrm{Li}^{+} / \mathrm{Na}^{+}$exchange and $\mathrm{Na}^{+}-\mathrm{K}^{+}-\mathrm{Cl}^{-}$cotransport systems in essential hypertension. Hypertension 1987; 10 (suppl.I): 14-I10

47. Mahnensmith RL, Aronson PS: The plasma membrane sodium-hydrogen exchanger and its role in physiologic and pathophysiologic processes. Circ Res 1985; 56: 773-788

48. Halkin A, Benjamin N, Doktor HS, Todd SD, Viberti GC, Ritter JM: Vascular responsiveness and cation exchange in insulin-dependent diabetes. Clin Sci 1991; 81: 223-232

49. Mangili R, Bending JJ, Scott G, Li LK, Gupta A, Viberti GC: Increased sodium-lithium countertransport in red cells of patients with insulin-dependent diabetes and nephropathy. $N$ Engl J Med 1988; 318: 146-150

50. Ohara T, Sussman KE, Draznin B: Effect of diabetes on cytosolic free $\mathrm{Ca}^{2+}$ and $\mathrm{Na}^{*} / \mathrm{K}^{+}$-ATPase in rat aorta. Diabetes 1991; 40: 1560-1563

51. Delano FA, Schmid-Schönbein GW, Skalak TC, Zweifach BW: Penetration of the systemic blood pressure into the microvasculature of rat skeletal muscle. Microvasc Res 1991; 41 : $92-110$

52. Ohgushi $M$, Yasue $H$, Kugiyama K, Murohara T, Sakaino N: Contraction and endothelium-dependent relaxation via $\alpha$-adrenoceptors are variable in various pig arteries. Cardiovasc Res 1993; 27: 779-784

53. Inman SR, Fleming JT: Dietary myo-inositol supplementation restores renal arteriolar reactivity to angiotensin II (ANG) in diabetic rats. Diabetes 1991; 40 (suppl. 1): 131A

54. Rhie FH, Christlieb AR, Sandor T, et al: Retinal vascular reactivity to norepinephrine and angiotensin $\amalg$ in normals and diabetics. Diabetes 1982; 30: 1056-1060 
PREVENTION OF INCREASED VASCULAR PERMEABILITY 



\section{CHAPTER 4}

Angiotensin converting enzyme-inhibition reduces urinary albumin excretion but not regional albumin clearance in experimental diabetes

M.S.P. Huijberts, B.H.R. Wolffenbuttel, F.R.L. Crijns, A.C. Nieuwenhuijzen Kruseman, M.H.A. Bemelmans, H. van Essen, J.F.M. Smits, H.A.J. Struijker Boudier

European Journal of Pharmacology 1993; 240: 207-212 



\section{SUMMARY}

Albuminuria and increased regional albumin clearance are known to develop concomitantly in diabetes. The anti-proteinuric effect of angiotensin converting enzyme-inhibitor therapy is well established. We studied whether angiotensin converting enzyme-inhibitor therapy with perindoprilat in comparison with conventional antihypertensive treatment could influence the development of increased regional albumin clearance as well as albuminuria in experimental diabetes. Rats with streptozotocin-induced diabetes were randomized into a saline group $(\mathrm{n}=7)$, a perindoprilat $(1 \mathrm{mg} / \mathrm{kg} /$ day) group $(\mathrm{n}=8)$, and a hydralazine ( $3 \mathrm{mg} / \mathrm{kg} /$ day) group $(\mathrm{n}=6) ; 6$ rats served as non-diabetic controls. After 6-8 weeks, blood pressures were equally reduced in the perindoprilat and hydralazine treated groups $(p<0.01)$. $24 \mathrm{~h}$ Urinary protein and albumin excretion were increased in diabetic rats compared to control rats $(p<0.001)$. Hydralazine did not reduce $24 \mathrm{~h}$ protein nor albumin excretion, whereas perindoprilat treatment reduced both $(p<0.001)$ to levels comparable to those of control rats. Regional albumin clearances, assessed in the eye, ileum, lung, skeletal muscle and skin, were clearly elevated in diabetic rats compared to control rats; However, neither drug therapy had any effect on albumin clearances.

\section{INTRODUCTION}

Increased vascular permeability is an established feature of diabetic angiopathy. Both experimental and clinical studies have shown that in addition to the increased urinary albumin or protein loss associated with diabetic nephropathy, a generalized increase in transvascular albumin passage exists.

In experimental diabetes, regional albumin clearance in many organs including the eye, sciatic nerve, aorta, diaphragm, skin, skeletal muscle, and intestine, is increased $(1,2)$. In addition, transcapillary escape rate of albumin is increased very shortly after diabetes induction (3). At that time increased glomerular albumin filtration can be shown which is compensated for by an increased tubular albumin reabsorption, but in the course of weeks albuminuria will develop (4). In clinical diabetes, increases in capillary permeability have been observed in both insulin-dependent and non insulin-dependent diabetic patients by measuring transcapillary escape rate of albumin or local clearance of various tracers $(5,6,7)$. It appears that increased vascular permeability occurs only in diabetic patients with increased urinary albumin excretion (8), suggesting a common mechanism (9). Albuminuria may be regarded as a reflection of generalized vascular damage, and it has been suggested that increased vascular permeability is related to alterations in the composition of the vessel wall extracellular matrix, although other authors favor hemodynamic mecha- 
nisms such as increased intraglomerular and capillary pressure as etiologic factors (10).

Studies evaluating the possible role of drugs in the reduction of vascular leakage are limited to a few animal studies reporting beneficial effects of aldose reductase inhibitors (11), although it is controversial whether these drugs reduce albuminuria $(11,12)$. Albuminuria in diabetic rats can be reduced modestly by conventional antihypertensive treatment and very effectively by angiotensin converting enzyme-inhibitors (13). In the treatment of human (incipient) nephropathy angiotensin converting enzyme-inhibitors seem very effective in the reduction of microalbuminuria (14) and proteinuria (15), probably irrespective of the hypotensive effects $(16,17)$. However, no reports exist on the effects of angiotensin converting enzyme-inhibitors on generalized albumin leakage.

In this study we assessed the effects of treatment with the angiotensin converting enzyme inhibitor perindoprilat on albuminuria and vascular permeability measuring regional albumin permeation in diabetic rats. In order to discriminate between effects related to blood pressure reduction and specific effects of perindoprilat, a second therapy group treated with the vasodilator hydralazine was studied.

\section{MATERIALS AND METHODS}

\section{Animals}

Male Wistar Rp rats (TNO-REPGO, Rijswijk, The Netherlands) were used. Diabetes was induced at the age of 6-8 weeks by intraperitoneal injection with $70 \mathrm{mg} / \mathrm{kg}$ streptozotocin (Sigma, St. Louis, MO, USA) in citrate buffer ( $\mathrm{pH} 4.5$ ). Rats in the non-diabetic control group $(n=6)$ were injected with the vehicle. Development of diabetes was verified by blood glucose measurements (hexokinase method). Immediately after diabetes induction, diabetic rats were randomized into three groups: a diabetic control group $(n=8)$ receiving saline, a group treated with hydralazine (Sigma, St. Louis, MO, USA) in a dose of 3 $\mathrm{mg} / \mathrm{kg} /$ day $(\mathrm{n}=8)$, and a group treated with the angiotensin converting enzyme-inhibitor perindoprilat (Servier, Courbevoie, France) in a dose of 1 $\mathrm{mg} / \mathrm{kg} /$ day $(\mathrm{n}=8)$. Saline and both drugs were administered subcutaneously by implantable osmotic minipumps (Alzet model 2002, Alza Corporation, Palo Alto, CA, USA). Rats were treated for a period of 6-8 weeks.

\section{Surgery}

Two days prior to the extravasation study rats were anesthetized with ether, and a polyethylene (PE-10)/vinyl catheter was implanted into the abdominal aorta through the left femoral artery. The caval vein was cannulated with a similar catheter through the left femoral vein. Both catheters were filled with 
saline, closed with metal plugs and exteriorized in the neck. The procedure was performed under a-septic conditions.

\section{Blood pressure measurements}

Since it has been shown that blood pressure data obtained with the indirect tail-cuff method are unreliable and artificially elevated in diabetic rats $(18,19)$, blood pressure was measured directly in this study. One day after surgery, the arterial catheter was connected to a low volume displacement pressure transducer (CP-01, Century Technology Company, Inglewood, CA, USA). The signal was recorded on a Grass 7D polygraph (Grass Instruments, Quincy, Mass., USA). Low-pass filtering of the signal yielded mean arterial pressure.

\section{Determination of $24 \mathrm{~h}$ urinary total protein and albumin excretion}

Three days before the extravasation study, rats were placed in metabolic cages in order to collect $24 \mathrm{~h}$ urine. Urinary production was determined and urinary samples were frozen until further analysis. To determine total protein content, urine samples were diluted 1:5 and centrifugated. Protein content was measured using a spectrophotometric method measuring absorption at $600 \mathrm{~nm}$ of a pyrogallol red-molybdate complex (Merck, Darmstadt, Germany). Urinary albumin content was measured by rocket immunoelectrophoresis (20) using a goat anti-rat albumin antibody (Nordic Immunological Laboratories, Tilburg, The Netherlands). Urine samples (diluted 1:5) and a rat albumin standard (Nordic) were added in $2 \mu \mathrm{l}$ quantities to agarose gel plates containing $1 \%$ antibody. Rocket heights were measured and compared with the standard curve. The lowest detection limit of the assay was $5 \mu \mathrm{g} / \mathrm{ml}$.

\section{Determination of regional albumin permeation}

Regional albumin permeation was determined in the eye, ileum, skin, forearm skeletal muscle and lung using a double label isotope technique. We used a slightly modified version of previously published methods $(1,21,22)$. In brief, $0.120 \mathrm{MBq}\left[{ }^{125} \mathrm{I}\right]$ human serum albumin ([125I]HSA, CIS bio international, Gif sur Yvette, France) in a volume of $100 \mu \mathrm{l}$ was injected through the venous catheter at $t=0 \mathrm{~min}$. Ten minutes later an arterial sample of $200 \mu \mathrm{l}$ was taken, and immediately afterwards $0.045 \mathrm{MBq}\left[{ }^{131} \mathrm{I}\right] \mathrm{HSA}$ (CIS bio international) was injected in a volume of $100 \mu \mathrm{l}$. After $2 \mathrm{~min}$, a second arterial sample was taken and rats were subsequently killed by injection of pentobarbital. Organs were excised without delay, blotted dry and weighed. Radioactivity of tissue and plasma samples was measured on a gamma-counter (1282 Compugamma, Wallac LKB/Pharmacia, Woerden, The Netherlands) programmed for simultaneous determination of ${ }^{125} \mathrm{I}$ and ${ }^{131} \mathrm{I}$. Counts were corrected for background and crosstalk.

Using this method, [ $\left.{ }^{125} \mathrm{I}\right] \mathrm{HSA}$ is considered as the permeating tracer while [ $\left.{ }^{131} \mathrm{I}\right]$ HSA is used as marker for the intravascular space. The circulation time of 10 
min for the permeating tracer has been shown to be sufficient, as albumin disappearance consists of two phases, a rapid one from 0-10 min after injection and a slower one from 10-60 min, accounting both for $50 \%$ of the albumin efflux per hour $(23,24)$. The amount of $\left[{ }^{125} I\right] H S A$ that was extravascular $\left(\left[{ }^{125} \mathrm{I}\right] \mathrm{HSA}_{\text {extra }}\right)$ could be calculated as:

$$
\left[{ }^{125} I\right] H S A_{\text {extra }}=\left[{ }^{125} \Pi\right] H S A_{\text {tissue }}-\frac{\left[\left[{ }^{125} \eta\right] H S A\right]_{\text {plasma, 1 }-12}}{\left[\left[{ }^{131} \eta\right] H S A\right]_{\text {plesma, ! }-12}} *\left[{ }^{131} \eta\right] H S A_{\text {tissue }}
$$

where $\left[{ }^{125} \mathrm{I}\right] \mathrm{HSA}_{\text {tissue }}$ and $\left.\left[{ }^{131}\right]\right] \mathrm{HSA}_{\text {tissue }}$ represent the amount of radioactive material in tissue 12 minutes after the start of the experiment and $\left[{ }^{125} \mathrm{I}\right] \mathrm{HSA}_{\text {plas- }}$ $\mathrm{ma}, \mathrm{t=12}$ and $\left[{ }^{131} \mathrm{I}\right] \mathrm{HSA}_{\mathrm{plasma}, \mathrm{t}=12}$ represent radioactivity in plasma at 12 minutes.

Clearance was calculated per tissue from extravascular [ $\left.{ }^{125} \mathrm{I}\right] \mathrm{HSA}$ and the area under the time concentration curve (AUC) for [ [ $\left.\left.{ }^{125} \mathrm{I}\right] \mathrm{HSA}\right]$ in plasma from $0-12$ min, using standard pharmacokinetic methods, assuming log-linear disappearance of albumin from plasma (22).

$$
\text { Clearance }=\frac{\left[{ }^{125} \Pi H S A_{\text {extra }}\right.}{A U C\left[{ }^{125} \Pi H S A\right]_{\text {plasma }}}
$$

Clearances were normalized for tissue weight and expressed as $\mu \mathrm{l} / \mathrm{g}$ tissue/ min.

Statistical analysis

All values are given as means \pm SEM, or as median with range when not normally distributed. Groups were compared with analysis of variance (ANOVA) with the Sidak post-hoc test for multiple comparisons or with the Kruskal Wallis test when not normally distributed (Crunch4 Manual, Crunch Software Corporation, Oakland, CA, USA). The box plots in the figures on regional albumin clearance represent the median value, the interquartile range $\left(25^{\text {th }}-75^{\text {th }}\right.$ percentile) and the $5^{\text {th }}$ and $95^{\text {th }}$ percentiles. 


\section{RESULTS}

\section{General characteristics}

During the treatment period two rats died in the hydralazine treated group and one rat in the saline treated diabetic group. Results were thus obtained in 6 non-diabetic control rats, 7 diabetic control rats, 6 hydralazine treated diabetic rats, and 8 perindoprilat treated diabetic rats. Body weights were comparable in all three diabetic groups after 6-8 weeks of treatment, $(200 \pm 9 \mathrm{~g}$ in diabetic control rats, $207 \pm 14 \mathrm{~g}$ in the hydralazine group and $194 \pm 14 \mathrm{~g}$ in the perindoprilat group), but were all markedly lower compared to non-diabetic control rats $(319 \pm 7 \mathrm{~g}, p<0.0001)$ Blood glucose concentrations were similarly elevated in all diabetic groups, and were in the $20-25 \mathrm{mmol} / 1$ range $(24.2 \pm 1.0$ $\mathrm{mmol} / \mathrm{l}, 25.0 \pm 1.1 \mathrm{mmol} / \mathrm{l}$ and $22.3 \pm 1.7 \mathrm{mmol} / \mathrm{l}$, vs. $6.9 \pm 1.1 \mathrm{mmol} / 1 \mathrm{in}$ nondiabetic controls, $p<0.0001$ ).

\section{Blood pressure}

Mean arterial blood pressure in the diabetic control group was slightly but non-significantly lower than in the non-diabetic control group $(106 \pm 3 \mathrm{mmHg}$ vs. $114 \pm 2 \mathrm{mmHg}$ ). Both antihypertensive treatments reduced mean arterial pressure to an equal extent $(91 \pm 4 \mathrm{mmHg}$ in the hydralazine group and $90 \pm 3$ $\mathrm{mmHg}$ in the perindoprilat group, both $p<0.01$, Fig. 1).

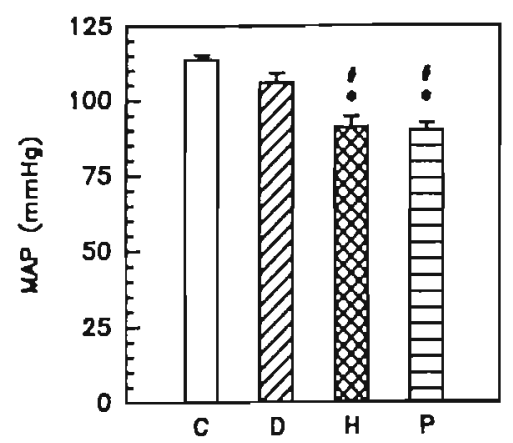

Figure 1: Mean arterial pressure in nondiabetic control rats $(C)$, diabetic control rats (D), hydralazine treated diabetic rats $(\mathrm{H}, 3 \mathrm{mg} / \mathrm{kg} /$ day), and perindoprilat $(\mathrm{P}, 1$ $\mathrm{mg} / \mathrm{kg} /$ day). Values represent means \pm SEM. ( significantly different from nondiabetic control rats, $p<0.01$, \# significantly different from diabetic control rats, $p<0.01$ )

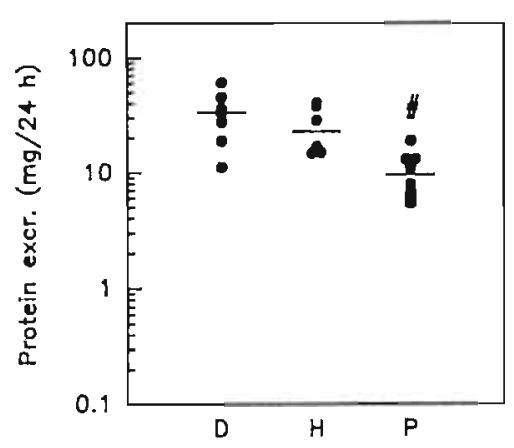

Figure 2: $24 \mathrm{~h}$ total protein excretion in diabetic control rats (D), hydralazine treated diabetic rats $(\mathrm{H})$ and perindoprilat treated diabetic rats (P)., " significantly different from diabetic and hydralazine treated diabetic rats $p<0.005$ ). 


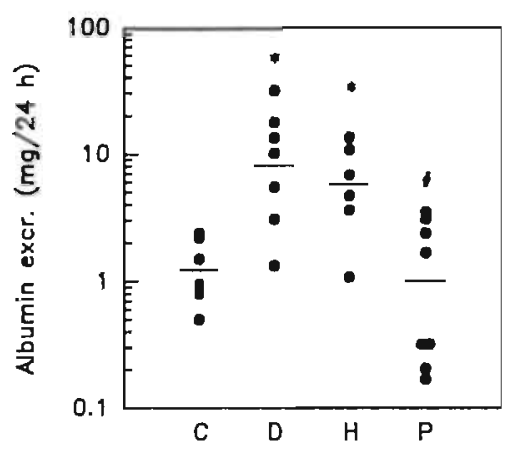

Figure 3: $24 \mathrm{~h}$ albumin excretion in nondiabetic control rats (C), diabetic control rats, hydralazine treated diabetic rats $(\mathrm{H})$ and perindoprilat treated diabetic rats $(P)$. ( significantly different from control rats $p<0.001$,

significantly different from diabetic and hydralazine treated diabetic rats $p<0.005$ ).
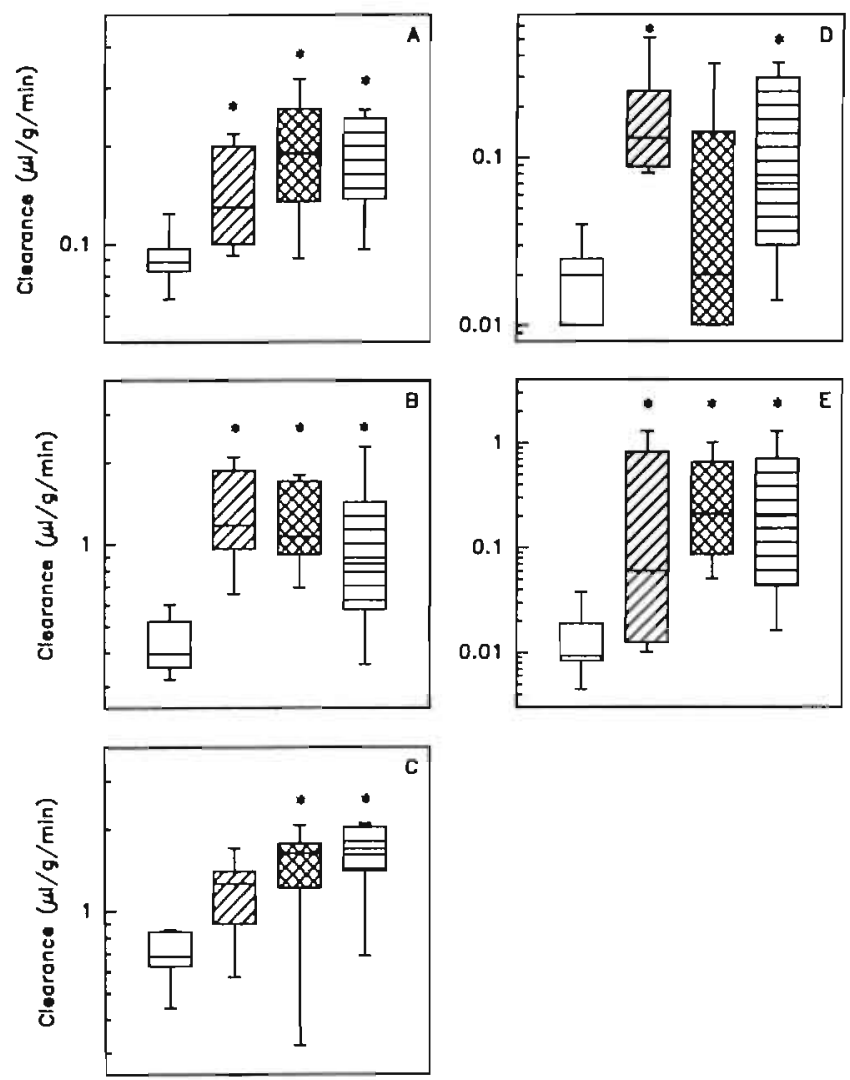

Figure 4: Regional albumin clearances in the eye (panel A), lung (panel B), ileum (panel C), skin (panel D), and skeletal muscle (panel E) of non-diabetic control rats (blank boxes), diabetic control rats (diagonally hatched boxes), hydralazine treated (crosshatched boxes) and perindoprilat treated (horizontally hatched boxes) diabetic rats. Box plots represent median, interquartile range and 5 th and 95 th percentiles. $\left(^{*}\right.$ significantly different from values in control rats, $p<0.05)$. 


\section{Urinary $24 h$ total protein and albumin excretion}

Median $24 \mathrm{~h}$ total protein excretion (Fig. 2) was $33.3 \mathrm{mg}$ (range 11.1-61.1) in the saline treated group, and was slightly but not significantly reduced in the hydralazine group (22.8 mg, (14.8-40.6)). From non-diabetic control rats, no total protein excretion rate values were obtained. Perindoprilat treatment strongly reduced protein excretion to $10.3 \mathrm{mg} / 24 \mathrm{~h}(5.3-19.0), p<0.001)$. Comparable results were obtained with specific albumin measurements. Urinary albumin excretion was markedly elevated in diabetic control rats compared to non-diabetic control rats $(8.2 \mathrm{mg} / 24 \mathrm{~h}(1.3-31.7)$ vs. $1.2 \mathrm{mg} / 24 \mathrm{~h}(0.5-2.4)$ $p<0.001$, Fig. 3). Hydralazine treatment did not reduce albumin excretion (5.8 $\mathrm{mg} / 24 \mathrm{~h},(1.1-13.6))$, whereas perindoprilat reduced albumin excretion to levels comparable to those of non-diabetic rats $(1.0 \mathrm{mg} / 24 \mathrm{~h},(0.2-3.5), p<0.001)$ compared to diabetic control rats).

\section{Effects on regional albumin permeation}

Albumin clearance was determined in the eye, ileum, lung, skeletal muscle, and skin. Clearances were significantly elevated in all tissues of diabetic rats compared to control rats except for the ileum ( $p=0.12$, Fig. 4). Conventional antihypertensive treatment with hydralazine nor perindoprilat treatment had any significant effects on albumin permeation in these organs.

\section{DISCUSSION}

In this study we have shown that treatment with the angiotensin converting enzyme-inhibitor perindoprilat completely prevented the development of albuminuria in diabetic rats, in contrast to the non-significant anti-proteinuric effects of the vasodilator hydralazine. However, neither drug had any effects on regional albumin clearance.

Our data regarding the anti-proteinuric effect of perindoprilat are in accordance with other studies in which angiotensin converting enzyme-inhibitors were shown to be effective in the prevention or reduction of both experimental and clinical (micro)albuminuria and proteinuria $(13,15,25,26)$. It has been assumed that these effects of angiotensin converting enzyme-inhibitors are related to their favorable effects on renal hemodynamics, such as a reduction of intraglomerular capillary pressure through a dilation of the efferent arteriole (13). Recently, attention has been focused on non-hemodynamic renal effects of angiotensin II. It has been suggested that the long-term anti-proteinuric effects of angiotensin converting enzyme-inhibition might be related to structural changes (27) and improvement of size and charge selectivity of the glomerular capillary wall $(28,29,30)$, which is probably affected in diabetes (31). 
Despite the clear effects of angiotensin converting enzyme-inhibitor treatment on albuminuria, no effects on increased regional albumin clearance could be observed in any of the organs that were studied. There is little knowledge about the mechanisms responsible for the increase in vascular permeability in organs other than the kidney, nor is it known whether the renin-angiotensin system plays a role in the etiology of the permeability changes. As the systemic increase in vascular permeability and changes in glomerular permeability might be associated, pathophysiologic theories considering systemic changes are mainly extensions from concepts about renal mechanisms. The existence of capillary hypertension in diabetes as an equivalent of glomerular capillary hypertension has been demonstrated only recently in insulin-dependent diabetic patients but not in non insulin-dependent diabetic patients $(32,33)$. The parallel changes in vascular permeability observed by the same group, that is increased permeability in insulin-dependent diabetes but not in non insulin dependent-diabetes (34), suggest that these phenomena are related. However, there are also indications that structural alterations in the extracellular matrix play a role. Loss of basement membrane charge selectivity, probably caused by loss of anionic heparan sulphate or alterations in the heparan sulphate/fibronectin ratio, has been demonstrated outside the glomeruli in Bruch's membrane and in arterial intima $(35,36)$. Angiotensin II might have effects on permeability by regulating transcapillary passage of macromolecules (37) through effects on the endothelium (38).

The finding that angiotensin converting enzyme-inhibition had no effects on increased vascular permeability, suggests that either no capillary hypertension exists or its development can not be prevented by treatment with perindoprilat. The latter might be conceivable as angiotensin II in the kidney increases intraglomerular capillary pressure through specific constriction of the efferent arteriole. Its counterpart in an organ capillary bed would be the postcapillary venules which are not likely to be affected by angiotensin II. It must however be noted that mean arterial blood pressure was rather low in our animals. Studies in diabetic spontaneously hypertensive rats showed reduction of vascular albumin leakage in the retina following treatment with different antihypertensive drugs (39). This suggests that -in addition to local vascular wall changes- the actual blood pressure level may play a role.

In conclusion, the effects of angiotensin converting enzyme-inhibitor therapy on urinary albumin excretion and regional albumin clearance are clearly distinct. Although common etiologic mechanisms are proposed for (micro)albuminuria and increased regional albumin clearance, this apparently does not mean that pharmacological reduction of (micro)albuminuria automatically affects systemic albumin leakage as well. Although human studies with angiotensin converting enzyme-inhibitors are required to confirm our obser- 
vations, it may be questioned whether a treatment aimed at reducing albuminuria, which does not affect generalized albumin leakage, will reduce cardiovascular morbidity and mortality associated with albuminuria in diabetic patients $(40,41)$. 


\section{REFERENCES}

1. Pugliese G, Tilton RG, Speedy A, et al: Modulation of hemodynamic and vascular filtration changes in diabetic rats by dietary myo-inositol. Diabetes 1990; 39: 312-322

2. Huijberts MSP, Smits JFM, Struijker Boudier HAJ, Nieuwenhuijzen Kruseman AC, Wolffenbuttel BHR: Effects of short- and long-term hyperglycemia on vascular permeability in diabetic rats. Diabetes 1991; 40 (suppl. 1): 211a

3. Tucker BJ: Early onset of increased transcapillary escape rate in awake diabetic rats. Diabetes 1990; 39: 919-923

4. Tucker BJ, Blantz RC, Rasch R: Glomerular filtration and tubular reabsorption of albumin in early and established STZ-diabetic rats. Diabetologia 1992; 35 (suppl. 1): A11

5. Parving $\mathrm{HH}$, Noer I, Deckert $\mathrm{T}$. The effect of metabolic regulation on microvascular permeability to small and large molecules in short-term juvenile diabetics. Diabetologia 1976; 12: 161-166

6. Bollinger A, Frey J, Jaeger K, Furrer J, Seglias J, Siegenthaler W: Patterns of diffusion through skin capillaries in patients with long-term diabetes. $N$ Engl J Med 1982; 307: 1305-1310

7. O'Hare JA, Ferriss JB, Twomey B, O'Sullivan DJ: Poor metabolic control, hypertension, and microangiopathy independently increase the transcapillary escape rate of albumin in diabetes. Diabetologia 1983; 25: 260-263

8. Feldt-Rasmussen B: Increased transcapillary escape rate of albumin in Type 1 (insulindependent) diabetic patients with microalbuminuria. Diabetologia 1986; 29: 282-286

9. Deckert T, Feldt-Rasmussen B, Borch-Johnsen K, Kofoed-Enevoldsen A: Albuminuria reflects widespread vascular damage: The Steno hypothesis. Diabetologia 1989; 32: 219226

10. Zatz R, Brenner BM: Pathogenesis of diabetic microangiopathy: the hemodynamic view. Am J Med 1986; 80: 443-453

11. Tilton RG, Chang KG, Pugliese G, et al: Prevention of hemodynamic and vascular albumin filtration changes in diabetic rats by aldose reductase inhibitors. Diabetes 1989; 38: 1258-1270

12. Koemer A, Celsi G, Ekloef A-C, Linne T, Persson B, Aperia A: Sorbinil does not prevent hyperfiltration, elevated ultrafiltration pressure and albuminuria in streptozotocin-diabetic rats. Diabetologia 1992; 35: 414-418

13. Anderson S, Rennke HG, Garcia DL, Brenner BM: Short and long term effects of antihypertensive therapy in the diabetic rat. Kidney Int 1989; 36: 526-536

14. Mimran A, Insua A, Ribstein J, Bringer J, Monnier L: Comparative effect of captopril and nifedipine in normotensive patients with incipient diabetic nephropathy. Diabetes Care 1988; 11: 850-853

15. Parving $\mathrm{HH}$, Hommel E, Damkjaer Nielsen M, Giese J: Effect of captopril on blood pressure and kidney function in normotensive insulin-dependent diabetics with nephropathy. Br Med J 1989; 299: 533-536

16. Marre M, Chatellier G, Leblanc G, Guyene TT, Menard J, Passa P: Prevention of diabetic nephropathy with enalapril in normotensive diabetics with microalbuminuria. Br Med J 1988; 297: 1092-1095

17. Rudberg S, Aperia A, Freyschuss U, Persson B: Enalapril reduces microalbuminuria in young normotensive Type 1 (insulin-dependent) diabetic patients irrespective of its hypotensive effect. Diabetes Metab Rev 1990; 33: 470-476

18. Kusaka M, Kishi K, Sokabe H: Does so-called streptozotocin hypertension exists in rats? Hypertension 1987; 10: 517-521 
19. Tomlinson KC, Gardiner SM, Bennett T: Blood pressure in streptozotocin-treated Brattleboro and Long Evans rats. Am J Physiol 1990; 258: R852-859

20. Laurell C-B: Electroimmunoassay. Scand J Lab Clin Invest 1972; 29 (suppl. 124): 21

21. Williamson JR, Holmberg SW, Chang KG, Marvel J, Sutera S, Needleman P: Mechanisms underlying atriopeptin-induced increases in hematocrit and vascular permeation in rats. Circ Res 1989; 64: 890-899

22. De Vries PJF, Tyssen C, Struijker Boudier HAJ, Smits JFM: Atrial natriuretic factor increases albumin extravasation in conscious rats. Eur J Physiol 1990; 41.5: 507-509

23. Bent-Hansen L: Initial plasma disappearance and tissue uptake of 1311 -albumin in normal rabbits. Microvasc Res 1991; 41: 345-356

24. Bent-Hansen L: Whole body capillary exchange of albumin. Acta Physiol Scand 1991; 143: 5-10

25. Zatz R, Dunn R, Meyer TW, Anderson S, Rennke H, Brenner BM: Prevention of diabetic glomerulopathy by pharmacological amelioration of glomerular capillary hypertension. J Clin Invest 1986; 77: 1925-1930

26. Bjoerck S, Mulec H, Johnsen SA, Nyberg G, Aurell M: Contrasting effects of enalapril and metoprolol on proteinuria in diabetic nephropathy. Br Med J 1990; 300: 904-909

27. Yoshida Y, Kawamura T, Ikoma M, Fogo A, Ichikawa I: Effects of antihypertensive drugs on glomerular morphology. Kidney Int 1989; 36: 626-635

28. Yoshioka T, Mitarai T, Kon V, Deen WM, Rennke H, Ichikawa I: Role for angiotensin II in overt functional proteinuria. Kidney Int 1986; 30: 538-545

29. Morelli E, Loon N, Meyer T, Peters W, Myers BD: Effects of converting enzyme inhibition on barrier function in diabetic glomerulopathy. Diabeles 1990; 39: 76-82

30. Stornello M, Valvo EV, Scapellato L: Persistent albuminuria in normotensive noninsulin dependent (type II) diabetic patients: comparative effects of angiotensinconverting enzyme inhibitors and beta-adrenoceptor blockers. Clin Sci 1992; 82: 19-23

31. Croggel GC, Stevenson J, Hovingh P, Linker A, Border WA: Changes in heparan sulfate correlate with increased glomerular permeability. Kidney Int 1988; 33: 517-523

32. Sandeman DD, Shore AC, Tooke JE: Relation of skin capillary pressure in patients with insulin-dependent diabetes mellitus to complications and metabolic control. $N$ Engl J Med 1992; 327: 760-764

33. Shore AC, Sandeman DD, Jaap AJ, Sampson KJ, Tooke JE: Is capillary pressure elevated in patients with non-insulin dependent diabetes? Int J Microcirc: Clin Exp 1992; 11 (suppl. 1): S210

34. Jaap AJ, Shore AC, Gartside IB, Gamble J, Tooke JE: A comparison of capillary filtration coefficient in type 1 and type 2 diabetes using a new plethysmographic technique. Int J Microcirc: Clin Exp 1992; 11 (suppl. 1): S208

35. Caldwell RB, Slapnick SM, McLaughlin BJ: Decreased anionic sites in Bruch's membrane of spontaneous and drug-induced diabetes. Invest Ophthalmol Vis Sci 1986;27: 1691-1697

36. Raz I, Havivi I, Yarom R: Reduced negative surface charge on arterial endothelium of diabetic rats. Diabetologia 1988; 31: 618-620

37. Thorball N, Olsen F: The permeability pathways in the walls of intestinal submucosal arterioles in acute angiotensin-induced hypertension in rats. Acta Pathol Microbiol Scand 1974; 82: 683-689

38. Bell L, Madri JA: Influence of the angiotensin system on endothelial and smooth muscle cell migration. Am J Pathol 1990; 137: 7-12

39. Cooper M, Gin T, Lim-Joon T, et al: Diabetic renal and retinal microvascular disease: are all antihypertensive agents equal? Diabetologia 1992; 35 (suppl. 1): A629 
40. Borch-Johnsen K, Kreiner S: Proteinuria - A predictor of cardiovascular mortality in insulin-dependent diabetes mellitus. $\mathrm{Br}$ Med J 1987; 294: 1651-1654

41. Schmitz A, Vaeth M: Microalbuminuria: A major risk factor in non-insulin dependent diabetes. A 10-year follow up study of 503 patients. Diabetic Med 1989; 5: 126-134 


\section{CHAPTER 5}

Aminoguanidine reduces regional albumin clearance but not urinary albumin excretion in streptozotocin-diabetic rats

M.S.P. Huijberts, B.H.R. Wolffenbuttel, F.R.L. Crijns, A.C. Nieuwenhuijzen Kruseman, M.H.A. Bemelmans, H.A.J. Struijker Boudier

Diabetologia 1994; 37: 10-14 



\section{SUMMARY}

Advanced glycosylation endproduct-formation is thought to play a role in the development of diabetic angiopathy. By altering the structure of different extracellular matrix components advanced glycosylation endproducts might affect vascular and glomerular permeability. In this study we investigated the effect of treatment with an inhibitor of advanced glycosylation endproductformation, aminoguanidine, on vascular permeability and the development of albuminuria in streptozotocin-induced diabetic rats. Male Wistar Rp rats were randomized into a control group, a diabetic group, and an aminoguanidine treated diabetic group. After 8 weeks, 24-h urine collections were made and rats were implanted with an arterial and a venous catheter. Mean arterial blood pressure was determined by intra-arterial measurement. Regional albumin clearances were assessed in the eye, ileum, lung, skeletal muscle and skin using an isotope technique. Mean arterial pressure in the diabetic group was significantly lower than in the control and aminoguanidine-treated group $(p<0.02)$. Regional albumin clearances were significantly increased in all tissues of diabetic rats compared to control rats $(p<0.05)$. Aminoguanidine treatment of diabetic rats resulted in a significant decrease of regional albumin clearance in all tissues except the lung ( $p<0.05$, lung $p=0.07$ ). The development of albuminuria in diabetic rats however, was not affected by aminoguanidine.

\section{INTRODUCTION}

The formation of advanced glycosylation endproducts (AGEs) on long-lived macromolecules has been implicated in the etiology of diabetic angiopathy. Numerous reports have shown that AGE-formation can alter the function of several systems that are involved in cardiovascular homeostasis (1).

Extracellular matrix components such as type IV collagen and laminin undergo marked structural changes following glycation $(2,3)$. The observed alterations might influence the interaction of these components with other basement membrane elements such as heparan sulphate-proteoglycan (HS-PG). Alterations in the density of HS-PG in glomerular basement membrane and the vascular wall are thought to play a role in the development of both glomerular and systemic permeability changes in diabetes $(4,5)$. Increases in vascular permeability and increases in urinary albumin excretion have been shown to develop simultaneously in both clinical and experimental diabetes (6-9).

Aminoguanidine, a nucleophilic hydrazine compound, prevents the formation of AGEs (10). This drug has been shown to decrease albuminuria in spontaneously hypertensive diabetic rats (11). In addition, experiments in a skin-chamber model suggest that it can reduce the increased vascular permeability induced by hyperglycaemia (12). We hypothesized that a beneficial effect of 
aminoguanidine would also imply reduction of increased regional albumin clearance in other organs. Therefore, in this study we assessed the effects of aminoguanidine treatment on blood pressure, albuminuria and the permeability of various vascular beds, by measuring regional albumin clearances in diabetic rats. In previous studies we and others have shown that a duration of experimental diabetes of 8 weeks is sufficient to develop serious vascular dysfunction, which resembles in many aspects the disturbances observed in human diabetes $(8,13-15)$. Moreover, this diabetes duration is characterized by significant accumulation of AGEs (16).

\section{MATERIALS AND METHODS}

\section{Animals}

Male Wistar Rp rats (TNO-REPGO, Rijswijk, The Netherlands) were used. Rats were randomized into a control group $(n=8)$, a diabetic group $(n=8)$ and an aminoguanidine treated diabetic group $(n=8)$. Diabetes was induced at the age of 6-8 weeks by intraperitoneal injection with $70 \mathrm{mg} / \mathrm{kg}$ streptozotocin (Sigma,

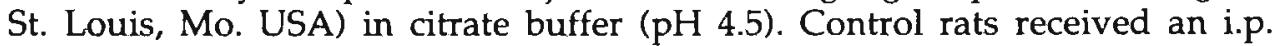
injection with the vehicle. Development of diabetes was verified by blood glucose measurements (hexokinase method), 3 days after streptozotocin administration. Only rats with blood glucose levels above $15 \mathrm{mmol} / 1$ were included in the study. Aminoguanidine-hemisulphate (Sigma) was administered in daily doses of $50 \mathrm{mg} / \mathrm{kg}$ by subcutaneous injection. Treatment was started immediately after diabetes induction and lasted for a period of 7 weeks. Urinary albumin excretion was measured in the original group of 24 rats and in an additional batch of 18 rats, randomized and treated as described above.

\section{Surgery}

Two days prior to the extravasation study rats were anaesthetized with ether, and a polyethylene (PE-10)/vinyl catheter was implanted into the abdominal aorta through the left femoral artery. The caval vein was cannulated with a similar catheter through the left femoral vein. Both catheters were filled with saline, closed with metal plugs and exteriorized in the neck. The procedure was performed under aseptic conditions.

\section{Blood pressure measurements}

Since it has been shown that blood pressure data obtained with the indirect tail-cuff method are unreliable and artificially elevated in diabetic rats $(17,18)$, blood pressure was measured directly in this study. One day after surgery, the arterial catheter was connected to a low volume displacement pressure transducer (CP-01, Century Technology Company, Inglewood, Calif., USA). The signal was recorded on a Grass 7D polygraph (Grass Instruments, Quincy, 
Mass., USA). Low-pass filtering of the signal yielded mean arterial pressure. During the measurements rats were allowed to move freely in their cages. Actual blood pressure measurements were performed following a stabilization period of $30 \mathrm{~min}$.

\section{Determination of urinary albumin excretion}

Three days before the extravasation study, rats were placed in metabolic cages in order to collect $24 \mathrm{~h}$ urine samples. Urinary production was determined and urine samples were frozen until further analysis (within 1 week). Urinary albumin content was measured by rocket immunoelectrophoresis (19) using a goat anti-rat albumin antibody (Nordic Immunological Laboratories, Tilburg, The Netherlands). Urine samples (diluted 1:5 or 1:10) and a rat albumin standard (Nordic) were added in $2 \mu$ l quantities to agarose gel plates containing $1 \%$ antibody. Rocket heights were measured and compared with the standard curve. The lowest detection limit of the assay was $5 \mu \mathrm{g} / \mathrm{ml}$.

\section{Determination of regional albumin permeation}

Regional albumin permeation was determined in the eye, ileum, skin, forearm skeletal muscle and lung using a double label isotope technique. We used a slightly modified version of previously published methods (20-22). In brief, $0.128 \mathrm{MBq}\left[{ }^{125} \mathrm{I}\right] \mathrm{human}$ serum albumin ([25I]HSA, CIS bio international, Gif sur Yvette, France) in a volume of $100 \mu \mathrm{l}$ was injected through the venous catheter at $t=0$. Ten min later a $200 \mu \mathrm{l}$ arterial sample was taken, and immediately afterwards $\left.0.099 \mathrm{MBq}{ }^{[131} \mathrm{I}\right] \mathrm{HSA}$ (CIS bio international) was injected in a volume of $100 \mu \mathrm{l}$. After $2 \mathrm{~min}$, a second arterial sample was taken and rats were subsequently killed by injection of pentobarbital. Organs were excised immediately, blotted dry and weighed. Radioactivity of tissue and plasma samples was measured on a gamma-counter (1282 Compugamma, Wallac LKB/Pharmacia, Woerden, The Netherlands) programmed for simultaneous determination of ${ }^{125} \mathrm{I}$ and ${ }^{131} \mathrm{I}$. Counts were corrected for background and crosstalk.

Using this method, $\left[{ }^{125} \mathrm{I}\right] \mathrm{HSA}$ is considered as the permeating tracer while $\left[{ }^{131} \mathrm{I}\right] \mathrm{HSA}$ is used as marker for the intravascular space. The circulation time of $10 \mathrm{~min}$ for the permeating tracer has been shown to be sufficient to obtain a significant albumin extravasation, as albumin disappearance consists of two phases, a rapid one from $0-10 \mathrm{~min}$ after injection and a slower one from 10-60 min, both accounting for $50 \%$ of the albumin efflux per hour $(23,24)$. In previous studies, both phases of albumin disappearance were shown to be increased in diabetic rats (25). The amount of extravascular $\left[{ }^{125} \mathrm{I}\right] \mathrm{HSA}\left(\left[{ }^{125} \mathrm{I}\right] \mathrm{HSA} \mathrm{extra}_{\text {er }}\right)$ could be calculated as: 


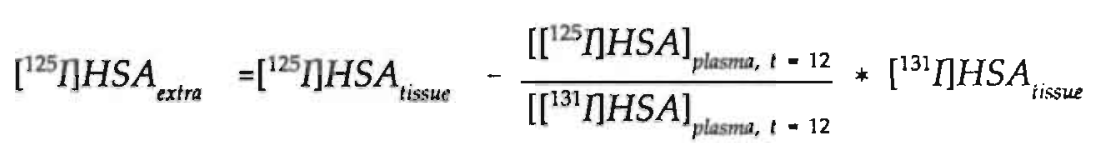

where $\left[{ }^{125} \mathrm{I}\right] \mathrm{HSA}_{\text {tissue }}$ and $\left[{ }^{131} \mathrm{I}\right] \mathrm{HSA} \mathrm{A}_{\text {tissue }}$ represent the amount of radioactive material in tissue 12 minutes after the start of the experiment and [125] ${ }^{125 S A_{\text {plas- }}}$ $m a, t=12$ and $\left[{ }^{131} \mathrm{I}\right] \mathrm{HSA} \mathrm{plasma,} \mathrm{r}=12_{2}$ represent radioactivity in plasma at 12 minutes.

Clearance was calculated per tissue from extravascular $\left[{ }^{125} \mathrm{I}\right] \mathrm{HSA}$ and the area under the time concentration curve (AUC) for $\left.\left.\left[{ }^{125}\right]\right] \mathrm{HSA}\right]$ in plasma from 0-12 min, using standard pharmacokinetic methods, assuming log-linear disappearance of albumin from plasma (22).

$$
\text { Clearance }=\frac{\left[{ }^{125} \Pi\right] H S A_{\text {extra }}}{\left.A U C\left[{ }^{125} I\right] H S A\right]_{\text {plasma }}}
$$

Clearances were normalized for tissue weight and expressed as $\mu \mathrm{l} / \mathrm{g}$ tissue $/ \mathrm{hr}$.

\section{Statistical analysis}

All values are given as means $\pm \mathrm{SD}$, or as median with range when not normally distributed. Groups were compared with analysis of variance (ANOVA) with the Sidak post-hoc test for multiple comparisons or with the Kruskal Wallis test when not normally distributed (Crunch4 Manual, Crunch Software Corporation, Oakland, CA, USA).

\section{RESULTS}

General characteristics

Body weight was lower in both groups of diabetic rats compared to control rats $(p<0.0001)$, while blood glucose levels were significantly elevated in the diabetic groups $(p<0.0001$, Table 1$)$. Between untreated diabetic rats and aminoguanidine-treated rats no differences in body weight nor blood glucose levels could be observed. Body weight and blood glucose levels of the additional 18 rats that were used to determine urinary albumin excretion are also given in Table 1. 
Blood pressure

Mean arterial blood pressure was significantly lower in diabetic rats compared to control rats $(p<0.02$, Table 1$)$, while rats treated with aminoguanidine had mean arterial pressures comparable to those of control rats.

Table 1. General characteristics of the study groups

\begin{tabular}{lcccc}
\hline & Body & $\begin{array}{c}\text { Bl. Glucose } \\
\text { Weight }(\mathrm{g})\end{array}$ & $\begin{array}{c}\text { Mean Arterial Pressure } \\
(\mathrm{mmol} / \mathrm{l})\end{array}$ \\
Control & 1 & $309 \pm 12$ & $6.0 \pm 2.5$ & $110 \pm 6$ \\
& 2 & $297 \pm 8$ & $6.5 \pm 1.5$ & $115 \pm 4$ \\
Diabetes & 1 & $223 \pm 34^{\mathrm{b}}$ & $16.5 \pm 2.5^{\mathrm{b}}$ & $100 \pm 5^{\mathrm{a}}$ \\
& 2 & $205 \pm 29^{\mathrm{b}}$ & $20.1 \pm 2.8^{\mathrm{b}}$ & $102 \pm 5^{\mathrm{a}}$ \\
Diabetes + & 1 & $225 \pm 25^{\mathrm{b}}$ & $18.2 \pm 2.9^{\mathrm{b}}$ & $109 \pm 5$ \\
Aminoguanidine & 2 & $198 \pm 27^{\mathrm{b}}$ & $19.3 \pm 3.1^{\mathrm{b}}$ & $115 \pm 6$ \\
\hline
\end{tabular}

- Significantly different from values in control rats, $p<0.02$

' Significantly different from values in control rats, $p<0.0001$

1 Original group of $24(3 \times 8)$ rats

2 Additional batch of $18(3 \times 6)$ rats

\section{Urinary albumin excretion}

Urinary albumin excretion rate $\left(\mathrm{U}_{\mathrm{alb}} \mathrm{V}\right)$ was significantly elevated in diabetic rats compared to control rats, although there was a large variation in the values of $U_{\mathrm{alb}} \mathrm{V}$ in diabetic rats (median $8.3 \mathrm{mg} / 24 \mathrm{~h}$ range (2.6-84.1) in diabetic rats vs $2.8 \mathrm{mg} / 24 \mathrm{~h}(0.5-8.8)$ in control rats, $p<0.01$, Fig. 1). Aminoguanidine treatment did not affect $U_{\text {alb }} \mathrm{V}$ in diabetic rats. In the aminoguanidine-treated group, the dispersal in $\mathrm{U}_{\text {alb }} \mathrm{V}$ values was comparable to that of untreated diabetic rats (median 10.1 (1.5-112.7), $p<0.001$ compared to control rats).

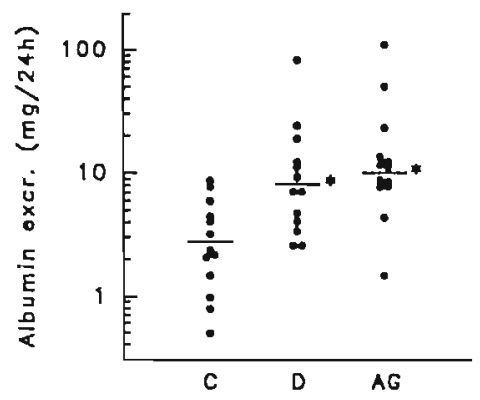

Figure 1: Urinary albumin excretion rate $\left(U_{\text {alb }} V\right) 8$ weeks after start of the study in control rats $(C, n=14)$, diabetic rats $(D$, $\mathrm{n}=14$ ) and aminoguanidine-treated diabetic rats $(A G, n=14)$. Individual $U_{\text {alb }} V$ values are given plus the median value for each group. Significantly different from values in control rats, ${ }^{*} p<0.01$. 
Effects on regional albumin permeation

In all organs regional albumin clearance was significantly increased in diabetic rats compared to control rats (Fig. 2). Diabetic rats treated with aminoguanidine had albumin clearances that were significantly lower than those of untreated rats and not different from values of control rats in all tissues, except the lung ( $p=0.07$ compared to diabetic rats).
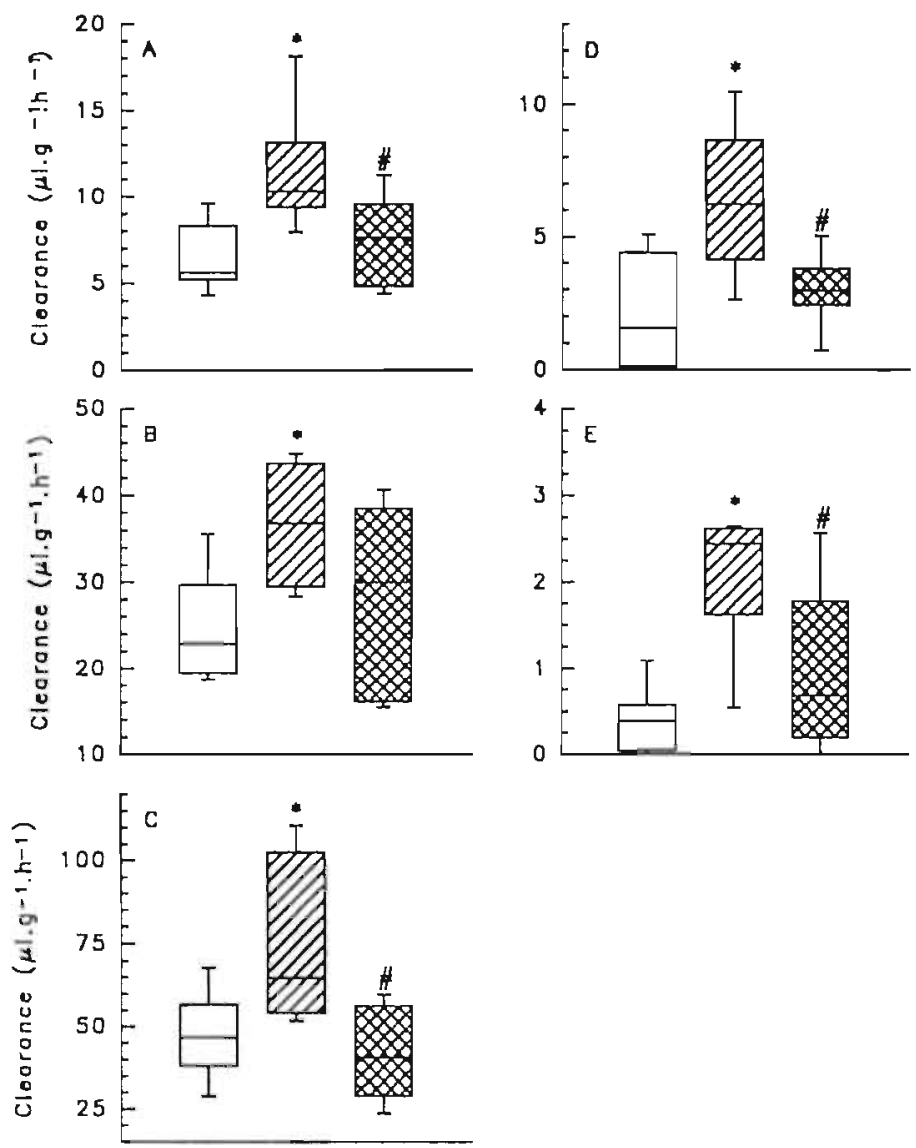

Figurc 2: Regional albumin clearances in the eye (A), lung (B), ileum (C), skin (D) and skeletal muscle (E) of control rats (blank boxes), diabetic rats (diagonally hatched boxes) and aminoguanidine treated diabetic rats (cross-hatched boxes). Box plots represent median, interyuartile range and 5 th and 95 th percentiles. * significantly different from control values, $p<0.05$. \# significantly different from values in diabetic rats, $p<0.05$. 


\section{DISCUSSION}

This study reveals a marked effect of long-term treatment with aminoguanidine, an inhibitor of AGE-formation, on increased regional albumin clearance in diabetic rats. However, no effects on urinary albumin excretion were observed. In addition we found a slight blood-pressure elevating effect of aminoguanidine.

The observed effects of aminoguanidine on regional albumin clearance are in accordance with the report of Corbett et al. (12) who showed a normalization of permeability induced by hyperglycemia in skin-chamber granulation tissue. They suggest that aminoguanidine normalizes increased vascular permeability by correcting nitric oxide (NO) overproduction, since other inhibitors of NOformation such as $N^{\mathrm{G}}$-Monomethyl-L-arginine (L-NMMA) had similar effects. In their study aminoguanidine administration also slightly raised blood pressure, although about 40 times less effectively than L-NMMA. Very recently, Tilton et al. showed that methylguanidine a compound with a comparable NOsynthase inhibiting action as aminoguanidine but no effects on AGE-formation, also prevented vascular dysfunction in experimental diabetes (26).

However, we measured increases in vascular permeability in vascular beds, such as skeletal muscle and skin, to which blood flow is decreased in experimental diabetes (27), which makes the concept of NO overproduction resulting in increased flow and increased vascular permeability, not generally applicable. In addition, in another study we have observed a very significant increase in vascular elasticity in diabetic rats following long-term treatment with aminoguanidine which could not be attributed to NO-dependent alterations in vascular tone (28), indicating that there are beneficial effects of aminoguanidine on vascular dysfunction in diabetes that are definitely not related to its NOinhibiting actions. Since we have not quantified effects of aminoguanidine treatment in non-diabetic rats, the possibility that aminoguanidine reduces albumin clearance per se, whether increased or not cannot be ruled out. On the other hand, Kihara et al. (29) have shown however that aminoguanidine treatment did not affect the unaltered albumin clearance of sciatic nerve tissue from diabetic rats.

Increased urinary albumin excretion was not affected by aminoguanidine in this study. This is in contrast to the results in spontaneously hypertensive diabetic rats (11) and in diabetic rats (30). In both studies rats were treated for a significantly longer period (24-32 weeks) which might explain the difference between our results and these studies. In addition, one study does not report effects on blood pressure (30) whereas the other refers to blood pressures that were determined by indirect tail-cuff plethysmography, and therefore cannot be interpreted properly. There is strong evidence that this method produces artificially elevated blood pressure recordings, as a result of either structural 
or hemodynamic alterations in the tail of diabetic rats $(17,18)$. In our own laboratory we also observed differences between direct intra-arterial blood pressure measurements and tail-cuff recordings. Taking into account the observed rise in mean arterial pressure following aminoguanidine treatment, one could speculate that effects on urinary albumin excretion are masked by an increase in blood pressure, although we did not find any relation between blood pressure and albuminuria in our animals. Urinary albumin excretion is certainly influenced by arterial pressure as has been demonstrated by the marked effects of different antihypertensive regimens on urinary albumin excretion in both experimental and clinical diabetes $(31,32)$.

The observed disparity in effects of aminoguanidine on regional albumin clearance and urinary albumin excretion might also indicate that the mechanisms involved in the development of systemic permeability changes and albuminuria are, at least partially, distinct. The fact that increased vascular permeability, assessed by measuring transcapillary escape rate of albumin, only develops in diabetic patients with some degree of albuminuria (6) together with the tremendous increase in cardiovascular disease that is associated with the development of albuminuria (33), has led to the hypothesis that albuminuria is a marker of widespread vascular damage (7). A decreased content of HS-PG, as a result of AGE-formation on basement membrane components (1) or a genetically determined defect in HS-PG regulation (34), has been proposed as one of the mechanisms responsible for both vascular and glomerular damage. On the basis of our results, it is speculative to explain why and how aminoguanidine normalizes increased vascular permeability in diabetic rats without affecting albuminuria. It is our opinion though, that in the kidney hemodynamic changes, which are perhaps not modified by aminoguanidine, play a more important role than in other tissues. It is important in this respect to remember that glomerular capillary pressure is several times higher than capillary pressures in other tissues. In previous studies it has been shown that the albuminuria in experimental diabetes is specially sensitive to ACE-inhibitors $(13,31)$. This would agree with angiotensin II-dependent intrarenal hemodynamic mechanisms being a major factor in the control of urinary albumin excretion.

In conclusion, we have shown that aminoguanidine treatment normalizes increased vascular permeability in diabetic rats, while in this study no effects of aminoguanidine on albuminuria were observed. The effects of aminoguanidine on vessel wall permeability suggest that this drug can protect the vascular system in (experimental) diabetes. 


\section{REFERENCES}

1. Brownlee M: Glycation products and the pathogenesis of diabetic complications. Diabetes Care 1992; 15: 1835-1843

2. Tsilbary EC, Charonis AS, Reger LA, Wohlhueter RM, Furcht LT: The effect of nunenzymatic glycosylation on the binding of the main non-collagenous $\mathrm{NCl}$ domain to type IV collagen. J Biol Chem 1988; 263: 4302-4308

3. Charonis AS, Reger LA, Dege JE, et al: Laminin alterations after in vitro non-enzymatic glycosylation. Diabetes 1990; 39: 807-814

4. Shimomura H, Spiro RG: Studies on macromolecular components of human glumerular basement membrane and alterations in diabetes: decreased levels of heparan sulfate proteoglycan and laminin. Diabetes $1987 ; 36: 374-381$

5. Wu V-Y, Wilson B, Cohen MP: Disturbances in glomerular basement membrane glycosaminoglycans in experimental diabetes. Diabetes 1987; 36: 679-683

6. Feldt-Rasmussen B: Increased transcapillary escape rate of albumin in type 1 (insulindependent) diabetic patients with microalbuminuria. Diabetologia 1986; 29: 282-286

7. Deckert T, Feldt-Rasmussen B, Borch-Johnsen K, Kofoed-Enevoldsen A: Albuminuria reflects widespread vascular damage: The Steno hypothesis. Diabetologia 1989; 32: 219 226

8. Williamson JR, Chang $\mathrm{K}$, Tilton $\mathrm{RG}$, et al: Increased vascular permeability in spontaneously diabetic $\mathrm{BB} / \mathrm{W}$ rats and in rats with mild versus severe streptozotocininduced diabetes. Prevention by aldose reductase inhibitors and castration. Diabetes 1987; 36: 813-821

9. Tucker BJ, Blantz RC, Rasch R: Glomerular filtration and tubular reabsorption of albumin in early and established STZ-diabetic rats. Diabetologia 1992; 35: A11

10. Thomas G, Ramwell PW: Effects of guanodino compounds on the endotheliumderived relaxing factor inhibitor $N^{G}$-monomethyl-L-arginine. J Pharmacol Exp Ther 1991; 259: $490-494$

11. Edelstein D, Brownlee M: Aminoguanidine ameliorates albuminuria in diabetic hypertensive rats. Diabetologia 1992; 35: 96-97

12. Corbett JA, Tilton RG, Chang K, et al: Aminoguanidine, a novel inhibitor of nitric oxide formation, prevents diabetic vascular dysfunction. Diabetes 1992; 41: 552-556

13. Huijberts MSP, Wolffenbuttel BHR, Crijns FRL, et al. Angiotensin converting enzymeinhibition reduces urinary albumin excretion but not regional albumin clearance in experimental diabetes. Eur J Pharmacol 1993; 240: 207-212

14. Bucala R, Tracey KJ, Cerami A: Advanced glycosylation products quench nitric oxide and mediate defective endothelium-dependent vasodilatation in experimental diabetes. J Clin Invest 1991; 87: 432-438

15. Tilton RG, Chang KG, Pugliese G, et al: Prevention of hemodynamic and vascular albumin filtration changes in diabetic rats by aldose reductase inhibitors. Diabetes 1989; 38: 1258-1270

16. Makita Z, Vlassara H, Cerami A, Bucala R: Immunological detection of advanced glycosylation endproducts in vivo. I Biol Chem 1992; 267: 5133-51.38

17. Kusaka M, Kishi K, Sokabe H: Does so-called streptozotocin hypertension exist in rats? Hypertension 1987; 10: 517-521

18. Tomlinson KC, Gardiner SM, Bennett $\mathrm{T}$ : Blood pressure in streptozotocin-treated Brattleboro and Long Evans rats. Am J Physiol 1990; 258: R852.859

19. Laurell C-B: Electroimmunoassay. Scand J Lab Clin Invest 1972; 29 (suppl. 124): 21

20. Pugliese G, Tilton RG, Speedy A, et al: Modulation of hemodynamic and vascular filtration changes in diabetic rats by dietary myo-inositol. Diabetes 1990; 39: 312-322 
21. Williamson JR, Holmberg SW, Chang KG, Marvel J, Sutera S, Needleman P: Mechanisms underlying atriopeptin-induced increases in hematocrit and vascular permeation in rats. Circ Res 1989; 64: 890-899

22. De Vries PJF, Tyssen C, Struijker Boudier HAJ, Smits JFM: Atrial natriuretic factor increases albumin extravasation in conscious rats. Eur J Physiol 1990; 415: 507-509

23. Bent-Hansen L: Whole body capillary exchange of albumin. Acta Physiol Scand 1991; 143: 5-10

24. Bent-Hansen L: Initial plasma disappearance and tissue uptake of 131I-albumin in normal rabbits. Microvasc Res 1991; 41: 345-356

25. Tucker BJ: Early onset of increased transcapillary escape rate in awake diabetic rats. Diabetes 1990; 39: 919-923

26. Tilton RG, Chang K, Hasan KS, et al: Prevention of vascular dysfunction by guanidines. Inhibition of nitric oxide synthase versus advanced glycation end-product formation. Diabetes 1993; 42: 221-232

27. Hill MA, Larkins RG: Alterations in the distribution of cardiac output in experimental diabetes in rats. Am I Physiol 1989; 257: H571-580

28. Huijberts MSP, Wolffenbuttel BHR, Struijker Boudier HAJ, et al: Aminoguanidine treatment increases elasticity and decreases fluid filtration of large arteries from diabetic rats. / Clin Invest 1993; 92: 1407-1411

29. Kihara M, Schmelzer JD, Poduslo JF, Curran GL, Nickander KK, Low PA: Aminoguanidine effects on nerve blood flow, vascular permeability, electrophysiology, and oxygen free radicals. Proc Natl Acad Sci USA 1991; 88: 6107-6111

30. Soulis-Liparota T, Cooper M, Papazoglou D, Clarke B, Jerums J: Retardation by aminoguanidine of development of albuminuria, mesangial expansion, and tissue fluorescence in streptozotocin-induced diabetic rat. Diabetes 1991; 40: 1328-1334

31. Anderson S, Rennke HG, Garcia DL, Brenner BM: Short and long term effects of antihypertensive therapy in the diabetic rat. Kidney Int 1989; 36: 526-536

32. Parving $\mathrm{H}-\mathrm{H}$, Andersen AR, Schmidt UM, Hommel E, Mathiesen ER, Svendsen PA: Effect of anti-hypertensive treatment on kidney function in diabetic nephropathy. $\mathrm{Br}$ Med J 1987; 294: 1443-1445

33. Borch-Johnsen K, Kreiner S: Proteinuria - A predictor of cardiovascular mortality in insulin-dependent diabetes mellitus. Br Med J 1987; 294:1651-1654

34. Deckert TD, Kofoed-Enevoldsen A, Norgaard K, Borch-Johnsen K, Feldt-Rasmussen $B$, Jensen T: Microalbuminuria. Implications for micro- and macrovascular disease. Diabetes Care 1992; 15: 1181-1191 
LARGE ARTERY PROPERTIES IN EXPERIMENTAL DIABETES 



\section{CHAPTER 6}

Effects of diabetes on large artery properties in the rat

M.S.P. Huijberts, B.H.R. Wolffenbuttel, A. C. Nieuwenhuijzen Kruseman, P. Poitevin, B.I. Lévy, H.A.J. Struijker Boudier

(submitted) 



\section{SUMMARY}

Diabetes is known to have major effects on the cardiovascular system. It is not well known though how diabetes influences functional arterial wall properties. We investigated the effects of experimental diabetes on arterial mechanical properties in diabetic $(n=11)$ and non-diabetic $(n=10)$ male Wistar Rp rats, using two independent methods: determination of characteristic impedance of the ascending aorta, as well as carotid artery compliance. The first variable was determined from phasic recordings of pressure and flow in the ascending aorta. Simultaneously, parameters of general cardiovascular function, i.e. blood pressure, heart rate, cardiac output, and total peripheral resistance were measured. Carotid compliance was determined in situ under control conditions and after poisoning of the smooth muscle mass with potassium cyanide. Diabetes was found to have marked effects on cardiovascular homeostasis. Mean arterial blood pressure was significantly reduced in diabetic rats, caused by a strong reduction in peripheral resistance with a simultaneous increase in cardiac output. Carotid compliance was significantly lower in diabetic rats compared with control rats at all pressure levels, both under control conditions and after treatment with $\mathrm{KCN}$ ( $p<0.01$ for control-, and $p<0.05$ for KCN-curves). Characteristic impedance of the ascending aorta was higher in the diabetic group $(p<0.05)$. From these observations we conclude that arterial wall compliance is decreased in diabetic rats. The observed compliance changes might have important effects on cardiovascular function in diabetes.

\section{INTRODUCTION}

Diabetes is known to cause severe vascular complications, such as enhanced arteriosclerosis. Evolution of arteriosclerosis in itself is not thought to be distinct in diabetes, but the risk of developing arteriosclerosis is greatly increased. Little is known about the changes in macrovessels in diabetes that precede the ultimate state of advanced arteriosclerosis. Altered arterial wall properties might influence important determinants of circulatory function, such as peripheral resistance, neural control mechanisms, and cardiac work (1). In contrast to disease states such as hypertension, arterial wall properties have not been extensively studied in diabetes. The studies that have been performed on vessel wall alterations in diabetes mainly concerned changes in vascular reactivity and structural changes in the arterial wall. Long-lived matrix proteins such as collagen and elastin have been reported to be relatively decreased in the aorta of diabetic rats (2). In experimental diabetes in general, collagen production is specifically decreased when compared to non-collagen protein production (3), although collagen content of the heart seems to be increased (4). Together with a quantitative alteration in collagen, there are probably qualita- 
tive collagen changes as well. In the last years attention has been focused on the role of advanced glycosylation end-products (AGE) in the etiology of diabetic complications $(5,6)$. Collagen is known to be affected by AGE-formation. Under hyperglycemic conditions heat-stable intermolecular bonds are formed, the so called cross-links, which alter drastically the structure of this matrix protein. Collagen from the aorta of diabetic rats was markedly more cross-linked than collagen from control animals (7).

It is not known how these structural alterations affect functional characteristics of the vessel wall such as local and systemic arterial compliance. In patients with non insulin-dependent diabetes (NIDDM), aortoiliac compliance, measured using a Doppler ultrasound technique, was significantly decreased and strongly correlated with blood glucose levels $(8,9)$. Whether this was due to preclinical arteriosclerotic lesions in the vessel wall or other factors was unclear. Very recently a paper has been published in which in vivo systemic arterial compliance calculated from a Windkessel-model of the arterial system was not found to be altered in streptozotocin-induced diabetes in rats (10). We designed the present study to evaluate the effects of experimental diabetes on functional arterial wall properties. Characteristic impedance of the aorta was measured together with local compliance of the carotid artery. Standard hemodynamic parameters were measured as well. To identify structural vessel wall changes, aortic collagen content was determined.

\section{MATERIALS AND METHODS}

\section{Animals}

Male Wistar Rp rats provided by TNO-REPGO, Rijswijk, The Netherlands, were used. Diabetes was induced in 11 animals at the age of 6-7 weeks by intraperitoneal injection with $70 \mathrm{mg} / \mathrm{kg}$ streptozotocin in citrate buffer $(\mathrm{pH}=$ $4.5)$, whereas rats in the control group $(n=10)$ received citrate buffer alone. Development of diabetes was assessed by blood glucose measurements using a hexokinase-method.

\section{Hemodynamic Study}

Rats were used three months after the induction of diabetes. The surgical procedure and hemodynamic measurements have been described in detail elsewhere (11). In summary, anesthesia was induced with $50 \mathrm{mg} / \mathrm{kg}$ pentobarbital i.p.. Rats were placed on a thermoregulated heating pad (Harvard, South Natick, Mass.), intubated, and ventilated with a rodent respirator (model 680, Harvard). A Teflon catheter $(0.9 \mathrm{~mm}$ i.d.) filled with saline, and coupled to a Statham P23ID pressure transducer (Gould Statham, Oxnard, Ca. USA), was inserted into the right carotid artery and placed into the ascending aorta. The catheter manometer system was checked for time and frequency, and showed 
a flat response beyond $60 \mathrm{~Hz}$. After performing a midsternal thoracotomy the ascending aorta was dissected free, and an adapted Doppler probe was positioned around the vessel to measure mean (cardiac output minus coronary blood flow) and phasic aortic blood flow. Following stabilization for $10 \mathrm{~min}-$ utes, aortic blood flow and pressure were recorded and processed by a microcomputer system (Vectra, Hewlett Packard, Palo Alto, Ca.) with analog digital converter (Metrabyte, Data Translation, Marlboro, Ma.). All parameters were calculated on a beat to beat basis for 30 seconds and then averaged. In this way systolic, diastolic and mean arterial pressure, mean cardiac output, and heart rate were determined.

The aortic input impedance spectrum was computed using Fourier analysis of the phasic aortic pressure and flow waves. Characteristic impedance was taken as the average value of the modulus of impedance for high frequencies (4th to 10th harmonic). The impedance modulus at 0 frequency represents total peripheral resistance.

\section{Determination of Carotid Artery Compliance}

After completion of the hemodynamic study, which never lasted more than 30 minutes, static mechanical properties of the carotid artery were measured. The distal end of the left carotid artery was dissected and cannulated with the tip of a non-distensible nylon catheter (length $10 \mathrm{~cm}$, internal diameter $0.6 \mathrm{~mm}$ ), filled with a Tyrode's solution containing $4 \%$ albumin and $0.03 \%$ Evans blue. Albumin was added to the solution to preserve the endothelium (12) and to maintain a physiologic osmotic gradient across the arterial wall. The tube was connected via a three way connector 1) to a pressure transducer (P50, Gould, Cleveland, Ohio), and 2) to a syringe mounted on a computer controlled automatic pump (760, Harvard).

The root of the carotid artery was then dissected and a removable clamp was positioned at the junction of the carotid artery and the aortic arch. This preparation allowed us to isolate, in situ, 18-25 $\mathrm{mm}$ of nonexposed carotid (Fig. 1). The pressure in the artery was controlled by negative feedback. The arterial pressure was measured using the pressure transducer, and digitized using the analog-to-digital converter board and the microcomputer system.

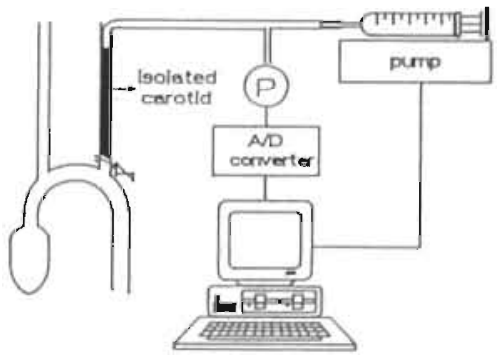

Figure 1: Schematic representation of the experimental system, permitting us to measure the volume-pressure relation in the in situ isolated carotid artery. 
A BASIC program was developed to compare the measured pressure ( $P_{\text {meas }}$ frequently ( 3 times per second) to a user specified reference pressure $\left(\mathrm{P}_{\text {ref }}\right)$, and to command the computer controlled pump to adjust the flow rate of fluid into the artery until $\mathrm{P}_{\mathrm{ref}}$ and $\mathrm{P}_{\text {meas }}$ were equal. Thus, the flow rate was set in proportion to the difference between the reference and measured values.

$$
\text { Flow rate }=\text { constant }\left(P_{\text {ref }}-P_{\text {meas }}\right)
$$

The constant, equaling the gain of the feedback loop, determined the dynamic response of the system. It was chosen large enough to assure that the response time of the feedback loop (less than 1 second) was much faster than the intrinsic response time of the artery and small enough to prevent overshoot of the arterial pressure above the reference pressure (the pump could not apply suction). Values between 0.5 and $1 \mu \mathrm{l} / \mathrm{min} / \mathrm{mmHg}$ were found to be appropriate. The reference pressure was changed at fixed intervals (every 5 minutes), and the volume of fluid pumped (net displacement of the syringe) was stored periodically as a function of time in the computer. To start the measurements, the segment of isolated artery was submitted to atmospheric pressure for 5 minutes and then to a pressure step of $25 \mathrm{mmHg}$. During the first 30 to 45 seconds the inflow was rapid, and then became constant with time.

The initial rapid increase in volume with pressure was assumed to result from the viscoelastic behavior of the tissue and the relaxation of the vascular smooth muscle. The later constant flow into the carotid artery after the initial increase in arterial volume was attributed to the fluid filtration across the vascular wall. An estimate of the static increase in volume, free of fluid filtration, was obtained by extrapolating the linear portion of the volume curve to the time when the pressure step was applied (Fig. 2). The slope of the late linear portion of the injected volume versus time relationship represents the filtration rate of fluid across the wall of the carotid artery.

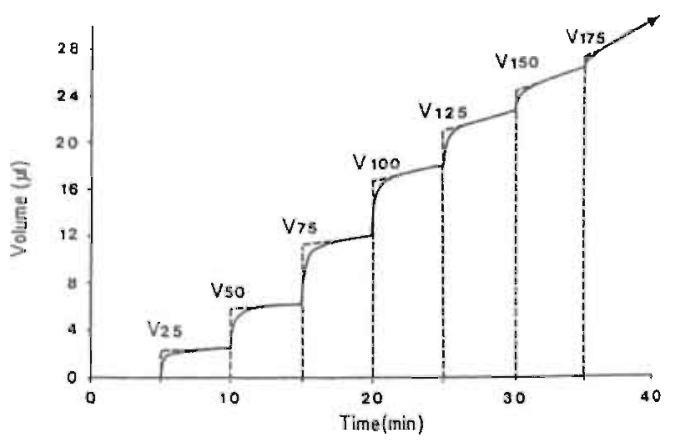

Figure 2: Pressure-volume relation in the carotid artery, including the effect of water filtration throughout the arterial wall. V25, V50, etc. are the successive volumes, free of viscoelastic and filtration effects, induced by the pressure steps. 
These measurements were repeated for pressures ranging from $25-200 \mathrm{mmHg}$ in steps of $25 \mathrm{mmHg}$. The static compliance of the isolated segment of carotid artery (carotid compliance: $\mathrm{CC} \mu \mathrm{l} / \mathrm{mmHg}$ ) was automatically calculated for each level of pressure, as the quotient of the extrapolated volume increase and the pressure step imposed $(25 \mathrm{mmHg})$. In preliminary experiments we have verified that the carotid compliance values were not different when measured for pressure increment (from 25 to $200 \mathrm{mmHg}$ ) or for pressure decrement (from 200 to $25 \mathrm{mmHg}$ ).

After termination of the measurements under control conditions, the carotid clamp was removed, and the artery was rinsed with the Tyrode's solution. Subsequently, the clamp was replaced and the artery filled with a saline solution containing $100 \mathrm{mg} / \mathrm{l}$ potassium cyanide (KCN). The KCN solution was maintained in the vessel for 30 minutes, in order to poison the smooth muscle mass completely. Afterwards the vessel was rinsed and refilled with the modified Tyrode's solution, and compliance measurements were performed again to determine carotid compliance in the fully relaxed state, depending only on passive elastic properties. Preliminary experiments, in which carotid compliance measurements were performed with a one hour interval, showed that the duration of total protocol did not affect static compliance values. After termination of the experiment when rats were still anesthetized, they were exsanguinated, and the heart and thoracic aorta were excised.

\section{Determination of aortic collagen content}

Assessment of collagen content was performed using a standard hydroxyproline determination as has been described previously $(13,14)$. In brief, collagen was extracted from the aortic samples by hydrolyzing the tissues in vacuum at a temperature of $110^{\circ} \mathrm{C}$. Consecutively, hydroxyproline concentration of the hydrolysate was determined spectrophotometrically. Collagen content of the specimens can be derived from hydroxyproline content, as hydroxyproline constitutes $12.77 \%$ of total collagen amount.

\section{Statistical Analysis}

All results are expressed as mean $\pm \mathrm{SD}$. Differences between groups were analyzed with an unpaired Students $t$ test. Carotid compliance curves were compared using repeated measurements Analysis Of Variance (ANOVA). Statistical significance was assumed at the $p<0.05$ level.

\section{RESULTS}

General Characteristics of the Study Groups

Blood glucose levels were strongly elevated in the diabetic group, while body weight was significantly decreased, (both $p<0.0001$, Table 1). Body surface area 
was calculated from body weight using previously published methods (15), which account for the relatively starved state of the diabetic rats, and was significantly lower in the diabetic animals compared to control animals, $p<0.0001$.

Table 1. General characteristics of the study groups

\begin{tabular}{lll}
\hline & $\begin{array}{l}\text { Control rats } \\
(\mathrm{n}=10)\end{array}$ & $\begin{array}{l}\text { Diabetic rats } \\
(\mathrm{n}=11)\end{array}$ \\
Blood glucose levels $(\mathrm{mM})$ & $7.0 \pm 2.0$ & $23.8 \pm 3.1^{*}$ \\
Body weight $(\mathrm{g})$ & $345 \pm 17$ & $194 \pm 17^{*}$ \\
Body surface area $\left(\mathrm{cm}^{2}\right)$ & $374 \pm 13$ & $260 \pm 15^{*}$ \\
\hline
\end{tabular}

All data are expressed as mean $\pm \mathrm{SD} .{ }^{*} p<0.0001$
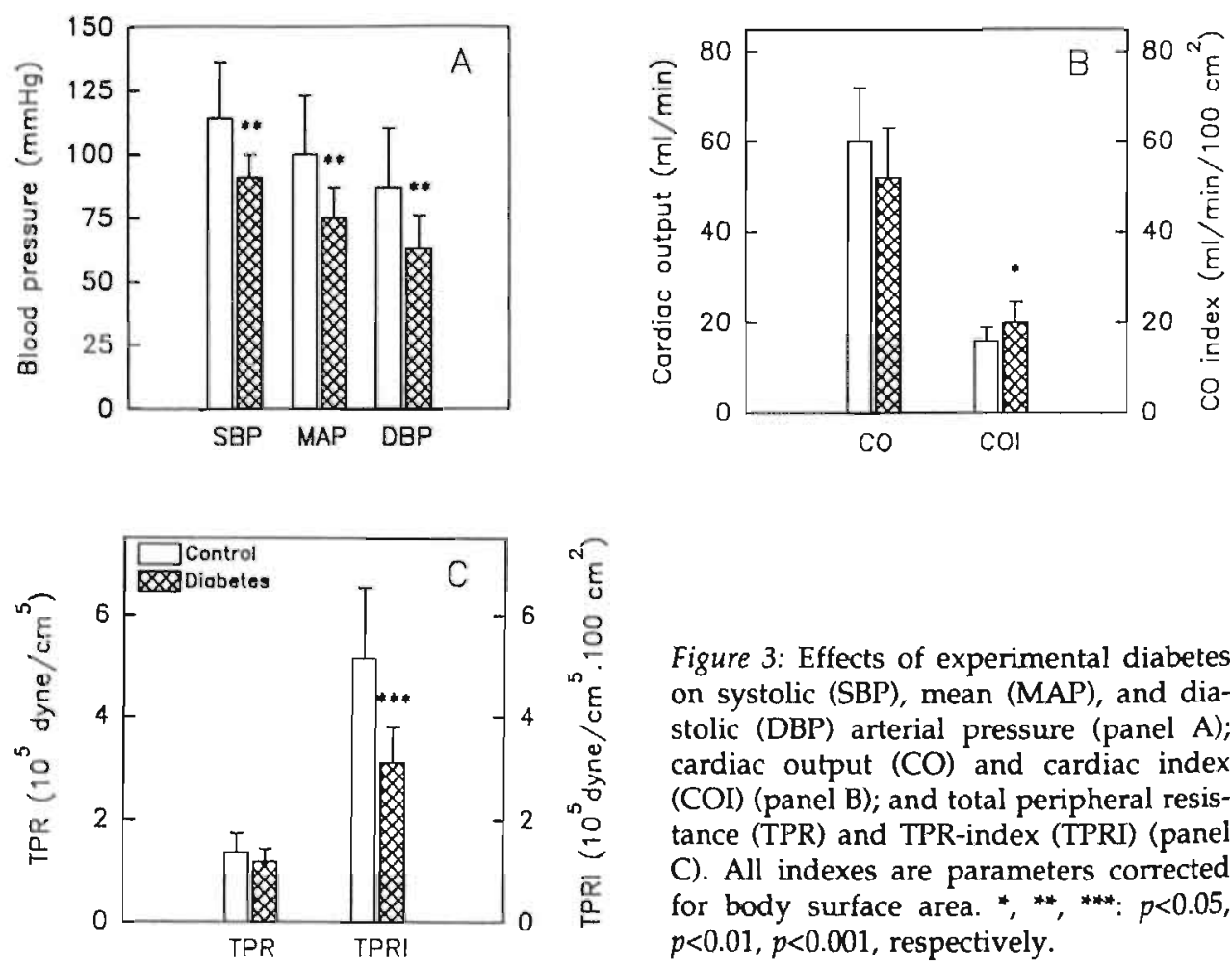

Figure 3: Effects of experimental diabetes on systolic (SBP), mean (MAP), and diastolic (DBP) arterial pressure (panel A); cardiac output $(\mathrm{CO})$ and cardiac index (COI) (panel B); and total peripheral resistance (TPR) and TPR-index (TPRI) (panel C). All indexes are parameters corrected for body surface area. *, ****: $p<0.05$, $p<0.01, p<0.001$, respectively. 


\section{Hemodynamic Study}

The hemodynamic status of the open-chest diabetic rats was found to be markedly altered when compared to the control group. Systolic, diastolic and mean arterial pressure were all lower in diabetic rats $(91 \pm 9 \mathrm{mmHg}$ vs. $114 \pm$ $22 \mathrm{mmHg}, 63 \pm 13 \mathrm{mmHg}$ vs. $87 \pm 23 \mathrm{mmHg}$, and $75 \pm 12 \mathrm{mmHg}$ vs. $100 \pm 23$ $\mathrm{mmHg}$, all $p<0.01$, Fig. $3 \mathrm{a}$ ), as was the heart rate ( $312 \pm 36$ beats $/ \mathrm{min}$, vs. $342 \pm 24$ beats $/ \mathrm{min}, p<0.05$ ). Cardiac output and total peripheral resistance (Fig. $3 \mathrm{~b}$ and $3 c$ ), tended to be somewhat lower in the diabetic group, but this difference was not statistically significant $(52 \pm 11 \mathrm{ml} / \mathrm{min}$ vs. $60 \pm 12 \mathrm{ml} / \mathrm{min}, p=0.12$, and $1.19^{*} 10^{5}$ dyne.sec $/ \mathrm{cm}^{5}$ vs. $1.37^{*} 10^{5}$ dyne.sec $/ \mathrm{cm}^{5}, p=0.19$ ). When corrected for body surface area, cardiac output was slightly elevated in the diabetic group $\left(20 \pm 5 \mathrm{ml} / \mathrm{min} / 100 \mathrm{~cm}^{2}\right.$ vs. $\left.16 \pm 3 \mathrm{ml} / \mathrm{min} / 100 \mathrm{~cm}^{2}, p<0.05\right)$, together with a decrease in total peripheral resistance $\left(3.10 \pm 0.70^{*} 10^{5}\right.$ dyne.sec $/ \mathrm{cm}^{5} .100 \mathrm{~cm}^{2}$ vs. $5.14 \pm 1.39 * 10^{5}$ dyne.sec $\left./ \mathrm{cm}^{5} .100 \mathrm{~cm}^{2}, p<0.001\right)$. Characteristic impedance was increased in diabetic rats $\left(19.7 \pm 10.0^{*} 10^{3}\right.$ dyne.sec $/ \mathrm{cm}^{5}$ vs. $10.5 \pm 4.8^{*} 10^{3}$ dyne.sec $/ \mathrm{cm}^{5}$ in diabetic rats, Fig. $4, p<0.05$ ).

Figure 4: Characteristic impedance of the aorta ( $\mathrm{ZC})$, in control and diabetic rats. $*: p<0.05$.

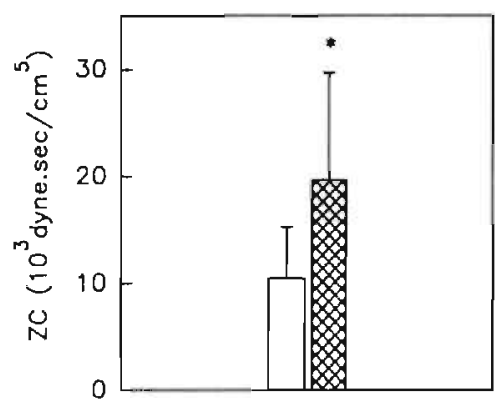

\section{Carotid Artery Compliance}

Static compliance in the carotid artery was at all pressure levels lower in diabetic animals, as can be seen in figure $5 \mathrm{a},(p<0.01)$. This figure clearly illustrates the pressure dependent nature of vessel wall compliance. In the fully relaxed state, obtained by treatment of the artery with potassium cyanide, carotid artery compliance in diabetic rats was again lower at all pressure levels $(p<0.05$, Fig. $5 b)$. To exclude that compliance changes were caused by a smaller carotid artery diameter in the diabetic group, diameter measurements were performed at the $100 \mathrm{mmHg}$ pressure level. In fact, diameters were slightly larger in diabetic rats $(1.12 \pm 0.06 \mathrm{~mm}$, vs. $1.02 \pm 0.06 \mathrm{~mm}$ in controls, $p<0.05)$. Thus, carotid artery distensibility (compliance/volume) was much smaller in diabetic rats $\left(1.10^{-2} \pm 0.3 .10^{-2}\right.$ vs. $1.6 .10^{-2} \pm 0.2 .10^{-2}, p<0.0005$, Fig. 6) 


\section{Aortic Collagen Content}

Collagen percentage of aortic wet weight was lower in diabetic rats (10.4 \pm $1.8 \%$ vs. $12.5 \pm 1.3 \%, p<0.01)$. The ratio dry to wet weight was not different between the two groups.
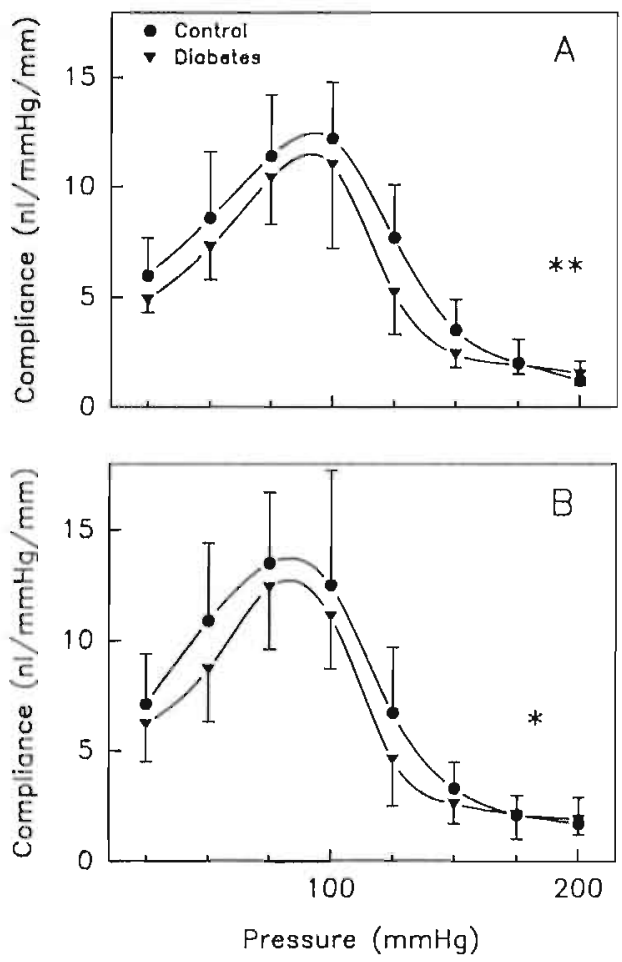

$\mathrm{KCN}$

Figure 5: Compliance of the isolated carotid artery vs. pressure, in control and diabetic rats under control conditions (panel A), and after incubation with potassium cyanide (panel B). ***: $p<0.05$, and $p<0.01$.

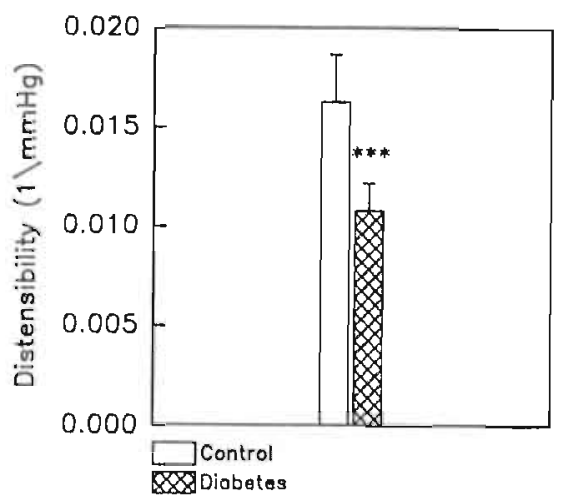

Figure 6: Distensibility values of the carotid arterial wall, calculated from compliance and carotid volume values at a transmural pressure of $100 \mathrm{mmHg}$. ***: $p<0.0005$. 


\section{DISCUSSION}

Induction of diabetes had many effects on cardiovascular homeostasis in our rats. After three months of diabetes, heart rate and systolic, diastolic and mean arterial pressure were decreased, together with an increase in cardiac index and a reduction of total peripheral resistance.

This decrease in arterial pressure in diabetic rats has been shown previously $(10,16,17)$. The effects in our animals are somewhat stronger than reported so far, which might be related to the comparatively long duration of diabetes in our study. The fall in arterial pressure is produced by a decrease in total peripheral resistance, as will be discussed later. Although it is known that myocardial contractility and ventricular diastolic relaxation are impaired in experimental diabetes $(18,19)$, an increase in cardiac index in diabetic rats is a common finding $(10,20)$. Some authors have suggested that the existence of an increased preload leads to cardiac output augmentation (20).

An important factor in the interpretation of the raised cardiac index, and other hemodynamic parameters as well, is the correction that must be made for the large differences in body weight. Diabetes inevitably leads to lower weight gain in the course of weeks. This is due in part to loss of fat mass, which does not play an important role in cardiac output distribution. In contrast, some organs such as the kidney (21) and the small intestine (22) have an increased weight in experimental diabetes. This suggest that a simple correction for body weight might not be correct. We corrected our data for body surface area instead of body weight, using a formula with different constant values for normal and starved rats. In terms of fat mass loss will resemble diabetic rats. However, after adjusting for body surface area cardiac output and total peripheral resistance were still significantly different in diabetic rats when compared to the control group.

The decrease in arterial pressure is caused by a strong decrease in total peripheral resistance, which is probably related to alterations in smooth muscle tone. Vascular dilation in diabetes has been demonstrated in a number of tissues including the kidney (23), retina (24), brain (25), and small intestine (26). Whether all vascular beds are affected in the same manner is not certain. Redistribution of cardiac output has been reported in experimental diabetes with a relative reduction of flow to the skin and skeletal muscle compartment (27). It is possible that the vasodilation in the kidney is a very important determinant of the reduced total peripheral resistance. In diabetic rats with renovascular hypertension, there was no decrease in blood pressure after induction of diabetes, whereas in spontaneously hypertensive rats diabetes induction resulted in a reduction in mean arterial pressure (28).

In diabetic rats carotid artery compliance was decreased compared to control rats for the whole pressure range, both under control conditions and in the 
fully relaxated state. Distensibility, representing the intrinsic mechanical wall property, was markedly reduced as well. Distensibility is calculated by dividing compliance for a given pressure by the arterial volume at that pressure. The decrease in carotid compliance and the increase in carotid volume result in a strongly reduced distensibility of the carotid arterial wall in diabetic rats, which indicates that the vessel wall of these rats is stiffer than that of control rats. The characteristic impedance of the ascending aorta, reflecting its mechanical properties, was increased, suggesting a decrease in elasticity of this vessel as well. Thus, there seem to be marked alterations in arterial wall properties after three months of experimental diabetes. However, it should be taken into account that the interpretation of our results is complicated by the differences in body weight and mean arterial pressure that exist between the two study groups.

In models of hypertension increases in arterial stiffness are partially attributed to an increased vascular wall collagen content. Collagen content of the aorta was found to be reduced in the diabetic animals, so this excludes that quantitative alterations in collagen are of importance in the etiology of these compliance changes. We did not measure elastin content in this study, which is an important determinant of vessel wall compliance as well, but it has been reported that elastin content is decreased together with the reduction in collagen (2). Since the quantitative collagen change that we observed would lead to an increase in compliance, there must be other (qualitative) matrixprotein alterations as well. AGE-formation, resulting in increased collagen cross-linking could form a good explanation for the observed decrease in vessel wall elasticity. As has been mentioned before, collagen cross-linking in aortas of diabetic rats was strongly increased when compared to control rats (7).

What might be the consequences of the decrease in arterial compliance that we have found? In the field of hypertension research vascular compliance is an extensively studied parameter. Many studies have been performed regarding the compliance changes in hypertension $(12,29,30)$, the effects of decreased compliance on cardiovascular function $(31,32)$, and the therapeutic modalities to influence this factor (33-36). A decrease in arterial compliance by itself does not affect mean arterial pressure as does an increase in peripheral resistance, but it modifies directly systolic (increase) and diastolic (decrease) pressure and thus amplifies the pulse pressure. Increased pulse pressure is an independent risk factor for cardiovascular complications (37). An increase in systolic blood pressure leads to a strong increase in end-systolic stress, which contributes to hypertrophy of the cardiac muscle. In fact, aortic compliance and characteristic impedance are strongly related to cardiac mass $(38,39)$. In this way arterial compliance changes can compromise the already disturbed cardiovascular function in diabetes. Further investigations are required to elucidate the exact cause of the observed changes in arterial wall properties and to extend these studies from experimental to clinical diabetes. 


\section{REFERENCES}

1. Cox RH, Bagshaw RJ: Effects of hypertension and its reversal on canine arterial wall properties. Hypertension 1988; 12: 301-309

2. Andreassen TT, Oxlund $\mathrm{H}$ : Changes in collagen and elastin of rat aorta induced by experimental diabetes and food restriction. Acta Endocrinol (Copenh) 1987; 115: 345-352

3. Spanheimer RG, Umpierrez GE, Stumpf V: Decreased collagen production in diabetic rats. Diabetes 1988; 37: 371-376

4. Reddi AS: Collagen metabolism in the myocardium of normal and diabetic rats. Exp Mol Pathol 1988; 48: 236-243

5. Kennedy L, Baynes JW: Non-enzymatic glycosylation and the chronic complications of diabetes: an overview. Diabetologia $1984 ; 26: 93-98$

6. Brownlee M, Cerami A, Vlassara H: Advanced glycosylation end products in tissue and the biochemical basis of diabetic complications. NEngl J Med 1988; 318: 1315-1321

7. Brownlee M, Vlassara H, Kooney A, Ulrich P, Cerami A: Aminoguanidine prevents diabetes induced arterial wall protein cross-linking. Science 1986; 232: 1629-1632

8. Lo CS, Relf IRN, Myers KA, Wahlqvist ML: Doppler ultrasound recognition of preclinical changes in arterial wall in diabetic subjects: compliance and pulse-wave damping. Diabetes Care 1986; 9: 27-31

9. Wahlquist ML, Lo CS, Myers KA, Simpson RW, Simpson JM: Putative determinants of arterial wall compliance in NIDDM. Diabetes Care 1988; 11: 787-790

10. Litwin SE, Raya TE, Daugherty S, Goldman G: Peripheral circulatory control of cardiac output in diabetic rats. Am J Physiol 1991; 261: H836-842

11. Benessiano J, Lévy BI, Michel JB: Instantaneous aortic blood flow measurements with range gated Doppler flowmeter in anesthetized rat. J Pharmucol Meth 1985; 14: 99 -110

12. Morrisson AD, Berwick L, Orci L, Winegrad AI: Morphology and metabolism of an aortic intima-media preparation in which an intact endothelium is preserved. J Clin Invest 1976; 57: 650-660

13. Fischer GM, Llaurado JG: Collagen and elastin content in canine arteries selected from functionally different vascular beds. Circ Res 1966; 19: 394-399

14. Neuman RE, Logan MA: The determination of collagen and elastin in tissue. J Biol Chem 1950; 186: 549-556

15. Petty MD: Miscellaneous. In: Research techniques in the rat. Springfield, Ill., Charles C Thomas, 1982, pp 271-306

16. Jackson CV, Carrier CO: Influence of short-term experimental diabetes on blood pressure and heart-rate in response to norepinephrine and angiotensin II in the conscious rat. I Cardiovasc Pharmacol 1983; 5: 260-265

17. Lash JM, Bohlen HG: Structural and functional origins of suppressed acetylcholine vasodilation in diabetic rat intestinal arterioles. Circ Res 1991; 69: 1259-1268

18. Fein FS, Kornstein LB, Strobeck JE, Capasso JM, Sonnenblick EH: Altered myocardial mechanics in diabetic rats. Circ Res 1980; 47: 922-933

19. Fein FS, Malhotra A, Miller-Green B, Scheuer J, Sonnenblick EH: Diabetic cardiomyopathy in rats: mechanical and biochemical response to different insulin doses. Am J Physiol 1984; 247: H817-823

20. Carbonell LF, Salom MG, Garcia-Estañ J, Salazar FJ, Ubeda M, Quesada T: Hemodynamic alterations in chronically conscious unrestrained diabetic rats. Am J Physiol 1987; 252: H900-905

21. Seyer-Hansen K: Renal hypertrophy in experimental diabetes mellitus. Kidney Int 1983; 23: $643-646$ 
22. Unthank JL, Bohlen HG: Intestinal microvascular growth during maturation in diabetic juvenile rats. Circ Res 1988; 63: 429-436

23. Kimura K, Tojo A, Nanba S, Matsuoka H, Sugimoto T: Morphometric analysis of arteriolar diameters in experimental nephropathies: application of microvascular casts. Virchows Arch 1990; 417: 319-323

24. Skouborg F, Nielsen AV, Lauritzen E: Diameters of the retinal vessels in diabetic and normal subjects. Diabetes 1969; 18: 292-298

25. McCuskey PA, McCuskey RS: In vivo and electron microscopic study of the development of the cerebral diabetic microangiopathy. Microcirc Endothel Lymphat 1984; 1: 221-244

26. Bohlen HG, Hankins KD: Early arteriolar and capillary changes in streptozotocin induced diabetic rats and intraperitoneal hyperglycemic rats. Diabetologia 1982; 22: 344-348

27. Hill MA, Larkins RG: Alterations in distribution of cardiac output in experimental diabetes in rats. Am J Physiol 1989; 257: H571-580

28. Mariani MJ, Sessa WC, Chichester CO, Rodgers RL: STZ-induced diabetes in SHR and renovascular hypertensive rats: dissociation between changes in arterial pressure and vascular collagen synthesis. Clin Exp Hypertension 1990; 12: 1003-1019

29. Safar ME, London GM: Arterial and venous compliance in sustained essential hypertension. Hypertension 1987; 10: 133-139

30. Safar ME, Lévy BI, Laurent SL, London GM: Hypertension and the arterial system: clinical and therapeutic aspects. I Hypertension 1990; 8 (suppl. 7): S113-119

31. O'Rourke MF: Systolic blood pressure: arterial compliance and early wave reflection and their modification by antihypertensive therapy. J Hum Hypertension 1989; 3: 47-52

32. Hickler RB: Aortic and large artery stiffness: current methodology and clinical correlations. Clin Cardiol 1990; 13: 317-322

33. Lévy BI, Benessiano J, Poitevin P, Safar ME: Endothelium-dependent mechanical properties of the carotid artery in WKY and SHR. Role of angiotensin converting enzyme inhibition. Circ Res 1990; 66: 321-328

34. Lévy BI, Poitevin P, Safar ME: Effects of indapamide on the mechanical properties of the arterial wall in deoxycorticosterone acetate-salt hypertensive rats. Am J Cardiol 1990; 65: 28H-32

35. Lévy BI, Poitevin P, Safar ME: Effects of $\alpha 1$-blockade on arterial compliance in normotensive and hypertensive rats. Hypertension 1991; 17: 534-540

36. Stefas L, Lévy BI: Effects of saralasin on arterial compliance in normotensive and hypertensive rats. Role of endothelium. Hypertension 1991; 18 (suppl. II): II30-36

37. Darne B, Girerd X, Safar ME, Cambien F, Guize L: Pulsatile versus steady component of blood pressure: a cross-sectional analysis and a prospective analysis on cardiovascular mortality. Hypertension 1989; 13: 392-400

38. Isnard RN, Pannier BM, Laurent S, London GM, Diebold B, Safar ME: Pulsatile diameter and elastic modulus of the aortic arch in essential hypertension: a non-invasive study. I Am Coll Cardiol 1989; 13: 399-405

39. Lévy BI, Babalis D, Lacolley P, Poitevin P, Safar ME: Cardiac hypertrophy and characteristic impedance in spontaneously hypertensive rats. J Hypertension 1988; 6 (suppl. 4): $\$ 110-111$ 


\section{CHAPTER 7}

Aminoguanidine treatment increases elasticity and decreases fluid filtration of large arteries from diabetic rats

M.S.P. Huijberts, B.H.R. Wolffenbuttel, H.A.J. Struijker Boudier, F.R.L. Crijns, A.C. Nieuwenhuijzen Kruseman, P. Poitevin, B.I. Lévy

Journal of Clinical Investigation 1993; 92: 1407-1411 



\section{SUMMARY}

The accumulation of advanced glycosylation endproducts (AGEs) on collagen and the subsequent stiffening of this matrix protein in diabetes has been described many years ago. Structural modification of collagen in the arterial wall might have important effects on arterial elasticity. Aminoguanidine is known to decrease the formation of AGEs. In this study we evaluated the effects of aminoguanidine treatment on different parameters reflecting arterial wall elasticity in diabetic rats. We demonstrated that treatment of diabetic rats with aminoguanidine resulted in a significant increase in carotid static compliance $(+39 \%, p<0.01$ under control conditions, and $+27 \%, p<0.01$ after abolition of vascular tone by $\mathrm{KCN}$ ), and a decrease in characteristic aortic input impedance $(-40 \%, p<0.01)$. The arterial pulse pressure in aminoguanidine treated rats was decreased $(-15 \%, p<0.05)$ and the pulsatile component of left ventricular power output was relatively diminished $(-35 \%, p<0.05)$. In addition, we observed a lower fluid filtration across the carotid wall. These results indicate an increased vascular elasticity, an improved left ventricular-arterial coupling, and a decreased vascular permeability in diabetic rats following aminoguanidine treatment, suggesting that AGE-accumulation on collagen negatively affects arterial wall properties in experimental diabetes.

\section{INTRODUCTION}

There is growing evidence that the formation of so-called advanced glycosylation endproducts (AGEs), is involved in the development of diabetic angiopathy, which remains one of the most severe complications of diabetes mellitus. AGEs are the final product of a series of complex rearrangements resulting from the reaction of circulating sugars with proteins. The formation of these products is irreversible, leading to accumulation of AGEs, especially on vascular wall proteins with a slow turnover rate. One of the firstly recognized features of AGE-formation is the accumulation of AGEs on collagen (1-3), forming intermolecular bonds leading to an increased stiffness of collagen fibers. The effects of AGE-accumulation on collagen fibers for the mechanical properties of the arterial wall are not completely known. Because large compliance arteries are not only conduit vessels but also play a major role in the transmission and damping of the pulse wave along the systemic arterial tree, the mechanical properties of the arterial wall are major determinants of the left ventricular-arterial coupling. Therefore, alterations of mechanical properties of the arterial wall might have important consequences on cardiovascular performance in diabetes. Aminoguanidine has been shown to block AGE-formation in vivo and in vitro $(4,5)$, primarily through reaction with Amadori-derived fragmentation products in solution (6). 
The aim of the present study was to evaluate the effects of long-term treatment with aminoguanidine on the mechanical properties of large compliance arteries in experimental diabetes. We demonstrated that large arterial elasticity was significantly increased by aminoguanidine treatment leading to a decreased pulse pressure and a decreased left ventricular weight to body weight index. In addition, fluid filtration across the carotid arterial wall was significantly reduced. Therefore, our results suggest that aminoguanidine improved mechanical arterial wall properties and cardiac load in diabetic rats: the increase of vascular elasticity and the reduced permeability of the vascular wall following aminoguanidine treatment might protect the vascular system in (experimental) diabetes.

\section{METHODS}

\section{Animals}

Male Wistar Rp rats were provided by TNO-REPGO, Rijswijk, The Netherlands. Diabetes was induced in all rats at the age of 10 weeks by intraperitoneal injection with $70 \mathrm{mg} / \mathrm{kg}$ streptozotocin in citrate buffer ( $\mathrm{pH} 4.5)$. After confirmation of the development of hyperglycemia ( 2 days later) by blood glucose determination using a hexokinase method, rats were randomized into a vehicle treated diabetic group ( $n=9)$, and a treatment group $(n=10)$ receiving daily injections with $50 \mathrm{mg} / \mathrm{kg}$ aminoguanidine hemisulphate (Sigma, St. Louis, MO, USA) in phosphate-buffered saline.

Determination of blood pressure, characteristic aortic input impedance and left ventricular power output.

Rats were studied 10-12 weeks after induction of diabetes. The surgical procedure and hemodynamic measurements have been described in detail elsewhere (7). In summary, anesthesia was induced with $50 \mathrm{mg} / \mathrm{kg}$ pentobarbital i.p. Rats were placed on a thermoregulated heating pad, intubated, and ventilated with a rodent respirator. A Teflon catheter $(0.9 \mathrm{~mm}$ i.d.) filled with saline, and coupled to a Statham P23ID pressure transducer (Gould Statham, Oxnard, Ca., USA) was inserted through the right carotid artery and placed into the ascending aorta. The catheter manometer system was checked for time and frequency, and showed a flat response beyond $60 \mathrm{~Hz}$. After performing a midsternal thoracotomy the ascending aorta was dissected free, and an adapted Doppler probe was positioned around the vessel to measure mean (cardiac output minus coronary blood flow) and phasic aortic blood flow. Following stabilization for 10 minutes, aortic blood flow and pressure were recorded and processed by a microcomputer system (Vectra 2821, Hewlett Packard, Palo Alto, Ca., USA) with analog digital converter (Metrabyte, Data Translation, 
Marlboro, Ma., USA). All parameters were calculated on a beat to beat basis for 30 seconds and then averaged.

The aortic input impedance spectrum was computed using Fourier analysis of the phasic aortic pressure and flow waves. Characteristic aortic input impedance was taken as the average value of the modulus of impedance for high frequencies (4th to 10th harmonic). Total external ventricular work per unit time can be divided into two components. The first component, "steady flow power" $\left(W_{s}\right)$ is determined mainly by the vascular resistance, and can be calculated as the product of mean pressure and mean flow. The second component, "oscillatory power" $\left(W_{\circ}\right)$, is determined primarily by the dimensions and elasticity of the aorta and its side branches and can be computed by multiplying the Fourier series expressions for pressure and flow. Total external left ventricular power output $\left(W_{t}\right)$ is the sum of $W_{s}$ and $W_{0}$. The ratio $W_{0} / W_{t}$ reflects the relative energy involved in pulsatile wave forms determined by characteristic aortic input impedance (8).

\section{Determination of Carotid Artery Compliance}

After completion of the hemodynamic study, which never lasted more than 30 minutes, static mechanical properties of the carotid artery were measured. The distal end of the left carotid artery was dissected and cannulated with the tip of a non-distensible nylon catheter (length $10 \mathrm{~cm}$, internal diameter $0.6 \mathrm{~mm}$ ), filled with a Tyrode's solution containing $4 \%$ albumin and $0.03 \%$ Evans blue. Albumin was added to the solution to preserve the endothelium (9) and to maintain a physiologic osmotic gradient across the arterial wall. The tube was connected via a three way connector 1 ) to a pressure transducer (P50, Gould, Cleveland, Ohio, USA), and 2) to a syringe mounted on a computer controlled automatic pump (760, Harvard). The root of the carotid artery was then dissected and a removable clamp was positioned at the junction of the carotid artery and the aortic arch. This preparation allowed us to isolate, in situ, 18-25 $\mathrm{mm}$ of nonexposed carotid (Fig. 1a). The pressure in the artery was controlled by negative feedback. The arterial pressure was measured using the pressure transducer, and digitized using the analog-to-digital converter board and the microcomputer system. A BASIC program was developed to compare the measured pressure $\left(P_{\text {meas }}\right)$ frequently ( 3 times per second) to a user specified reference pressure $\left(\mathrm{P}_{\text {ref }}\right)$, and to command the computer-controlled pump to adjust the flow rate of fluid into the artery until $\mathrm{P}_{\text {ref }}$ and $\mathrm{P}_{\text {meas }}$ were equal. Thus, the flow rate was set in proportion to the difference between the reference and measured values.

Flow rate $=$ constant $\left(P_{\text {ref }}-P_{\text {meas }}\right)$ 
The constant, equaling the gain of the feedback loop, determined the dynamic response of the system. It was chosen large enough to assure that the response time of the feedback loop (less than 1 second) was much faster than the intrinsic response time of the artery and small enough to prevent overshoot of the arterial pressure above the reference pressure (the pump could not apply suction). The reference pressure was changed at fixed intervals (every 5 minutes), and the volume of fluid pumped (net displacement of the syringe) was stored periodically (every 3 seconds) as a function of time in the computer. To start the measurements, the segment of isolated artery was submitted to atmospheric pressure for 5 minutes and then to a pressure step of $25 \mathrm{mmHg}$. During the first 30 to 45 seconds the inflow was rapid, and then became constant with time.

The initial rapid increase in volume with pressure was assumed to result from the viscoelastic behavior of the tissue and the relaxation of the vascular smooth muscle. The later constant flow into the carotid artery after the initial increase in arterial volume was attributed to the fluid filtration across the vascular wall. An estimate of the static increase in volume, free of fluid filtration, was obtained by extrapolating the linear portion of the volume curve to the time when the pressure step was applied (Fig. 1b). The slope of the late linear portion of the injected volume versus time relationship represents the filtration rate of fluid across the wall of the carotid artery. These measurements were repeated for pressures ranging from $25-200 \mathrm{mmHg}$ in steps of $25 \mathrm{mmHg}$. The static compliance of the isolated segment of carotid artery was automatically calculated for each level of pressure, as the quotient of the extrapolated volume increase and the pressure step imposed $(25 \mathrm{mmHg})$. In preliminary experiments we have verified that the carotid compliance values were not different when measured for pressure increment (from 25 to $200 \mathrm{mmHg}$ ) or for pressure decrement (from 200 to $25 \mathrm{mmHg}$ ).

After termination of the measurements under control conditions, the carotid clamp was removed, and the artery was rinsed with the Tyrode's solution. Subsequently, the clamp was replaced and the artery filled with a saline solution containing $100 \mathrm{mg} / \mathrm{l}$ potassium cyanide $(\mathrm{KCN})$. The $\mathrm{KCN}$ solution was maintained in the vessel for 30 minutes, in order to poison the smooth muscle mass completely. Afterwards the vessel was rinsed and refilled with the modified Tyrode's solution, and compliance measurements were performed again to determine carotid compliance in the fully relaxed state, depending only on passive elastic properties. Preliminary experiments, in which carotid compliance measurements were performed with a one hour interval, showed that the duration of total protocol did not affect static compliance values. 

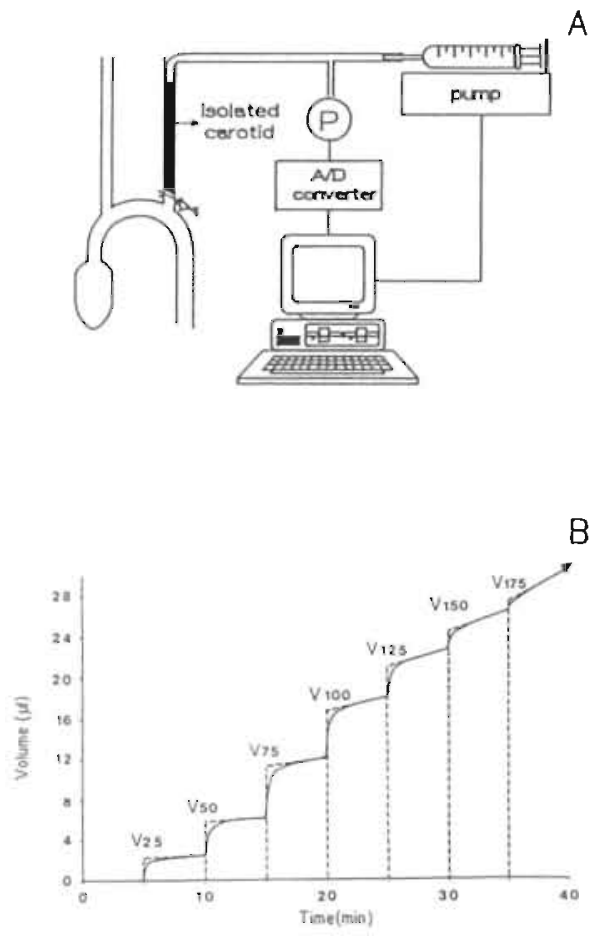

Figure 1:

(A) Schematic representation of the experimental set-up permitting us to measure the volume-pressure relation in the in situ isolated carotid artery.

(B) Pressure-volume relation in the carotid artery. This figure illustrates the pressurevolume relation in the carotid artery, including the effect of fluid filtration across the arterial wall. V25, V50 are the successive volumes, free of viscoelastic and filtration effects, induced by the pressure steps.

Fluid filtration rate

The slope of the late linear portion of the injected volume vs. time relationship represents the filtration rate of fluid through the wall of the carotid artery. This filtration rate was calculated for each pressure step imposed, and expressed as $\mathrm{nl} / \mathrm{sec} / \mathrm{mm}$ artery.

Ratio left ventricular weight/body weight

After termination of the experiment when rats were still anesthetized, the heart was excised, and after removal of both atria and the right ventricle left ventricular weight was determined and corrected for the body weight of the animal.

\section{Statistical Analysis}

All results are expressed as mean $\pm S D$. Differences between groups were analyzed using Analysis Of Variance (ANOVA). Carotid compliance curves were compared using one-way ANOVA for each pressure level. Fluid filtration curves were compared using logistic regression. Statistical significance was assumed at the $p<0.05$ level. 


\section{RESULTS}

\section{General characteristics}

Body weights were comparable in both groups and relatively low ( $188 \pm 33 \mathrm{~g}$ in untreated diabetic rats vs. $188 \pm 23$ in the aminoguanidine treated group) as a result of the prolonged hyperglycemia. Blood glucose levels were equally elevated in both groups $(22.8 \pm 2.3 \mathrm{mmol} / \mathrm{l}$ in untreated diabetic rats vs. 23.5 $\pm 2.9 \mathrm{mmol} / \mathrm{l}$ in aminoguanidine treated rats). The ratio left ventricular weight/body weight was slightly but significantly lower in aminoguanidine treated rats compared to untreated rats $(3.1 \pm 0.2 \mathrm{mg} / \mathrm{g}$ body weight vs. $3.5 \pm$ $0.4 \mathrm{mg} / \mathrm{g}$ body weight, $p<0.05$ ).

\section{Hemodynamic parameters}

Systolic, diastolic and mean arterial blood pressure determined under anesthetized open-chest conditions, were slightly but not significantly higher $(p=0.13)$ in the aminoguanidine treated group (Fig. 2). Pulse pressure, an indirect parameter of arterial elasticity was $15 \%$ lower in aminoguanidine treated animals ( $p<0.05$, Fig. 2). Cardiac output was comparable in both groups ( $71 \pm$ $12 \mathrm{ml} / \mathrm{min}$ in diabetic rats vs. $77 \pm 11$ in aminoguanidine treated diabetic rats). Aminoguanidine treatment also resulted in a $40 \%$ lower characteristic aortic input impedance in diabetic rats $\left(p<0.01\right.$, Fig. 3a). The ratio $W_{o} / W_{t}$ reflecting the relative contribution of oscillatory power to total ventricular power output and therefore the efficacy of coupling between the left ventricle and the arterial system, was also markedly lower following aminoguanidine treatment $(-35 \%$, $p<0.05$, Fig. 3b).

Figure: 2: Systolic, diastolic and mean arterial blood pressure in anesthetized, open-chest diabetic and aminoguanidine treated diabetic rats. The upper level of the box represents systolic blood pressure (SBP), the middle line mean arterial blood pressure (MAP), and the lower level of the box diastolic bluod pressure (DBP). The height of the box reflects the pulse pressure (PP). SBP, MAP, and DBP were slightly but not significantly higher $(p=0.13)$ in aminoguanidine treated diabetic rats (hatched box) compared to diabetic rats (blank box). PP was significantly lower in aminoguanidine treated rats $(* p<0.05)$.

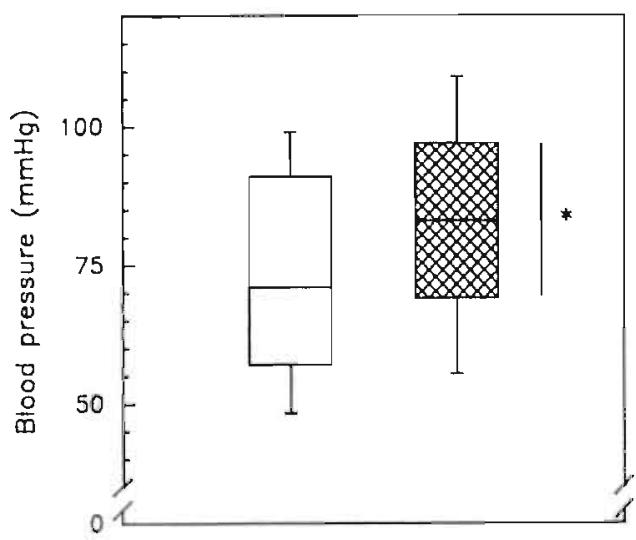




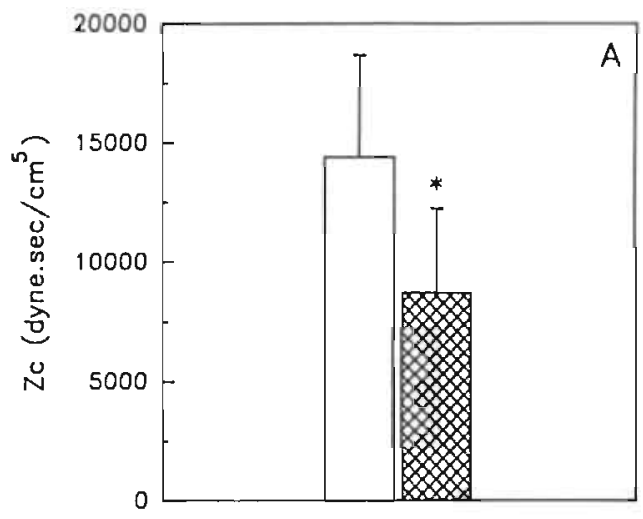

Figure 3: Characteristic aortic input impedance ( $\mathrm{Zc}$, panel $\mathrm{A}$ ) and the ratio left ventricular oscillatory power output to total power output $\left(W_{0} / W_{1}\right.$, panel $\left.B\right)$. Both parameters were determined from Fourier series of aortic pressure and flow. $Z_{c}$ and $W_{0} / W_{t}$ were equally reduced in aminoguanidine treated rats (hatched bars) compared to diabetic rats (blank bars) ${ }^{*} p<0.01$ and $p<0.05$ respectively.

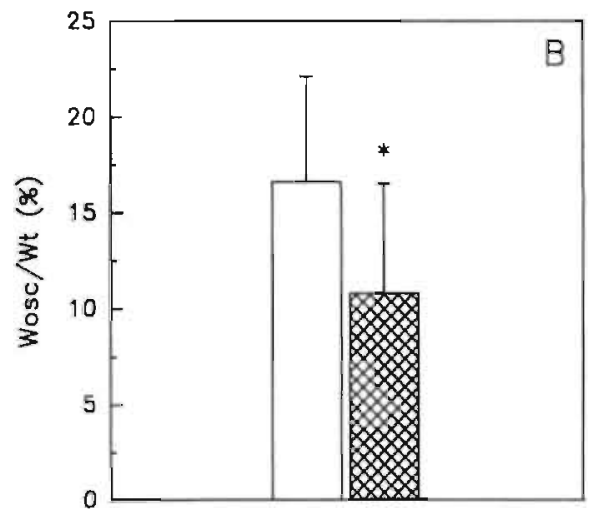

\section{Carotid artery compliance}

Static compliance of the carotid artery under basal conditions and after incubation of the vessel with $\mathrm{KCN}$ is depicted in Figure 4a and b. Carotid artery compliance is pressure dependent and was markedly higher in aminoguanidine treated diabetic rats compared to untreated rats in the range of 100-125 $\mathrm{mmHg}(+39 \%, p<0.01)$. Incubation of the carotid artery with $\mathrm{KCN}$, resulting in maximal dilation of the vessel, shifted both curves to the left. Under dilated conditions, carotid compliance was clearly elevated in the aminoguanidine group compared to the untreated diabetic group in the range of $75-100 \mathrm{mmHg}$ $(+27 \%, p<0.01)$.

\section{Fluid filtration rate}

Fluid filtration showed a linear relation with pressure and was significantly lower over the complete pressure range in aminoguanidine treated rats (Fig. 5). 

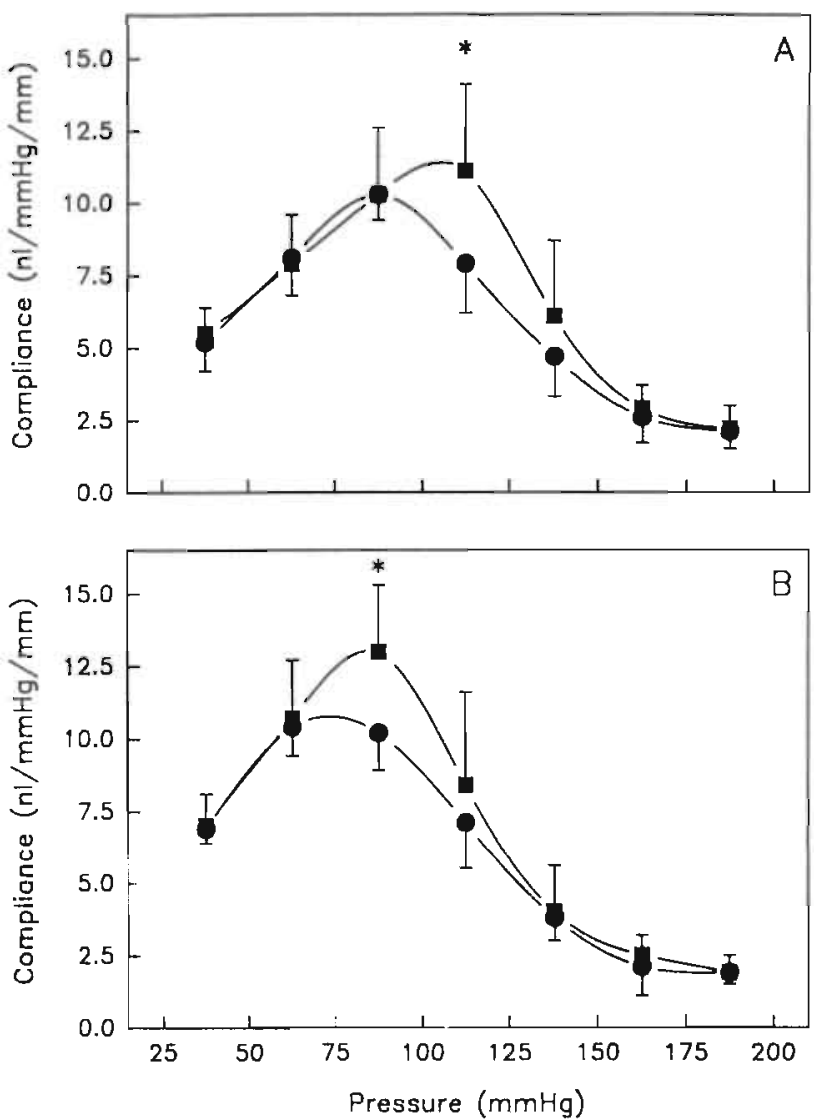

Figure 4: Carotid artery compliance. Static compliance of the in situ isolated carotid artery vs. Fressure. Panel A reflects compliance under control conditions while panel B reflects compliance after incubation with $\mathrm{KCN}$ to abolish vascular tone. Carotid compliance was significantly higher in aminoguanidine treated rats (closed squares, $p<0.01$ ) compared to diabetic rats (closed circles) in the range of $100-125 \mathrm{mmHg}$, matching the operating pressure in these rats. After incubation with KCN, both curves shifted to the left, but carotid compliance remained higher in aminoguanidine treated rats $(p<0.01)$.

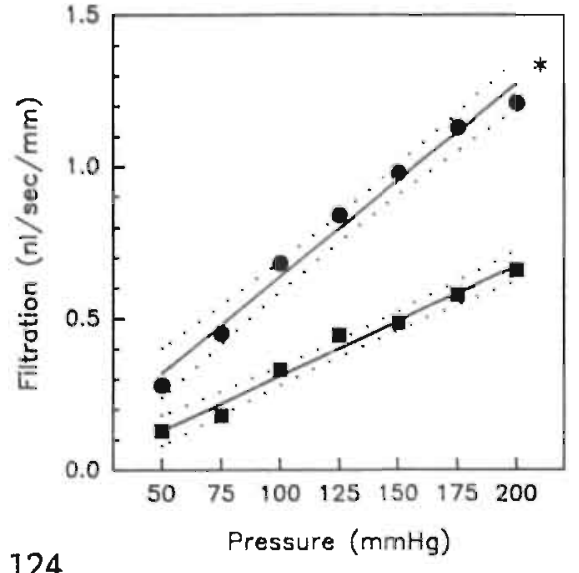

124
Figure 5: Fluid filtration rate. Fluid filtration rate across the carotid artery wall showed a linear relation with the applied intravascular pressure. Regression lines through the mean filtration rate values for each pressure and $95 \%$ confidence intervals are shown for diabetic rats (closed circles) and aminoguanidine treated diabetic rats (closed squares). Fluid filtration across the carotid arterial wall of aminoguanidine treated rats was significantly lower compared to untreated rats $(p<0.05)$. 


\section{DISCUSSION}

In this study we investigated whether treatment with aminoguanidine, a drug known to inhibit AGE-accumulation on collagen, influences mechanical properties of large compliance arteries in diabetic rats. This approach allows us to quantify arterial wall properties in rats that are comparable in body weight. The large differences in body weight that develop between control and streptozotocin diabetic rats in long-term studies $(10,11)$ would make it difficult to interpret parameters that are influenced by vascular dimensions, such as characteristic aortic input impedance and carotid artery compliance.

Aminoguanidine treatment resulted in a slight increase in mean arterial pressure. Cardiac output was almost comparable between the two groups, suggesting that an increased total peripheral resistance might contribute to this small rise in blood pressure. Corbett et al. (12) have shown that aminoguanidine is able to inhibit nitric oxide formation and thus can increase systemic blood pressure, although its effects are much weaker than those of established nitric oxide synthase inhibitors such as $N^{G}$-Monomethyl-L-arginine (NMMA). However, in both groups of rats mean arterial pressure, determined under anesthetized open-chest conditions, was relatively low. This is in agreement with the results of Litwin et al. (13), who showed that thoracotomy lowered mean arterial pressure about 25 percent in diabetic rats, in contrast to a 10 percent decrease in control rats. Indeed mean arterial pressure in diabetic rats of this strain in the conscious state ranges in our laboratory from 100-120 $\mathrm{mmHg}$.

In comparison with untreated rats, carotid compliance in rats treated with aminoguanidine was markedly higher in the pressure range of $100-125 \mathrm{mmHg}$, the pressure that matches the actual blood pressure in these rats; The increase in carotid compliance was observed both under basal conditions and after abolition of vascular tone by KCN. This makes it unlikely that carotid compliance is solely enhanced through a modulation of vascular tone induced by aminoguanidine treatment. Bucala et al. (14) have shown that AGEs are able to quench nitric oxide and in this way interfere with its vasoactive properties. Aminoguanidine treatment could thus, by inhibiting the formation of AGEs on vascular wall proteins, prevent this quenching, resulting in a relative dilation of vessels and probably a larger arterial compliance in the aminoguanidine treated group, although this would be contradictory to the inhibiting effects on NO-formation described above. Nevertheless, after maximal dilation induced by $\mathrm{KCN}$ incubation, carotid compliance was still substantially higher in the aminoguanidine treated group, indicating that passive arterial wall properties are changed markedly by aminoguanidine treatment.

Characteristic aortic input impedance constitutes another index of vascular elasticity which is determined independently of carotid compliance. The 
observed decrease in characteristic aortic input impedance following aminoguanidine treatment supports our hypothesis that aminoguanidine treatment, by preventing AGE-accumulation on collagen, can increase vascular elasticity in diabetes. The decreased ratio of left ventricular oscillatory power output to total ventricular power output indicates that less energy was lost in pulsatile components, as was reflected also in a lower pulse pressure in the aminoguanidine treated group. Moreover, left ventricular weight to body weight ratio was also decreased, suggesting a diminished left ventricular load, despite the slight increase in mean arterial pressure.

Alterations in arterial elasticity have gained much attention in hypertension research. Many studies have been performed regarding mechanical arterial wall properties, such as arterial compliance, in both clinical and experimental hypertension (15-17). The important consequences of alterations in vascular elasticity on cardiovascular performance have been shown unequivocally. A decrease in arterial compliance by itself does not affect mean arterial pressure but it amplifies the pulse pressure. Increased pulse pressure is an independent risk factor for cardiovascular complications (18). Besides, aortic compliance and characteristic aortic input impedance are strongly related to cardiac mass $(19,20)$. Although similar studies have not yet been performed in diabetic patients, changes in arterial elasticity are likely to have important (negative) effects on cardiovascular functioning in diabetes as well.

In addition to the compliance measurements of the carotid artery, we were able to quantify fluid filtration across the carotid wall, and showed that aminoguanidine treatment resulted in a marked decrease of fluid filtration. Increased vascular permeability is a well established feature of diabetic angiopathy and has been shown in both experimental $(21,22)$ and clinical $(23,24)$ studies. Whereas fluid filtration represents hydraulic conductivity of the vascular wall and is not exactly analogous to vascular permeability, measurement of fluid filtration might give an indication of vascular permeability to macromolecules as well. By which mechanisms aminoguanidine might reduce vascular permeability is not well known yet. In experimental diabetes however, aminoguanidine was shown to diminish albuminuria $(25,26)$, a reflection of increased glomerular permeability, possibly by preventing the decreased binding of heparan-sulphate to AGE-modified basement membrane components $(27,28)$. Summarizing our results, we provided evidence that treatment of diabetic rats with aminoguanidine significantly increased vascular elasticity, indicating that AGE-accumulation on vascular wall collagen markedly affects mechanical arterial wall properties. Moreover, aminoguanidine treatment reduced fluid filtration across the carotid arterial wall, which might be a reflection of normalized vascular permeability. Together with its already published beneficial effects (14), this suggests that aminoguanidine can protect the cardiovascular system in (experimental) diabetes. 


\section{REFERENCES}

1. Monnier VM, RR Kohn, Cerami A: Accelerated age-related browning of human collagen in diabetes mellitus. Proc Natl Acad Sci USA 1984; 81: 583-587

2. Schnider SL, Kohn RR: Glycosylation of human collagen in aging and diabetes mellitus. J Clin Invest 1980; 66: 1179-1181

3. Yue DK, McLennan S, Delbridge L, Handelsman DJ, Reeve T, Turtle JR: The thermal stability of collagen in diabetic rats: correlation with severity of diabetes and nonenzymatic glycosylation. Diabetologia $1983 ; 24: 282-285$

4. Brownlee, M, Vlassara $H$, Kooney A, Ulrich P, Cerami A: Aminoguanidine prevents diabetes-induced arterial wall protein cross-linking. Science 1986; 232: 1629-1632

5. Kumari I, Umar S, Bansal V, Sahib MK: Inhibition of diabetes associated complications by nucleophilic compounds. Diabetes 1991; 40: 1079-1084

6. Edelstein D, Brownlee M: Mechanistic studies of advanced glycosylation endproduct inhibition by aminoguanidine. Diabetes 1992; 41: 26-29.

7. Benessiano J, Lévy BI, Michel JB: Instantaneous aortic blood flow measurements with range gated Doppler flowmeter in anesthetized rat. J Pharmacol Meth 1985; 14: 99-110

8. Milnor WR: Cardiac dynamics. In: Hemodynamics. N. Collins, Ed. Baltimore, Williams \& Wilkins, 1989, pp 275-293

9. Morrisson AD, Berwick L, Orci L, Winegrad AI: Morphology and metabolism of an aortic intima-media preparation in which an intact endothelium is preserved. I Clin Invest 57: 650-660.

10. Suarez, G, Rajaram R, Bhuyan KC, Oronsky AL, Goidi JA: Administration of an aldose reductase inhibitor reduces a decrease of collagen fluorescence in diabetic rats. J Clin Invest 1988; 82: 624-627

11. Lash JM, Bohlen HG: Structural and functional origins of suppressed acetylcholine vasodilation in diabetic rat intestinal arterioles. Circ Res 1991; 69: 1259-1268

12. Corbett JA, Tilton RG, Chang $\mathrm{K}$ et al: Aminoguanidine, a novel inhibitor of nitric oxide formation, prevents diabetic vascular dysfunction. Diabetes 1992; 41: 552-556

13. Litwin SE, Raya TE, Daugherty TE, Goldman S: Peripheral control of cardiac output in diabetic rats. Am J Physiol 1991; 30: H836-842

14. Bucala R, Tracey KJ, Cerami A: Advanced glycosylation products quench nitric oxide and mediate defective endothelium-dependent vasodilatation in experimental diabetes. J Clin Invest 1991; 87: 432-438

15. Safar ME, London GM: Arterial and venous compliance in sustained essential hypertension. Hypertension 1987; 10: 133-139

16. Lévy BI, Benessiano J, Poitevin P, Safar ME: Endothelium-dependent mechanical properties of the carotid artery in WKY and SHR. Role of angiotensin converting enzyme inhibition. Circ Res 1990; 66:321-328

17. Lévy BI, Poitevin P, Safar ME: Effects of alphal-blockade on arterial compliance in normotensive and hypertensive rats. Hypertension 1991; 17: 534-540

18. Darne B, Girerd X, Safar ME, Cambien F, Guize L; Pulsatile versus steady component of blood pressure: a cross-sectional analysis and a prospective analysis on cardiovascular mortality. Hypertension 1989; 13:392-400

19. Isnard RN, Pannier BM, Laurent S, London GM, Diebold B, Safar ME: Pulsatile diameter and elastic modulus of the aortic arch in essential hypertension: a noninvasive study. I Am Coll Cardiol 1989; 13: 399-405

20. Lévy BI, Babalis D, Lacolley P, Poitevin P, Safar ME: Cardiac hypertrophy and characteristic impedance in spontaneously hypertensive rats. J Hypertension 1988; 6 (suppl.4): S110-S111 
21. Williamson JR, Chang $\mathrm{K}$, Tilton $\mathrm{RG}$ et al : Increased vascular permeability in spontaneously diabetic $\mathrm{BB} / \mathrm{W}$ rats and in rats with mild versus severe streptozotocininduced diabetes. Prevention by aldose reductase inhibitors and castration. Diabetes 1987; 36: 813-821

22. Pugliese G, Tilton RG, Speedy A et al: Modulation of hemodynamic and vascular filtration changes in diabetic rats by dietary myo-inositol. Diabetes $1990 ; 39$ : 312-322

23. Bollinger A, Frey J, Jaeger K, Furrer J, Seglias J, Siegenthaler W: Patterns of diffusion through skin capillaries in patients with long-term diabetes. N Engl J Med 1982; 307: 1305-1310

24. Feldt-Rasmussen B: Increased transcapillary escape rate of albumin in Type 1 (insulindependent) diabetic patients with microalbuminuria. Diabetologia 1986; 29: 282-286

25. Edelstein D, Brownlee M: Aminoguanidine ameliorates albuminuria in diabetic hypertensive rats. Diabetologia 1992; 35: 96-97

26. Soulis-Liparota T, Cooper M, Papazoglou D, Clarke B, Jerums J: Retardation by aminoguanidine of development of albuminuria, mesangial expansion, and tissue fluorescence in streptozotocin-induced diabetic rat. Diabetes 1991; 40: 1328-1334

27. Charonis AS, Reger LA, Dege JE et al: Laminin alterations after in vitro non-enzymatic glycosylation. Diabetes $1990 ; 39: 807-814$

28. Brownlee $\mathrm{M}$ : Glycation products and the pathogenesis of diabetic complications. Diabetes Care 1992; 15: 1835-1843 


\section{CHAPTER 8}

General discussion 



\section{GENERAL DISCUSSION}

Diabetes mellitus is very often complicated by the development of vascular dysfunction. There is growing insight in the mechanisms involved in the pathogenesis of these complications but there are many topics that remain controversial or ill-defined. In the studies presented in this thesis an effort is made to clarify the mechanisms responsible for the development of vascular dysfunction in (experimental) diabetes. Pharmacological interventions aiming at prevention or reduction of vascular damage in diabetes are investigated.

\section{Microvascular alterations}

The functional alterations that have been observed at the onset of experimental as well as clinical diabetes mellitus mainly consist of signs of increased flow in parallel with vasodilation. These observations have led to the theory of "hyperperfusion-damage" as a primary factor in the etiology of diabetic angiopathy. In this theory, early hemodynamic changes such as vasodilation and increased flow cause damage to the vascular wall resulting in vascular sclerosis (1). Important evidence supporting this hypothesis origins from renal micropuncture studies in rats by Zatz and Brenner (2), rat studies demonstrating increased permeability and flow in many organs by Williamson et al. (3), studies of Kohner c.s. in the human retinal microcirculation (4) and human studies measuring flow and capillary pressure by Houben, and Tooke and coworkers $(5,6,7)$.

Recently, a number of reports have questioned the existence of increased flow as a general phenomenon in (early) diabetes. Studies in the retina of diabetic rats and diabetic humans showed -in contrast- a decreased flow in early diabetes (8). Our observations in the skeletal muscle microcirculation of conscious streptozotocin-diabetic rats demonstrate no major alterations in arteriolar nor venular diameter except for the smallest arterioles in which a slight but significant decrease in vessel diameter was observed (chapter 2). Although we did not perform flow measurements these data indicate vasoconstriction and perhaps decreased flow, especially when it is taken into account that blood viscosity is generally believed to be increased (9). Rendell et al. showed that in early experimental diabetes nutritive skin flow is reduced, probably as a consequence of decreased erythrocyte velocity (10). In humans with insulin-dependent diabetes no changes in basal skin blood flow but a markedly diminished blood flow after local heating was demonstrated; the changes correlated with the existence of both retinopathy and microalbuminuria (11). In addition, a functionally important parameter such as transcutaneous oxygen pressure was reported to be reduced in patients with insulindependent diabetes, even in those with short duration of disease (12).

Combining our observations and these recently reported studies it can be concluded that the role of hyperperfusion in the genesis of diabetic angiopathy 
is still controversial. Although there is sufficient evidence for the presence of increased flow in some vascular beds, this phenomenon does not have to be causally related to the observed vascular dysfunction. Likely, other hyperglycemia-induced disturbances such as increased transvascular passage and deposition of macromolecules, as well as enhanced tissue damage by increased oxidative stress and free radical production play a more important role in the genesis of diabetic angiopathy.

\section{Vascular reactivity}

Many studies on vascular reactivity changes in diabetes have been carried out in isolated vessels. The observation by Heesen et al. that responses of vessels from diabetic animals to vasoactive agents are dependent on ambient glucose concentrations (13) complicates the interpretation of many of these previous studies, since most were performed using standard in vitro glucose concentrations. It is important to study vasoreactivity in diabetes in vivo, in a situation in which vessels can be studied in their own milieu. With the dorsal microcirculatory chamber model it is possible to perform in vivo measurements of the skeletal muscle microcirculation. Our studies on vasoreactivity to different vasopressor and vasodilating drugs in experimental diabetes are presented in chapter 3 . We observed disturbances in reactivity to all vasoactive agents that were studied: both impaired relaxation and hyperreactivity to vasoconstrictive agents were observed.

It is of interest that we did not see any differences in endothelium-dependent relaxation compared with endothelium-independent relaxation. Specific defects in endothelium-dependent relaxation have been regarded for a long time as one of the characteristics of diabetic angiopathy. However, in the last years a number of (in vivo) studies could not confirm the presence of a special disturbance in endothelium-dependent vasorelaxation (14). Our results merely point in the direction of a more general defect in intracellular processes involved in vascular contraction and relaxation. There are a number of these intracellular mechanisms which have been reported to be altered in experimental diabetes. An important intracellular messenger involved in vascular contractility and growth is protein kinase $C(P K C)$. PKC activation has been observed in a number of tissues including vascular smooth muscle (15) mesangial cells cultured in high glucose (16), hepatocytes (17) and aortas and hearts from diabetic rats $(18,19)$. Activation of PKC in the diabetic state might lead to increased vascular contractility (chapter 3) and cell growth (chapter 2). Recently, it has been shown that PKC can modulate nitric oxide synthase enzyme activity (20) while also cyclic AMP accumulation may be affected (21), which may constitute ways in which alterations in PKC activation can influence vasorelaxation (chapter 3). 
Alterations in intracellular cations such as $\mathrm{Ca}^{2+}$ and $\mathrm{Na}^{*}$ have also been demonstrated in a number of tissues and cells, such as kidneys from rats exposed to hyperglycemia (22), cardiac myocytes from diabetic rats (23) and platelets from both insulin-dependent and non insulin-dependent diabetic patients (24). These changes in intracellular cation homeostasis can be induced by alterations in cation exchange mechanisms in diabetes such as $\mathrm{Na}^{+} / \mathrm{K}^{+}$-ATPase which has been reported to be depressed (25), an increased $\mathrm{Ca}^{2+}$-ATPase activity (24), or increased activity of the $\mathrm{Na}^{+} / \mathrm{H}^{+}$-antiporter (26). Increased intracellular cation concentration can play a role in cellular growth and hyperreactivity $(27,28)$, and may in this way explain the observed signs of vascular dysfunction in our model.

\section{Vascular permeability}

Increased vascular permeability has previously been shown using several models and experimental setups in clinical and animal diabetes. We could confirm the presence of increased vascular leakage in our diabetic rat model. In contrast to some studies we observed increased regional albumin clearance reflecting vascular leakage in all the organs that were studied, including skeletal muscle and skin. Using different techniques such as FITC-Dextran clearance and electron microscopy, the existence of increased vascular leakage in such tissues has been corroborated by others $(29,30)$. The occurrence of increased vascular permeability in tissues in which flow is not increased such as skeletal muscle and skin (see paragraph above) emphasizes once more that this phenomenon is probably more related to structural changes in the vessel wall than to hemodynamic changes which increase intracapillary pressure.

Increased vascular leakage and albuminuria tend to develop in parallel. It has been suggested that both events are features of a common pathophysiologic mechanism and reflect widespread vascular damage (31), resulting in increased cardiovascular morbidity and mortality (32). In our studies we demonstrated that different treatments can differentially modulate the development of increased vascular leakage or albuminuria, with anti-proteinuric effects of ACE-inhibitor therapy (chapter 4) and permeability reducing effects of aminoguanidine (chapter 5). These observations suggest that in the etiology of increased protein permeation and albuminuria at least partially distinct mechanisms are involved. In the kidney, angiotensin II dependent mechanisms such as intraglomerular pressure seem to play a more important role than in other vascular beds. It cannot be ruled out, however, that both investigated treatments exert a symptomatic effect that is not related to intervention in the pathophysiologic pathway involved. Especially in the study in which the effects of aminoguanidine on albuminuria and regional albumin clearance were studied it might be possible that the treatment period was not sufficiently long; 
other studies did report beneficial effects of aminoguanidine treatment on albuminuria (33).

Albuminuria and proteinuria are associated with a tremendous increase in cardiovascular morbidity and mortality in diabetic patients (34), due to the development of accelerated damage to the cardiovascular system. Our study has demonstrated that ACE-inhibitor treatment, although very effective in reducing albuminuria, did not prevent the development of increased vascular albumin permeation which is a reflection of generalized vascular damage. Thus, it may be questioned whether treatments that reduce albuminuria per se, will have any beneficial effects on the development of cardiovascular disease in diabetes and life expectancy of the diabetic patient. Until now, no studies have been reported concerning the effects of reduction or prevention of albuminuria/proteinuria on cardiovascular morbidity and mortality in diabetic patients. These effects may prove to be very disappointing. In contrast, aminoguanidine treatment may have vasculoprotective effects in diabetes. We observed beneficial effects on vascular permeability (chapter 5) and vascular elasticity (chapter 7). Several other studies have shown advantageous effects of this drug on a number of features of diabetic vascular dysfunction. Human studies are currently being designed and the first results are promising (34). The observed inhibiting effects of aminoguanidine on the enzyme nitric oxide synthase warrant caution, although the dose of aminoguanidine which will be used in clinical studies is probably too low to induce effects on NO-synthase. New compounds that strongly inhibit the formation of advanced glycosylation endproducts (AGEs) but have no effects on nitric oxide production have already been developed (35).

\section{Vascular elasticity}

The existence of alterations in vascular elasticity is a relatively new topic in diabetes research, and has until now gained little attention. A decrease in vascular elasticity in diabetes can be a result of the development of accelerated atherosclerosis in non-insulin dependent diabetic patients or in association with proteinuria in insulin-dependent diabetes. We have shown that increased vascular stiffness develops in diabetic rats after 3 months of diabetes duration in a vascular system in which no signs of atherosclerosis are present. This indicates that there are also other mechanisms which can induce decreased vascular elasticity in diabetes.

Treatment with aminoguanidine markedly reduced vascular stiffness. This suggests that AGE-formation plays an important role in this process. AGEformation can negatively affect vascular elastic properties by structural modification of collagen which is an important constituent of the arterial wall. Sequelae of decreased arterial compliance include systolic ventricular stress and cardiac hypertrophy (36). In experimental models, reduced aortic compliance has been shown to impose a markedly increased energetic demand on the 
heart (37). Altogether, this will have substantial adverse effects on cardiac function in a pathological condition in which the heart function is already compromised by factors such as coronary atherosclerosis and microangiopathy.

\section{Final remarks}

In the streptozotocin-induced diabetic rat many signs of vascular dysfunction develop at different levels of the cardiovascular system. The observed features of diabetic angiopathy together with the many defects affecting cardiovascular homeostasis that have been reported in the literature illustrate the plurifold nature of the adverse effects of hyperglycemia on the cardiovascular system. Consequently, there will not be one exclusive, but a number of pathophysiologic mechanisms which should be considered of importance in the etiology of diabetic vascular dysfunction. Therefore, therapeutic options will probably not be restricted to only one class of drugs. The results of the studies in this thesis suggest that aminoguanidine or other drugs which prevent the formation of advanced glycosylation endproducts may form one class of drugs from which beneficial effects in the prevention or treatment of clinical diabetic angiopathy can be foreseen. Future research should be aimed at a yet more precise definition of basic processes involved in the genesis of diabetic vascular dysfunction. In the development of new drugs an advantageous profile with respect to sideeffects and toxicity is of major importance considering the (life)long duration of treatment which can be envisioned. 


\section{REFERENCES}

1. Zatz R, Brenner BM: Pathogenesis of diabetic microangiopathy. The hemodynamic view. Am / Med 1986; 80: 443-453

2. Zatz R, Meyer TW, Rennke HG, Brenner BM: Predominance of hemodynamic rather than metabolic factors in the pathogenesis of diabetic glomerulopathy. Proc Natl Acad Sci USA 1985; 82: 5963-5967

3. Williamson JR, Chang $K$, Tilton $R G$, et al.: Increased vascular permeability in spontaneously diabetic $B B / W$ rats and in rats with mild versus severe streptozotocininduced diabetes: prevention by aldose reductase inhibitors and castration. Diabetes 1987; 36: 813-821

4. Kohner EM: Retinal blood flow in diabetes. Diabetologia 1975; 11: 27-33

5. Houben AJHM, Schaper NC, Slaaf DW, Tangelder GJ, Nieuwenhuijzen Kruseman AC: Skin blood cell flux in insulin-dependent diabetic subjects in relation to retinopathy or incipient nephropathy. Eur J Clin Invest 1992; 22: 67-72

6. Sandeman DD, Pym CA, Green EM, Seamark C, Shore AC, Tooke JE: Microvascular vasodilatation in feet of newly diagnosed non-insulin dependent diabetic patients. $\mathrm{Br}$ Med J 1991; 302: 1122-1123

7. Tooke JE: Microvascular pathology and its clinical relevance with special reference to diabetes. Q J Med 1992; 84: 567-573

8. Bursell SE, Clermont AC, Shiba T, King GL: Evaluating retinal circulation using video fluorescein angiography in control and diabetic rats. Curr Eye Res 1992; 11: 287-295

9. McMillan DE: The effect of diabetes on blood flow properties. Diabetes 1983; 32 (suppl. 2): 56-63

10. Rendell MS, Kelly ST, Finney D, et al: Decreased skin blood flow early in the course of streptozotocin-induced diabetes mellitus in the rat. Diabetologia 1993; 36: 907-911

11. Rendell M, Bamisedun O: Diabetic cutaneous microangiopathy. Am J Med 1992; 93: 611-618

12. Breuer HWM, Breuer J, Berger M: Transcutaneous oxygen pressure measurements in type 1 diabetic patients for early detection of functional diabetic microangiopathy. Eur J Clin Invest 1988; 454-459

13. Heesen BJ, Ido Y, Wolffenbuttel BHR, Williamson JR: Acetylcholine induced relaxation of isolated aortas is modulated by ambient glucose, l-arginine and myo-inositol. Diabetes 1992; 41 (suppl. 1): 480

14. McVeigh GE, Brennan GM, Johnston GD et al : Impaired endothelium-dependent and independent vasodilation in patients with Type 2 (non insulin-dependent diabetes mellitus. Dinbetologia 1992; 35: 771-776

15. Williams B, Shrier RW: Characterization of glucose-induced in situ protein kinase C activity in cultured vascular smooth muscle cells. Diabetes 1992; 41: 1464-1472

16. Studer RK, Craven PA, DeRubertis FR: Role for protein kinase $C$ in the mediation of increased fibronectin accumulation by mesangial cells grown in high glucose medium. Diabetes 1993; 42: 118-126

17. Tang EY, Parker PJ, Beattie J, Houslay MD: Diabetes induces selective alterations in the expression of protein kinase C isoforms in hepatocytes. FEBS Lett 1993; 326: 117 123

18. Inoguchi T, Battan R, Handler E, Sportsman JR, Heath W, King GL: Preferential elevation of protein kinase $\mathrm{C}$ isoform beta II and diacylglycerol levels in the aorta and heart of diabetic rats: differential reversibility to glycemic control by islet cell transplantation. Proc Natl Acad Sci USA 1992; 89: 11059-11063 
19. Tanaka Y, Kashiwagi A, Saeki S, Shigeta Y: Abnormalities in cardiac $\alpha 1$-adrenoceptor and its signal transduction in streptozotocin-induced diabetic rats. Am J Physiol 1992; 263: $E 425-429$

20. Bredt DS, Ferris CD, Snyder SH: Nitric oxide synthase regulatory sites. Phosphorylation by cyclic AMP-dependent protein kinase, protein kinase $C$, and calcium/calmodulin protein kinase; identification of flavin and calmodulin binding sites. J Biol Chem 1992; 267: 10976-10981

21. Gusovsky F, Gutkind JS: Selective effects of activation of protein kinase C isozymes on cyclic AMP accumulation. Mol Pharmacol 1991; 39: 124-129

22. Dowd TL, Gupta RK: NMR studies of hyperglycemia on intracellular cations in rat kidney. J Biol Chem 1993; 268: 991-996

23. Warley A: Changes in sodium concentration in cardiac myocytes from diabetic rats. Scanning Microsc 1991; 5: 239-244

24. Mazzanti L, Rabini RA, Faloia E, Fumelli P, Bertoli E, De Pirro R: Altered cellular Ca ${ }^{2+}$ and $\mathrm{Na}^{+}$transport in diabetes mellitus. Diabetes 1990; 39: 850-854

25. Hermenegildo C, Felipo V, Minana MD, Romero FJ, Grisolia S: Sustained recovery of $\mathrm{Na}^{+} / \mathrm{K}^{+}$-ATPase activity in sciatic nerve of diabetic mice by administration of $\mathrm{H} 7$ or calphostin C, inhibitors of PKC. Diabetes 1993; 42: 257-262

26. Davies JE, $\mathrm{Ng} \mathrm{LL}$, Kofoed-Enevoldsen $\mathrm{A}$, et al.: Intracellular $\mathrm{pH}$ and $\mathrm{Na}^{+} / \mathrm{H}^{+}$antiport activity of cultured skin fibroblasts from diabetics. Kidney Int 1992; 42: 1184-1190

27. Weidmann P. Ferrari P: Central role of sodium in hypertension in diabetic subjects. Diabetes Care 1991; 14: 220-232

28. Nelissen-Vrancken HJMG: Local renin angiotensin systems and peripheral ischemia. Thesis, Maastricht 1992, pp 111-120

29. Beals CC, Bullock J, Jauregui ER, Duran WN: Microvascular clearance of macromolecules in skeletal muscle of spontaneously diabetic rats. Microvasc Res 1993; 45: 11-19

30. Yamaji T, Fukuhara T, Kinoshita M: Increased capillary permeability to albumin in diabetic rat myocardium. Circ Res 1993; 72: 947-957

31. Deckert T, Feldt-Rasmussen B, Borch-Johnsen K, Jensen T, Kofoed-Enevoldsen A: Albuminuria reflects widespread vascular damage: the Steno hypothesis. Diabetologia 1989; 32: 219-226

32. Edelstein D, Brownlee $M$ : Aminoguanidine ameliorates albuminuria in diabetic hypertensive rats. Diabetologia 1992; 35: 96-97

33. Deckert T: Microalbuminuria. Implications for micro- and macrovascular disease. Diabetes Care 1992; 15: 1181-1191

34. Bucala R, Cerami A, Makita Z, et al.: Inhibition of advanced glycosylation by aminoguanidine reduces plasma LDL levels in diabetes. Clin Res 1993

35. Mallon VM, Ulrich PC, Boyd TA, Miyauchi I, Takasu T, Yamin M: N-[2-(4-morpholino) ethyl]- $\mathrm{N}^{\prime}$-aminoguanidine (MEAG) in hibits AGE-formation in vitro and diabetic changes without inhibiting diamine oxidase (DAO) or nitric oxide. Diabetes 1993; 42 (suppl. 1): 106A

36. London GM, Marchais SJ, Safar ME: Arterial compliance in hypertension. I Hum Hypertension 1989; 3: 53-56

37. Kelly RP, Tunin R, Kass DA: Effect of reduced aortic compliance on cardiac efficiency and contractile function of the in situ canine left ventricle. Circ Res 1992; 71: 490-502 



\section{SUMMARY}

Diabetes mellitus is a disease with a high prevalence in the general population. Two forms of diabetes mellitus can be distinguished. Insulin-dependent diabetes mellitus (IDDM) is characterized by its juvenile onset and a state of absolute insulin deficiency caused by destruction of the insulin producing pancreatic B cells. Insulin therapy is necessary in these patients. The prevalence of IDDM is relatively low compared to the prevalence of non insulin-dependent diabetes mellitus (NIDDM) which affects mainly older people. In NIDDM defects in insulin secretion coexist with a relative insulin resistance often related to obesity. NIDDM patients may be treated with diet only, but in most cases addition of oral agents and/or eventually insulin treatment is warranted.

Morbidity and mortality as well as quality of life of patients with diabetes mellitus are to a large extent determined by the development of vascular complications. Vascular dysfunction in diabetes has many features which vary from mild signs such as microalbuminuria and background retinopathy to severe conditions like end-stage renal failure, vision-threatening proliferative retinopathy and atherosclerosis. Because of the high prevalence of diabetes mellitus and the substantial amount of diabetic patients that develop vascular complications, diabetic angiopathy poses an important problem in health care in clinical terms as well as with respect to health care costs.

Although the development of diabetic vascular complications has been recognized already many years ago, this has not yet led to a complete understanding of the mechanisms which are responsible for its development. A number of possible etiologic mechanisms have been proposed. Glycosylation, induced by chemical reactions between proteins and circulating sugars has been shown to interfere with a number of systems important in cardiovascular regulation. Increased metabolism of glucose through the polyol pathway might induce alterations in intracellular homeostatic mechanisms such as alterations in redox potential. Finally, alterations in vasoactive or growth promoting hormones may also be involved in the development of diabetic angiopathy.

In this thesis, characteristics of vascular dysfunction were studied using an experimental diabetes model. The use of an animal model allowed us to study different aspects of vascular dysfunction at a more basal level. In the studies presented in this thesis, changes occurring in the streptozotocin-induced diabetic rat are described. 
In chapter 2 and chapter 3 the effect is described of diabetes induction on small vessels, arterioles and venules, in a striated muscle preparation, the so-called dorsal microcirculatory chamber. Using this preparation, diameters of arterioles and venules were measured sequentially for 6-8 weeks in conscious rats.

In chapter 2 the effects of diabetes induction on microvascular diameters and microvascular density are observed: Male Wistar Rp rats were implanted with a dorsal microcirculatory chamber at the age of 6-7 weeks. After three weeks recovery, rats were divided into a control group and a diabetic group in which diabetes was induced by i.p. injection with $70 \mathrm{mg} / \mathrm{kg}$ streptozotocin. Using intravital microscopy, recordings of selected arterioles and venules were made before diabetes induction and then weekly for a period of 6 weeks. Vessel diameters were measured off-line with an image-shearing device. In parallel, photographic pictures were taken of all the preparations; vascular densities of different vessel categories were determined from these slides using a standard grid-counting method. No effects on diameters of larger A1 and A2 arterioles were observed in diabetic animals. However, the smallest A3/A4 arterioles showed a gradual constriction after streptozotocin administration. In addition, 4 and 6 weeks after diabetes induction an increased density of venules was observed. These results indicate that also in microvascular beds -such as the striated muscle microcirculation- which are not specifically known for diabetesrelated damage, vascular alterations develop already shortly after diabetes induction.

In chapter 3 vascular reactivity of microvessels was studied using the same microcirculatory preparation. The effects of the endothelium-dependent vasodilator acetylcholine and the potassium-channel opener BRL 38227, and the vasoconstricting effects of the $\alpha 1$-adrenoceptor agonist phenylephrine and angiotensin II on blood pressure and striated muscle arteriolar diameter were studied six weeks after diabetes induction, and compared with non-diabetic control rats. Changes in arteriolar diameters were measured in the cutaneous maximus muscle, using the dorsal microcirculatory chamber model. The decrease in mean arterial pressure following acetylcholine infusion was approximately $30 \%$ lower in diabetic rats. Arteriolar diameter responses to acetylcholine were markedly lower in diabetic rats; the effect was most pronounced in A2 arterioles. Systemic and arteriolar responses to BRL 38227 were similarly decreased. The increase in blood pressure after phenylephrine was greater in control rats than in diabetic rats, but this drug caused a stronger arteriolar constriction in diabetic animals relative to control animals. Angiotensin II had no effect on vessel diameters in control animals, whereas the highest dose induced a marked vasoconstriction in diabetic rats. Thus, vascular relaxation is impaired in skeletal muscle arterioles from conscious diabetic rats, while constriction to both angiotensin II and phenylephrine is increased. Syste- 
mic responses to these vasopressor agents, however, are unchanged or even decreased. These findings point to significant functional disturbances of vasoregulatory mechanisms in experimental diabetes, which are not limited to the endothelium.

Chapter 4 and chapter 5 deal with alterations in vascular permeability as a result of diabetes. It has been demonstrated in experimental studies that increased vascular permeability develops already shortly after diabetes induction. In parallel with the development of increased protein leakage across the vessel wall albuminuria develops. Albuminuria and increased vascular albumin leakage are both believed to be markers of generalized vascular damage. Treatments which prevent the development of this generalized vascular "leakiness" would be of considerable importance. In chapter 4 the effects of angiotensin converting enzyme (ACE)-inhibition are studied. The antiproteinuric effect of ACE-inhibitor therapy is well established. Diabetic rats were treated with saline, perindoprilat, or hydralazine. After 6-8 weeks, blood pressures were equally reduced in the perindoprilat- and hydralazine-treated groups. $24 \mathrm{~h}$ Urinary protein and albumin excretion were increased in diabetic rats compared to control rats. Hydralazine did not reduce $24 \mathrm{~h}$ protein nor albumin excretion, whereas perindoprilat treatment reduced both to levels comparable to those of control rats. Regional albumin clearances, assessed in the eye, ileum, lung, skeletal muscle and skin, were clearly elevated in diabetic rats compared to control rats; However, neither drug had any effect on albumin clearance. This indicates that ACE-inhibition despite its beneficial effects on urinary albumin excretion can not prevent the development of vascular leakage induced by diabetes. At the same time our results indicate that increased protein leakage across the vascular wall and increased renal albumin loss are not simply exponents of the same vascular disturbances.

Advanced glycosylation endproduct-formation is thought to play a role in the development of diabetic angiopathy. By altering the structure of different extracellular matrix components advanced glycosylation endproducts might affect vascular and glomerular permeability. In chapter 5 we investigated the effect of treatment with an inhibitor of advanced glycosylation endproductformation, aminoguanidine, on vascular permeability and the development of albuminuria using the same study design as in the previous study. Mean arterial pressure in the diabetic group was significantly lower than in the control and aminoguanidine-treated group. Regional albumin clearances were significantly increased in all tissues of diabetic rats compared to control rats. Aminoguanidine treatment of diabetic rats prevented the development of increased regional albumin clearance in all tissues except the lung. The development of albuminuria, however, was not affected. 
Since processes such as glycosylation might induce marked structural modification of important vessel wall proteins and thus might influence functional arterial wall properties, we investigated the effects of experimental diabetes on arterial mechanical properties in diabetic and non-diabetic male Wistar Rp rats, using two independent methods: determination of characteristic impedance of the ascending aorta, as well as carotid artery compliance (chapter 6).

The first variable was determined from phasic recordings of pressure and flow in the ascending aorta. Simultaneously, parameters of general cardiovascular function, i.e. blood pressure, heart rate, cardiac output, and total peripheral resistance were measured. Carotid compliance was determined in situ under control conditions and after poisoning of the smooth muscle mass with potassium cyanide. Diabetes was found to have marked effects on cardiovascular homeostasis. Carotid compliance was significantly lower in diabetic rats compared with control rats at all pressure levels, both under control conditions and after treatment with $\mathrm{KCN}$. Characteristic impedance of the ascending aorta was higher in the diabetic group. From these observations we conclude that arterial wall compliance is decreased in diabetic rats. The observed compliance changes might have important effects on cardiovascular function in diabetes. In view of our hypothesis that glycosylation or so-called Advanced Glycosylation Endproduct (AGE)-formation might lead to structural modification of vascular wall proteins resulting in decreased vascular elasticity we were interested in the effects of treatment with an inhibitor of these glycosylation processes, aminoguanidine. In chapter 7 we demonstrated that treatment of diabetic rats with aminoguanidine resulted in a significant increase in carotid static compliance $(+39 \%$, under control conditions, and $+27 \%$, after abolition of vascular tone by $\mathrm{KCN}$ ), and a decrease in characteristic aortic input impedance $(-40 \%)$. The arterial pulse pressure in aminoguanidine treated rats was decreased by about $15 \%$, and the pulsatile component of left ventricular power output was relatively diminished $(-35 \%)$. In addition, we observed a lower fluid filtration across the carotid wall. These results indicate an increased vascular elasticity, an improved left ventricular-arterial coupling, and a decreased vascular permeability in diabetic rats following aminoguanidine treatment, suggesting that AGE-accumulation on collagen negatively affects arterial wall properties in experimental diabetes.

In this thesis studies are presented concerning different aspects of diabetic angiopathy. We demonstrated that microvascular alterations develop already shortly after diabetes induction, and showed that in striated muscle diabetes mellitus leads to vasoconstriction in contrast to many studies reporting vasodilation in (experimental) diabetes. Vascular reactivity is also affected by diabetes induction and implies alterations in both endothelium-dependent and endothelium independent vasoreactivity. Vascular permeability is increased, and ACE- 
inhibitor treatment prevents the development of albuminuria but not of general albumin leakage. Aminoguanidine treatment, in contrast, did prevent the increase of general albumin leakage. Aminoguanidine also has advantageous effects on arterial elasticity. In view of these effects, this drug or its derivatives may be effective in the treatment of diabetic angiopathy. However, its beneficial effects and safety first have to be confirmed in human studies. 



\section{SAMENVATTING}

Diabetes mellitus of suikerziekte komt relatief vaak voor in de algemene bevolking. Twee verschillende vormen kunnen worden onderscheiden. Insuline-afhankelijke diabetes mellitus (IADM) wordt gekenmerkt door het ontstaan op jeugdige leeftijd waarbij er een absoluut insuline tekort bestaat dat wordt veroorzaakt door destructie van de insuline producerende $\beta$-cellen van de pancreas. Om te overleven zijn deze patiënten afhankelijk van insuline. De prevalentie van IADM is relatief laag in verhouding tot het voorkomen van niet insuline-afhankelijke diabetes mellitus (NIADM), een aandoening die vooral bij ouderen voorkomt. In NIADM bestaat er een gestoorde insuline secretie waarbij er ook sprake is van een relatieve ongevoeligheid van weefsels voor insuline, hetgeen (deels) samenhangt met de aanwezigheid van overgewicht. Mensen met NIADM kunnen in sommige gevallen worden behandeld met een dieet, maar hebben meestal orale bloedsuiker-verlagende medicatie nodig en soms ook insuline.

Morbiditeit en mortaliteit en dus ook de kwaliteit van leven van patiënten met diabetes mellitus worden in belangrijke mate bepaald door het al dan niet optreden van vasculaire complicaties. Er zijn meerdere uitingsvormen van vaatbeschadiging als gevolg van diabetes die variëren van lichte netvliesbeschadiging en microalbuminurie (albumine-verlies in de urine) tot zeer ernstige aandoeningen zoals nierinsufficiëntie, visusstoornissen ten gevolge van vaatwoekeringen in het netvlies (proliferatieve retinopathie), en atherosclerose. Doordat diabetes mellitus vaak voorkomt en een groot deel van de diabetespatiënten vasculaire complicaties ontwikkelt vormt deze diabetische angiopathie een belangrijk probleem binnen de gezondheidszorg.

Alhoewel men al langere tijd geleden het optreden van diabetische angiopathie heeft onderkend, weten we tot op heden nog steeds niet waardoor deze vaatafwijkingen nu precies ontstaan. Er zijn verschillende mechanismen die mogelijk een rol spelen in de ontwikkeling van diabetische angiopathie. Glycosylering, een proces veroorzaakt door de reactie van circulerende suikers zoals glucose met eiwitten, interfereert met de functie van een aantal systemen die belangrijk zijn in de regulatie van het cardiovasculaire systeem. Toegenomen metabolisme van glucose via de "polyol pathway" kan veranderingen induceren in intracellulaire mechanismen zoals een gestoorde redox potentiaal. Daarnaast kunnen vasoactieve of groeistimulerende hormonen betrokken zijn bij het ontstaan van diabetische angiopathie. 
Dit proefschrift beschrijft onderzoek dat is verricht met als doel het nader karakteriseren van diabetische angiopathie, waarbij wij gebruik hebben gemaakt van een diermodel. Met behulp van dit diermodel, de streptozotocinegeïnduceerde diabete rat, was het mogelijk om basale vasculaire veranderingen te beschrijven die ontstaan ten gevolge van diabetes mellitus.

In hoofdstuk 2 en hoofdstuk 3 worden de effecten beschreven van diabetes inductie op kleine bloedvaten, arteriolen en venulen, in een preparaat bestaand uit dwarsgestreept spierweefsel, de "dorsale microculatie kamer". Via een operatie wordt dit kamertje geïmplanteerd op de rug van de rat, waarbij zich na de operatie in de kamer een enkele laag spierweefsel bevindt. Aan de kleine vaten in dit preparaat kunnen metingen worden verricht gedurende een periode van 6-8 weken in wakkere ratten. In hoofdstuk 2 wordt de uitwerking beschreven van diabetes inductie op diameters van arteriolen en venulen alsmede op vaatdichtheid. Diameters werden bepaald van behulp van wekelijks gemaakte video opnames van de preparaten van ratten met en zonder streptozotocine-geïnduceerde diabetes. Het blijkt dat er na diabetes inductie weinig veranderingen in vaatdiameters optreden, en slechts de kleinste arteriolen tekenen van vernauwing vertonen. Behalve de vaatdiameter werd ook de vaatdichtheid in het preparaat bepaald voor en na het induceren van diabetes. De vaatdichtheid werd bepaald door op dia's van de verschillende preparaten met behulp van een raster het aantal vaten te tellen. Bij ratten met diabetes werd na 4 en na 6 weken een toename van het aantal venulen gevonden. Deze resultaten laten zien dat ook in de microcirculatie van dwarsgestreept spierweefsel veranderingen ontstaan op relatief korte termijn na het ontstaan van diabetes mellitus.

In hoofdstuk 3 worden de effecten beschreven van diabetes inductie op reacties van vaatwand op verschillende stoffen, zoals vaatverwijders en stoffen die tot een vernauwing van de bloedvaten (vasoconstrictie) leiden. De effecten van de vaatverwijdende stoffen acetylcholine en BRL 38227, alsmede de effecten van stoffen met een vasoconstrictief effect (phenylephrine en angiotensine II) werden bestudeerd in ratten met en zonder diabetes, in hetzelfde model als hierboven is beschreven.

Het bloeddrukdalend effect van acetylcholine, als ook het vaatverwijdend effect op arteriolen was $30 \%$ minder in ratten met diabetes in vergelijking tot ratten uit de controle groep. Ook na toediening van BRL 38227 werden minder sterke effecten geobserveerd in ratten met diabetes. Na het toedienen van phenylephrine en angiotensine II werd echter een veel sterkere vaatvernauwing gevonden in ratten met diabetes. Verrassend genoeg was het effect op de bloeddruk van deze stoffen juist weer veel minder uitgesproken dan in ratten uit de controle groep. Deze bevindingen wijzen erop dat er belangrijke veranderingen in vaatwandreactiveit van arteriolen ontstaan na diabetes inductie. 
Deze veranderingen betreffen zowel endotheel-afhankelijke reactiviteit maar ook endotheel-onafhankelijke vaatwandreactiviteit.

Hoofdstuk 4 en hoofdstuk 5 betreffen veranderingen in vasculaire permeabiliteit ten gevolge van diabetes. Het is al langer bekend dat er toegenomen lekkage van eiwit door de vaatwand bestaat in diermodellen maar ook bij patiënten met diabetes. Naast het ontstaan van eiwitlekkage door de vaatwand ontstaat er ook eiwitverlies via de nier (albuminurie/proteinurie). Beide processen worden gezien als exponenten van eenzelfde proces, te weten gegeneraliseerde vaatbeschadiging als gevolg van diabetes. Medicamenten die deze eiwitlekkage zouden kunnen voorkomen of verminderen kunnen van groot belang zijn in de behandeling van patiënten met vasculaire complicaties als gevolg van diabetes mellitus. Van angiotensin converting enzyme (ACE)-inhibitors is beschreven dat zij albuminurie en proteinurie kunnen reduceren. In hoofdstuk 4 worden de resultaten beschreven van een studie naar de effecten van behandeling met de ACE-inhibitor perindoprilat op albuminurie en albumine-lekkage door de vaatwand. Albuminurie werd gekwantificeerd door de albumine concentratie te bepalen in de verzamelde 24-uurs urine. Albumine-lekkage werd bepaald in meerdere organen met behulp van radioactief humaan serum albumine. De studies werden 6-8 weken na diabetes-inductie verricht, waarbij de ratten gedurende deze periode ook behandeld werden. Perindoprilatbehandeling voorkwam het ontstaan van albuminurie. De versterkte albumine lekkage door de vaatwand werd echter niet beïnloed door perindoprilat.

Advanced Glycosylation Endproduct (AGE)-vorming, als uiteindelijk gevolg van glycosylerings-reacties, speelt mogelijk een rol in de ontwikkeling van de verschillende vormen van diabetische angiopathie. Door structurele modificatic van extracellulaire matrix componenten zou AGE-vorming kunnen leiden tot veranderingen in vasculaire en glomerulaire permeabiliteit. In hoofdstuk 5 hebben we de effecten onderzocht van behandeling met aminoguanidine, een stof die vorming van AGE-produkten tegengaat. De studie opzet was vergelijkbaar met de hierboven beschreven studie. In tegenstelling tot de effecten van ACE-remming resulteerde aminoguanidine behandeling wel in een normalisatie van de versterkte eiwitlekkage in de verschillende organen maar was er geen effect op albuminurie. Dit wijst erop dat eiwitlekkage door de vaatwand en eiwitverlies via de nier niet eenvoudigweg als markers van hetzelfde pathofysiologisch proces kunnen worden gezien, en differentieel kunnen worden beïnvloed.

Omdat glycosyleringsprocessen kunnen leiden tot modificatie van belangrijke eiwitten in de vaatwand en dus ook tot veranderingen in de fysische eigenschappen van de vaatwand, hebben we in hoofdstuk 6 de effecten bestudeerd van langer bestaande diabetes (12 weken) in ratten op mechanische eigenschappen van de vaatwand. Er werd gekeken naar effecten van diabetes op 
verschillende parameters van vasculaire elasticiteit zoals compliantie van de halsslagader (arteria carotis) en karakteristieke compliantie van de aorta. Deze parameters werden bepaald in verdoofde ratten met behulp van verschillende technieken zoals intravasculaire drukmetingen en het meten van flow middels een Doppler probe. Er werden aanwijzingen gevonden dat er in langer bestaande experimentele diabetes sprake is van een verminderde elasticiteit van het vaatstelsel. Deze verminderde elasticiteit van de vaatwand heeft belangrijke negatieve consequenties voor het functioneren van onder andere het hart.

Of de beschreven veranderingen in arteriële elasticiteit nu werkelijk veroorzaakt worden door AGE-vorming in de vaatwand hebben we trachten te bestuderen in hoofdstuk 7. In dit hoofdstuk zijn de resultaten beschreven van aminoguanidine-behandeling, en dus inhibitie van AGE-vorming, op de hierboven beschreven parameters van vasculaire elasticiteit in ratten met een relatief langere diabetesduur. Aminoguanidine behandeling leidde tot een aanzienlijke verbetering van de vasculaire elasticiteit, hetgeen erop duidt dat AGE-vorming in de vaatwand belangrijke negatieve effecten heeft op vaatwandelasticiteit. Daarnaast bleek aminoguanidine ook nog een gunstig effect te hebben op filtratie van vloeistof door de vaatwand.

Samenvattend wordt in dit proefschrift onderzoek beschreven naar verschillende aspecten van diabetische angiopathie. We hebben aangetoond dat er al kort na het ontstaan van diabetes in de microcirculatie veranderingen optreden. In dwarsgestreept spierweefsel lijkt er eerder vasoconstrictie te ontstaan, dan de vasodilatatie die in diverse andere studies beschreven wordt. Vasculaire reactiviteit in diabetes mellitus is ook duidelijk gestoord, waarbij er veranderingen optreden in zowel endotheel-afhankelijke als endotheel-onafhankelijke reactiviteit. Zoals bekend ontstaat er als gevolg van diabetes een toegenomen eiwitlekkage door de vaatwand als uiting van een toegenomen vasculaire permeabiliteit, met ook een toegenomen eiwitverlies (albuminurie) via de nier. Behandeling met de ACE-inhibitor perindoprilat heeft een gunstig effect op albuminurie maar niet op gegeneraliseerde eiwitlekkage, terwijl aminoguanidine de toegenomen vasculaire permeabiliteit wel normaliseert. Aminoguanidine heeft ook gunstige effecten op de verminderde arteriële elasticiteit die ontstaat ten gevolge van langdurige diabetes mellitus. Gezien deze gunstige effecten van aminoguanidine lijkt deze stof of een van haar afgeleiden op termijn interessant voor de behandeling van patiënten met diabetische angiopathie. De positieve effecten alsmede de veiligheid van aminoguanidine moeten hiertoe eerst in humane studies worden bevestigd. 


\section{DANKWOORD}

Vaak heb ik mezelf en ook anderen erop "betrapt" bij het lezen van een proefschrift met name ook het dankwoord aandachtig te lezen. Om de lezers van dit proefschrift niet teleur te stellen, maar natuurlijk ook (vooral ook) om mijn oprechte dank uit te spreken jegens al diegenen die in deze promotieperiode belangrijk voor mij zijn geweest, de volgende woorden.

Bruce Wolffenbuttel, mijn begeleider en co-promotor, wil ik als eerste noemen. Beste Bruce, het schijnt dat het aantal grijze haren op je hoofd de afgelopen vier jaar significant sterker is toegenomen dan op grond van normale veroudering kan worden aangenomen. Op je bekende subtiele wijze heb je me meerdere malen laten weten dat er een directe relatie bestaat tussen het aantal grijze haren op je hoofd en het aantal dagen dat je mijn begeleider was. Misschien is het je opgevallen dat de eerste grijze haar op mijn hoofd nog niet is verschenen. Ik denk dat dit de prima omstandigheden aangeeft waarin ik de afgelopen vier jaar heb kunnen functioneren. Jij hebt mij veel vrijheid gegeven om de lijnen van dit onderzoek uit te zetten, waarbij je anderzijds altijd beschikbaar was op momenten dat het nodig was. Ik ben je zeer erkentelijk voor alle mogelijkheden die ik heb gekregen om me wetenschappelijk ook buiten het BMC te ontplooien, waarbij de reis met de ratten naar Parijs natuurlijk het wetenschappelijke (en gastronomische) hoogtepunt vormde. Mijn promotor Professor Struijker Boudier verleende mij drie jaar lang gastvrijheid binnen de vakgroep Farmacologie. Beste Harry, alle faciliteiten en lopende technieken op jullie lab hebben het voor mij een stuk makkelijker gemaakt dit onderzoek uit te voeren. Jouw creatieve ideeën en enthousiasme zijn heel belangrijk geweest voor het tot stand komen van dit proefschrift. Daarnaast vind ik alle interesses die je op ander gebied hebt en je uitgebreide kennis van kunst en literatuur een voorbeeld. Het zal echter nog wel enige tijd duren eer ik zover ben dat ik in mijn vakantie "A la recherche du temps perdu" ga lezen.

Mijn promotor Professor Nieuwenhuijzen Kruseman heeft mij de afgelopen jaren vanuit de kliniek begeleid en is nu als hoofd van de werkgroep endocrinologie en waarnemend opleider mijn directe baas. Beste Arie, in de afgelopen jaren ben je steeds meer betrokken geraakt bij dit onderzoek en heb je met je analytisch vermogen en scherpe inzicht veel hoofdstukken van dit proefschrift aanzienlijk verbeterd. Buiten de werkvloer kom je vaak onverwacht voor de dag: tijdens promotiefeesten doe je sketches in de meest wilde vermommingen en op de snelweg ontpop je je tot iemand die zowel de weg als ook de vluchtstrook onveilig maakt. 
Docteur Bernard Lévy m'a gentiment donné la possibilité de travailler dans son laboratoire. Monsieur Pierre Poitevin (PP) a fait presque tous les expériments à Paris. Professor Joe Williamson has always been very interested in our experimental work and has reviewed this thesis very carefully. De overige leden van de beoordelingscommissie, Professor de Leeuw, Professor Arends en Professor Tangelder dank ik voor hun aandachtige beoordeling van dit proefschrift.

Ook alle andere leden van de vakgroep Farmacologie namen mij gastvrij in hun midden op. De collega's van het lab, Helma, Jacques, Peter, Caroline, Elsbeth, Frenk, Ben en Jan, zorgden voor een prima sfeer. Marjorie en Marcel, en Ferdi (zeg maar Ferdinand) en Lilian waren mijn gewaardeerde kamergenoten op het oude en nieuwe BMC, met wie ik vele niet-wetenschappelijke gesprekken voerde. Professor Jos Smits verleende buitengewoon veel hulp bij het opzetten, uitvoeren en uitwerken van de albumine-extravasatie experimenten, waarvoor dank. Het hart van de vakgroep Farmacologie wordt gevormd door het secretariaat; Mia en Els, bedankt voor jullie secretariële en nietsecretariële ondersteuning. Bij het experimentele werk kreeg ik veel hulp van Helma van Essen en Francy Crijns. Helma, er zijn maar weinig mensen van wie je het "proefdiervak" beter kunt leren dan van jou, je hebt een gave om met dieren om te gaan en je kunt beter opereren dan veel chirurgen. Francy, binnen de kortste keren heb je je in al je bescheidenheid ontpopt tot een ervaren onderzoekster. Ik heb erg prettig met je samengewerkt, en vind het leuk dat jij nu ons onderzoek voortzet en samen met Bart-Jeroen Heesen en Paul (Pibo) Leurs het lab "experimentele diabetes" vorm geeft. De medewerkers van het CPV hebben hard gewerkt om alle ratten van hun "natje en droogje" te voorzien. Vanuit de afdeling Klinische Chemie kregen wij ook de nodige hulp: Dr. Paul Menheere gaf ons de mogelijkheid de radioactiviteitsbepalingen voor de extravasatie-studie te verrichten en hielp ook met de praktische uitvoering ervan. Mia Haasen-Meers en Lucien Habets verrichtten met zorg de totaal-eiwit bepalingen. Karin Scheele bewerkte met zorg het manuscript en maakte het tot een echt boekje.

Mijn petenicht Ank Cleven verleende mij vele weken gastvrijheid in haar piepkleine maar erg gezellige huis in Parijs. Lieve Ank, misschien dat ik nu jullie in the States wonen nog eens een experimentje in Washington kan plannen. Mijn (club)vriendinnen en aanhang Lianne en Theun, Corrie, Vera en Bert-Jan, Mares en Reinier, Irene en Huw plus Pippi, mijn paranymfen Caroline en Caroline, en onze "echte vrienden" (Dick Advocaat, Zwoelie, TV, Maupiemannetje en Wien) zorgden voor veel lol in de weinige vrije tijd die er over was. De ouders van Marc, Leon en Rietje, hebben niet alleen Marc maar ook mij gesteund met hun continue interesse en zorg. Mijn broer(tje) Gerben heeft mij inmiddels hoog in de lucht ver achter zich gelaten, maar heeft jarenlang de 
last moeten torsen van een ijverige zus die op school erg braaf haar best deed en altijd goede punten haalde. Toch was je altijd geïnteresseerd in mijn wel en wee en zorgde met je laconieke houding voor de nodige relativering, waarvoor mijn dank. Mijn ouders kan ik in deze paar regels onmogelijk danken voor alles wat ze voor mij gedaan hebben. Daamaast zou ik me eigenlijk ook nog moeten verontschuldigen voor de weinige weekeinden die er "en famille" overbleven, en voor alle goedbedoelde raadgevingen die in de wind geslagen werden. Toch hoop ik dat jullie het net als ik allemaal de moeite waard hebben gevonden.

Liefste Marc, omdat wij elkaar door de ratten en muizen (en een zwarte kip) hebben leren kennen vind ik deze promotieperiode al helemaal geslaagd. Waarschijnlijk zullen we over een paar jaar stoere verhalen vertellen over alle weekeinden en feestdagen dat we gewerkt hebben, de nachtelijke expedities naar het BMC en de gevaarlijke bijtende ratten die we (jij) moesten temmen. Gelukkig was gedeelde promotiesmart halve promotiesmart. Vrijdag $27 \mathrm{mei} \mathrm{zal}$ blijken dat gedeelde promotievreugd ook dubbele promotievreugd is. 



\section{PUBLICATIONS}

During the course of the experimental work, the following publications were realized:

Huijberts MSP, Wolffenbuttel BHR, Crijns FRL, Nieuwenhuizen Kruseman AC, Bemelmans MHA, van Essen H, Smits JFM, Struijker Boudier HAJ: Angiotensin converting enzyme-inhibition reduces urinary albumin excretion but not regional albumin clearance in experimental diabetes. Eur J Pharmacol 1993; 240: 207-212

Huijberts MSP, Wolffenbuttel BHR, Struijker Boudier HAJ, Crijns FRL, Nieuwenhuijzen Kruseman AC, Poitevin P, Lévy BI: Aminoguanidine treatment increases elasticity and decreases fluid filtration of large arteries from diabetic rats. J Clin Invest 1993; 92: 1407-1411

Huijberts MSP, Wolffenbuttel BHR, Crijns FRL, Nieuwenhuizen Kruseman AC, Bemelmans MHA, Struijker Boudier HAJ: Aminoguanidine reduces regional albumin clearance but not urinary albumin excretion in streptozotocin-diabetic rats. Diabetologia 1994; 37: 10-14

Huijberts MSP, Crijns FRL, Wolffenbuttel, Nieuwenhuijzen Kruseman AC, van Essen $\mathrm{H}$, Struijker Boudier HAJ: In vivo arteriolar reactivity in experimental diabetes. (submitted)

Huijberts MSP, Wolffenbuttel BHR, Crijns FRL, Nieuwenhuijzen Kruseman AC, van Essen $H$, Struijker Boudier HAJ: Changes in microvascular diameters and microvascular density following diabetes induction. (submitted)

Huijberts MSP, Wolffenbuttel BHR, Nieuwenhuijzen Kruseman AC, Poitevin P, Lévy BI, Struijker Boudier HAJ: Effects of diabetes on large artery properties in the rat. (submitted)

Struijker Boudier HAJ, Messing MWJ, Nelissen HJMG, Huijberts MSP, Le Noble FAC, Smits JFM: Vascular actions of ACE-inhibitors in hypertension: structural and functional consequences. In: Current advances in ACE-inhibition, MacGregor GA, Sever PS, Eds. Edingburgh, Churchill Livingstone, 1991, pp 240-244 
Struijker Boudier HAJ, Le Noble JLML, Messing MWJ, Huijberts MSP, Le Noble FAC, van Essen H: The microcirculation and hypertension. I Hypertension 1992; 10 (suppl. 7): 147-156

Struijker Boudier HAJ, Messing MWJ, Nelissen HJMG, Huijberts MSP, Le Noble FAC: Smits JFM: Vascular actions of ACE-inhibitors in hypertension: structural and functional consequences. I Hypertension, in press

Wolffenbuttel BHR, Huijberts MSP: Aminoguanidine, a potential drug for the treatment of diabetic complications. Neth J Med 1993; 42: 205-208

Wolffenbuttel BHR, Huijberts MSP, Heesen BJ, Leurs PB, Nieuwenhuijzen Kruseman HAJ: Goede instelling van diabetes verkleint de kans op diabetische complicaties. Ned Tijdschr Geneeskd 1993; 137: 2179-2183 


\section{CURRICULUM VITAE}

Maya Huijberts werd geboren op 4 december 1964 te Goirle. Na het behalen van het Gymnasium B diploma aan het Jeroen Boschcollege te 's-Hertogenbosch begon zij in 1983 met de studie geneeskunde aan de Rijksuniversiteit Limburg te Maastricht. Tijdens haar studie was zij als student-assistent en later als onderzoeks-assistent werkzaam op het electrofysiologisch laboratorium van de vakgroep Fysiologie (hoofd Prof. dr. M.A. Allessie en Prof. dr. F.I.M. Bonke). Zij behaalde in 1987 het doctoraalexamen en in september 1990 het artsexamen. Vanaf maart 1990 tot april 1993 was zij als Assistent In Opleiding (AIO) verbonden aan de werkgroep Endocrinologie (hoofd Prof. dr. A.C. Nieuwenhuijzen Kruseman) van de vakgroep Interne Geneeskunde. Het promotie-onderzoek werd grotendeels uitgevoerd op het hemodynamisch en microcirculatie-laboratorium van de vakgroep Farmacologie (hoofd Prof. dr. H.A.J. Struijker Boudier). Sinds 1 april 1993 is zij als Assistent Geneeskundige In Opleiding (AGIO) werkzaam op de afdeling Interne Geneeskunde van het Academisch Ziekenhuis Maastricht (opleider wijlen Prof. dr. J.A. Flendrig, waarnemend opleider Prof. dr. A.C. Nieuwenhuijzen Kruseman). 


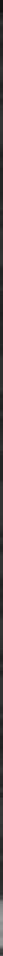

